LBNL-55269

\title{
A New Approach for Modeling the Peak Utility Impacts from a Proposed CUAC Standard
}

\author{
Prepared for the \\ Office of Building Technologies \\ Assistant Secretary for Energy Efficiency and Renewable Energy \\ U.S. Department of Energy
}

Principal Authors

Kristina Hamachi LaCommare, Etan Gumerman, Chris Marnay, Peter Chan, and Katie Coughlin

Ernest Orlando Lawrence Berkeley National Laboratory

1 Cyclotron Road, MS 90R4000

Berkeley CA 94720-8061

October 2004

This work described in this paper was funded by the Assistant Secretary of Energy Efficiency and Renewable Energy, Office of Building Technologies of the U.S. Department of Energy under Contract No. DE-AC03-76SF00098 



\section{Table of Contents}

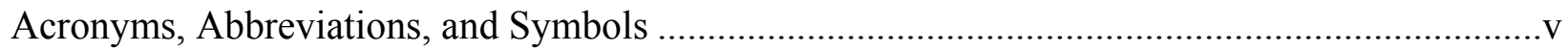

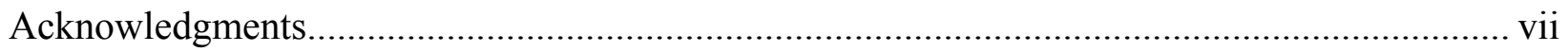

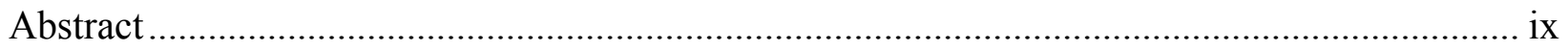

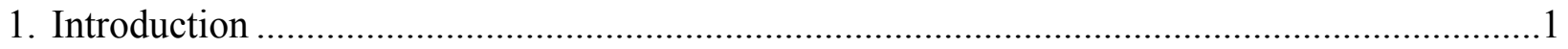

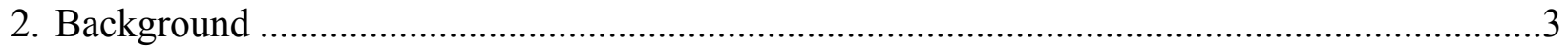

2.1 Key Findings from Previous Work ............................................................................ 3

2.2 Traditional Approach ........................................................................................

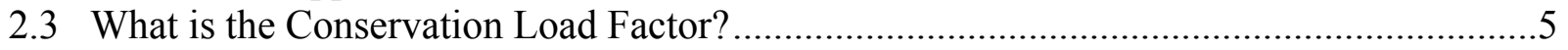

2.4 Results Using Traditional Approach.................................................................. 6

3. Validating the Load Shapes in NEMS .........................................................................

3.1 End-Use Space Cooling and Ventilation Load Shapes in NEMS.................................. 10

3.2 Comparison of End-Use Load Shapes with Simulations ............................................. 12

3.2.1 Simulation of Load Shapes ............................................................................13

3.2.2 Comparison of NEMS Commercial Space Cooling Load Shape with Simulated

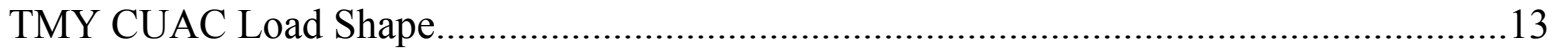

3.3 Comparison of NEMS System Load Shape with Historical Data and TMY System Load17

3.4 Comparison of Space Cooling Load Shape with System Load Shape in NEMS .............23

3.5 Summary of Load Shape Comparisons....................................................................25

4. The New Double Decrement Approach ......................................................................2

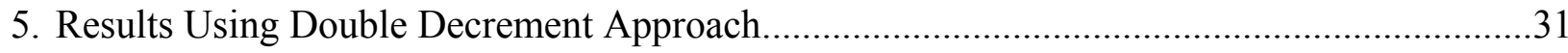

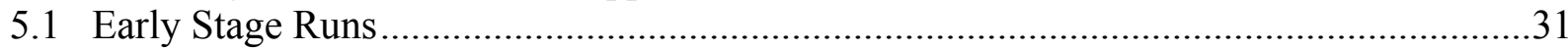

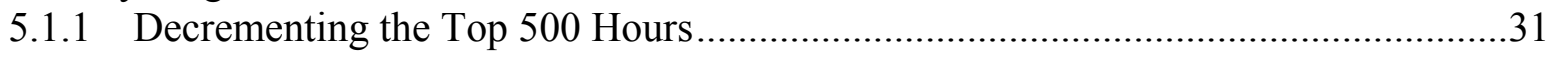

5.1.2 Decrementing 20\% of the Topmost Summer Peak Hours .....................................32

5.1.3 Summary of the Preliminary Runs.........................................................................32

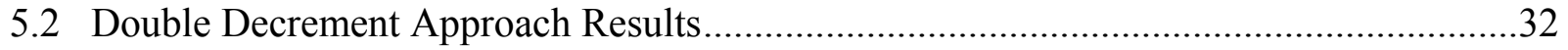

5.2.1 Results Using Double Decrement Approach with NEMS Space Cooling Load Shape32

5.2.2 Results Using Double Decrement Approach with TMY CUAC Load Shape ...........33

5.2.3 Comparing the Results from the Traditional and Double Decrement Approaches ...34

5.3 Substitution of TMY System Load and TMY CUAC Load Shape ..................................34

5.3.1 Results from Substituting the TMY System Load into NEMS Reference Case.........35

5.3.2 Results from Substituting the TMY System and CUAC Load Shapes into NEMS

Using the Double Decrement Approach ...................................................................... 35

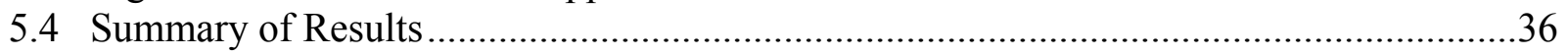

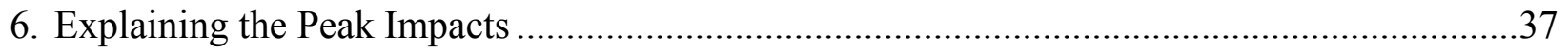

6.1 Output Hourly System Load by EMM Region and Year ............................................37

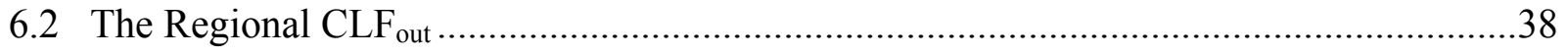




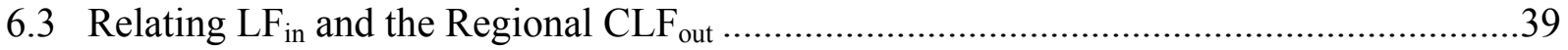

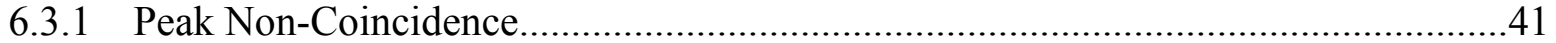

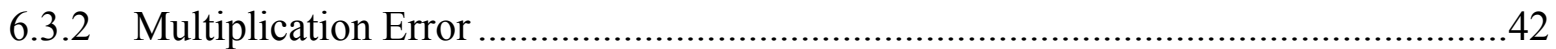

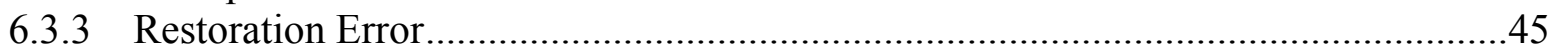

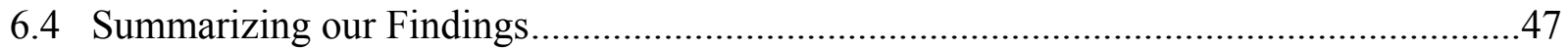

6.5 The 11 Blocks that Represent the LDC in NEMS ..........................................................48

7. Summary of Findings and Conclusions.............................................................................

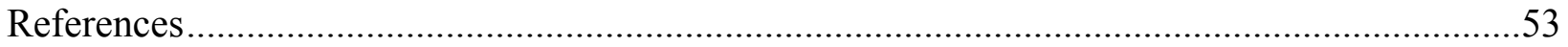

Appendix A. Mathematical Representation of Load Demand in NEMS......................................55

Appendix B. Code Modifications for Implementing the Double Decrement Approach ...............61

Appendix C. Comparison Plots of Space Cooling and Ventilation Load Shapes in NEMS with Simulations

Appendix D. Derivation of Code Changes to Restore Decremented System Hourly Loads.........77

Appendix E. Code Modifications for Outputting the Hourly System Load .................................79

Appendix F. The Innocence of the Squelch: Understanding the Difference Between the Years

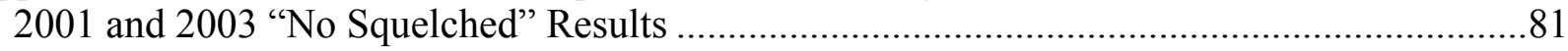

Appendix G. Effect of Modified TMY System Load .................................................................. 


\section{List of Figures and Tables}

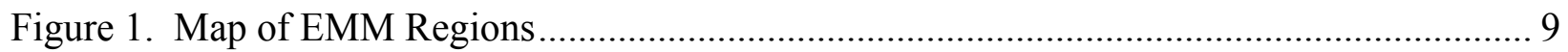

Figure 2. NEMS July Space Cooling Load Shapes for ECAR ................................................... 11

Figure 3. NEMS July Ventilation Load Shapes for ECAR ……......................................... 12

Figure 4. Comparison of NEMS Space Cooling and Simulated TMY CUAC Load Shapes ...... 14

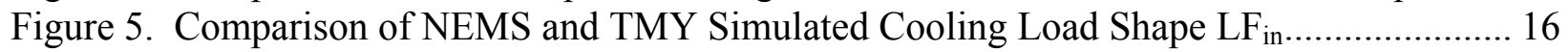

Figure 6. Comparison of NEMS Ventilation and Simulated TMY Ventilation Load Shapes..... 16

Figure 7. Comparison of System Load Peak Day in ECAR from NEMS, TMY, and Historical

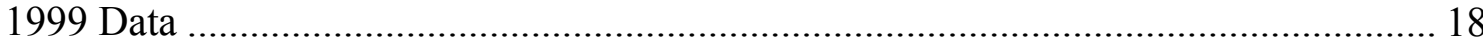

Figure 8. Root Mean Square Difference of ECAR System Load.............................................. 19

Figure 9. Root Mean Square Difference of System Load for ECAR as Percentage of Daily Load

Figure 10. Peak Hour Energy as a Percentage of Total Demand by Month and EMM Region:

NEMS vs. TMY System Loads ................................................................................ 21

Figure 11. Peak Hour Energy as a Percentage of Total Demand by Month and EMM Region:

NEMS vs. Historical 1999 System Loads ..................................................................... 21

Figure 12. Total Energy by Month and EMM Region: NEMS vs. TMY System Loads ............. 22

Figure 13. Total Energy by Month and EMM Region: NEMS vs. Historical 1999 System Loads

Figure 14. July NEMS System Load with Simulated AC Load Shape in ECAR ………............. 24

Figure 15. July NEMS System Load with NEMS Space Cooling Load Shape in ECAR ............ 24

Figure 16. Flowchart of Double Decrement Approach in NEMS-BT ......................................... 28

Figure 17. The LDC from 6x TSL 4 for ECAR Region in Year 2025 ...................................... 38

Figure 18. Example of Peak Non-Coincidence in MAPP in 2025 for Selected Multiples of TSL

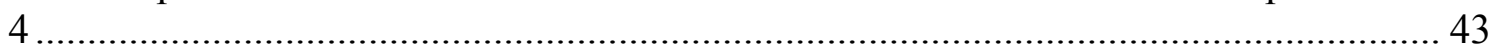

Figure 19. An Example of the Load Duration Curve in NEMS .............................................5 50

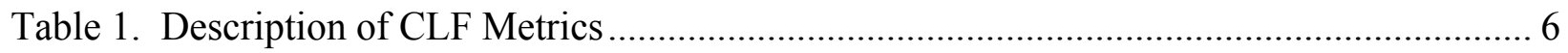

Table 2. CUAC Cooling-Only Results in Year 2020 Using the Traditional Approach in the 2003

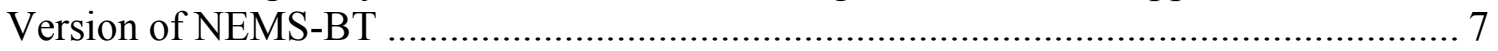

Table 3. Comparison of Multipliers used for each CUAC TSL ………...................................... 7

Table 4. Impact of Results for CUAC TSL 4 Due to Multipliers................................................. 7

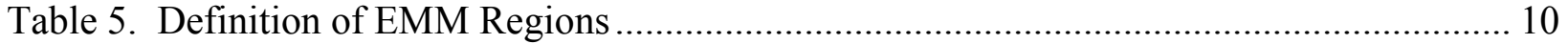

Table 6. Commercial Space Cooling LF in and Peak Hour from Input Load Shape of AEO2003

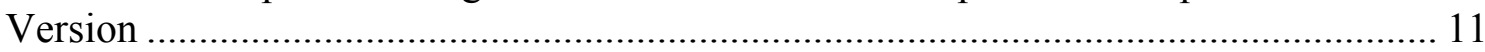

Table 7. Composition of Commercial Space Cooling Load Shape in NEMS ............................. 15

Table 8. Month and Time of Peak Hour from End Use and System Loads ............................... 25

Table 9. TSL 4 Cooling-Only Results Using Double Decrement Approach with NEMS Space Cooling Load Shape .................................................................................................... 33

Table 10. Cooling-Only Results for Year 2020 Using Double Decrement Approach with TMY

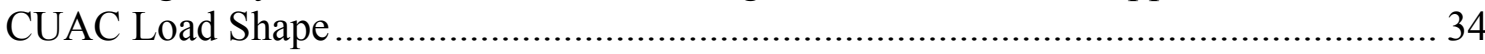

Table 11. TSL 4 Cooling-Only Results Using Double Decrement Approach with TMY System Load Shape and TMY CUAC Load Shape ………………............................................. 36

Table 12. Summary of TSL 4 Cooling-Only Results for Year 2020 ……..................................... 36

Table 13. Comparison of $\mathrm{LF}_{\text {in }}$ and the Regional $\mathrm{CLF}_{\text {out }}$ from 3x TSL 4 .................................. 39 
Table 14. Identifying Peak Non-Coincidence Between the TMY CUAC End-Use and Reference Case System Load Shapes in Year 2025 ................................................................... 41

Table 15. Peak Non-coincidence Factor by Region for Selected Multiples of TSL 4 in Year 2025

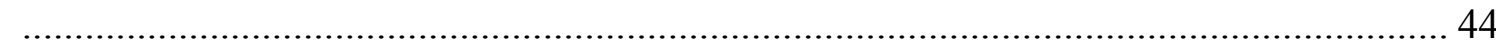

Table 16. Energy Decrement for 3x TSL 4 by Region in Year 2025 (TWh) ............................. 46

Table 17. Peak Hour Demand for 3x TSL 4 by Region in Year 2025 (TWh) ............................ 47

Table 18. Summary of Metrics used to Evaluate Selected Multiples of TSL 4 for MAPP .......... 48

Table 19. Summary of Load Duration Curve Parameters in NEMS .......................................... 49

Table 20. Total Installed Capacity (and Difference from AEO2003 Reference Case) in GW..... 88 


\section{Acronyms, Abbreviations, and Symbols}

$\begin{array}{ll}\text { AEO } & \text { Annual Energy Outlook } \\ \text { BLAST } & \text { Building Loads and System Thermodynamics } \\ \text { BT } & \text { DOE's Building and Technologies program } \\ \text { CBECS } & \text { Commercial Buildings Energy Consumption Survey } \\ \text { CLF } & \text { conservation load factor } \\ \text { CUAC } & \text { commercial unitary air conditioner } \\ \text { DOE } & \text { U.S. Department of Energy } \\ \text { EIA } & \text { Energy Information Administration } \\ \text { EMM } & \text { Electricity Market Module of NEMS } \\ \text { GW } & 10^{9} \text { (giga)watt } \\ \text { kW } & 10^{3} \text { (kilo)watt } \\ \text { LCC } & \text { life cycle cost } \\ \text { LDC } & \text { load duration curve } \\ \text { LDSM } & \text { Load and Demand Side Management NEMS sub-module } \\ \text { MEF } & \text { marginal emissions factor } \\ \text { NEMS } & \text { National Energy Modeling System } \\ \text { NERC } & \text { North American Reliability Council } \\ \text { NES } & \text { National Energy Savings model } \\ \text { PNNL } & \text { Pacific Northwest National Laboratory } \\ \text { RCAC } & \text { residential central air conditioning } \\ \text { RMS } & \text { root mean square } \\ \text { SEER } & \text { seasonal energy efficiency ratio } \\ \text { TSL } & \text { trial standard level (e.g. TSL 4) } \\ \text { TMY } & \text { typical meteorological year } \\ \text { TWh } & 10 \text { (12 (tera)watt hour } \\ \Delta & \text { mathematical symbol for “change in" } \\ & \end{array}$





\section{Acknowledgments}

The work described in this report was funded by the Assistant Secretary of Energy Efficiency and Renewable Energy, Building Technologies Program of the U.S. Department of Energy under Contract No. DE-AC03-76SF00098. The authors would also like to thank Greg Rosenquist and Diane Fisher for their useful input to the research. 



\begin{abstract}
This report describes a new Berkeley Lab approach for modeling the likely peak electricity load reductions from proposed energy efficiency programs in the National Energy Modeling System (NEMS). This method is presented in the context of the commercial unitary air conditioning (CUAC) energy efficiency standards. A previous report investigating the residential central air conditioning (RCAC) load shapes in NEMS revealed that the peak reduction results were lower than expected. This effect was believed to be due in part to the presence of the squelch, a program algorithm designed to ensure changes in the system load over time are consistent with the input historic trend. The squelch applies a system load-scaling factor that scales any differences between the end-use bottom-up and system loads to maintain consistency with historic trends. To obtain more accurate peak reduction estimates, a new approach for modeling the impact of peaky end uses in NEMS-BT has been developed. The new approach decrements the system load directly, reducing the impact of the squelch on the final results. This report also discusses a number of additional factors, in particular non-coincidence between end-use loads and system loads as represented within NEMS, and their impacts on the peak reductions calculated by NEMS.

Using Berkeley Lab's new double-decrement approach reduces the conservation load factor (CLF) on an input load decrement from 25\% down to 19\% for a SEER 13 CUAC trial standard level, as seen in NEMS-BT output. About $4 \mathrm{GW}$ more in peak capacity reduction results from this new approach as compared to Berkeley Lab's traditional end-use decrement approach, which relied solely on lowering end use energy consumption. The new method has been fully implemented and tested in the Annual Energy Outlook 2003 (AEO2003) version of NEMS and will routinely be applied to future versions. This capability is now available for use in future enduse efficiency or other policy analysis that requires accurate representation of time varying load reductions
\end{abstract}





\section{Introduction}

Berkeley Lab has developed a new approach for modeling the peak utility impacts from a peak coincident end use using the National Energy Modeling System (NEMS). The impetus for developing this new approach stems from Berkeley Lab's prior difficulties with adequately representing efficiency improvements to a peaky end use in NEMS.

Developed and maintained by the Energy Information Administration (EIA), NEMS is a midrange energy forecast model that has been used for the utility analysis and environmental assessment portions of various appliance energy efficiency standards' rulemakings for nearly a decade. NEMS relies upon a set of assumptions, which are fairly transparent due to the exposure and scrutiny each Annual Energy Outlook (AEO) receives. The Annual Energy Outlook is the annual forecast prepared by the Energy Information Administration (EIA) using NEMS. NEMS also offers a sophisticated picture of the effect of appliance standards because its scale allows it to measure the interactions between the various energy supply and demand sectors and the economy as a whole. Berkeley Lab calls the version of NEMS used to model proposed energyefficiency standards NEMS-BT because this work is conducted under the auspices of the Department of Energy (DOE) Building and Technologies (BT) program. EIA requires that any modified version of NEMS be named differently, to distinguish them from EIA's Annual Energy Outlook (AEO) Reference Case version. Throughout this memo, NEMS-BT is used to refer to the appliance standards' modified version used at Berkeley Lab. The AEO version of the model is referred to as simply NEMS.

A previous effort investigated how the residential central air conditioning (RCAC) load shape is represented in NEMS-BT, and presented some alternative approaches to modeling this end use to achieve more accurate peak effects. Analysis of the RCAC end use was the first rulemaking analysis Berkeley Lab has performed using NEMS-BT for a highly peak-load-coincident end use. Also, the California electricity market problems of 2000 and the northeast blackout of 2003 dramatically heightened policy interest in peak effects. The RCAC analysis first alerted Berkeley $\mathrm{Lab}$ to the stunted peak impacts resulting from input energy savings. This work discovered the presence of the squelch, which was believed to be masking the peak impacts. The current work will show that a number of factors affect the peak reduction calculations, that in this case the squelch does not significantly impact the results, and that a more important factor is the degree of coincidence between this peaky end use and the system load. A new method for producing accurate peak effects could not be developed in time to meet the aggressive schedule of the RCAC rulemaking, but this experience led Berkeley Lab to immediately begin working on developing a new approach to be used in the CUAC and other upcoming analyses.

The new Berkeley Lab approach decrements the hourly system load directly instead of simply lowering energy use by the end use. This report explains the new approach and presents preliminary results. Extensive analysis of the CUAC end use and system load shapes are also presented to validate that the load shapes used are credible. The focus of this report is the current CUAC rulemaking, although this approach was designed for other end uses, notably utility distribution transformers. 
The structure of this work is:

- Section 2 provides background information and summarizes what Berkeley Lab has learned about the behavior of load shapes in NEMS from our previous work. This section includes a description of the conservation load factor (CLF), which is a helpful indicator of how well NEMS translates energy savings from a peaky end use to peak load reductions.

- Section 3 presents a comparison of the end use and system load shapes in NEMS with those from an externally produced source. This section also reports some statistical measurements that seek any consistent trends in the differences.

- Section 4 details Berkeley Lab's new double decrement approach.

- Section 5 presents some preliminary results using the new double decrement approach, including some sensitivity analysis runs.

- Section 6 discusses some of the tools Berkeley Lab uses to interpret results.

- Section 7 summarizes the findings and conclusions from this work. 


\section{Background}

This work builds upon a previous report that sought to explore how the RCAC load shapes were treated in NEMS (LaCommare et al. 2002). This section summarizes previous work. Subsection 2.1 revisits earlier findings, while subsection 2.2 provides an overview of the traditional energy decrement only approach Berkeley Lab established to model the utility impacts from proposed energy efficiency standards. Subsection 2.3 discusses a measure used in this work to evaluate how well NEMS-BT is capturing the peak impacts from a proposed CUAC energy efficiency standard. Results using the traditional approach are presented in subsection 2.4.

\subsection{Key Findings from Previous Work}

Berkeley Lab's analysis of the treatment of RCAC load shapes in NEMS-BT uncovered some problems that help explain the puzzling small peak impacts found in analysis of proposed RCAC standards.

Our key findings were:

- NEMS was using an inappropriate load shape to represent residential space cooling. Berkeley Lab found that the residential space-cooling end use was represented in the AEO2001 (or earlier) version of NEMS by an October-peaking load profile, rather than a more credible one like the RSFCAO67 load shape that was included in inputs but not activated. The CLF dropped from $35 \%$ to $23 \%$ for proposed RCAC Trial Standard Level (TSL) 4 when the autumn-peaking load shape was replaced with the summer-peaking RSFCAO67. A TSL is a certain feasible combination of technical energy efficiency improvements to an appliance. Within NEMS, this corresponds to a specified percent reduction in the amount of energy consumed for that end-use. Subsequent to this finding, EIA responded by updating a number of end-use load shapes, including the residential space cooling load shape, rectifying this problem.

- NEMS uses a squelch factor to scale down system load so that it coincides with the historical data used to initialize the model. Removing this squelch has a dramatic effect on forecast peak growth, e.g. a 3.5\% increase in the AEO2001 Reference Case installed capacity in 2020. Note that the squelch lowers all NEMS peak load growth forecasts. Although conclusions from the RCAC analysis pointed to the squelch as the primary culprit for the limited peak impacts, in the present analysis of the CUAC standard, we find that the degree of coincidence between the end-use and the system loads is the most important factor. Please refer to Appendices A and D for more detail on how loads are modeled, and how the squelch is implemented, and to Appendix F for an example analysis of case runs with and without the squelch.

- NEMS updated AEO2002 load shapes with the traditional end-use energy only decrement approach was used for the RCAC rulemaking analysis. This chosen combination decreased the CLF in the AEO2001 analysis from $45 \%$ to $33 \%$.

The discovery of both the inappropriate space-cooling load shape in the 2001 version of NEMSBT and the squelch factor helped to explain the troublesome results. However, as previously 
mentioned, recent work has revealed that the squelch actually has little to do with our lowerthan-expected peak utility impacts. Instead, as will be discussed in Section 5.4.3, noncoincidence appears to account for the majority of the difference between the input and output CLF. Appendix F presents a detailed explanation of how the squelch does little to impact the peak load.

EIA responded in a timely manner to Berkeley Lab's request to refine the NEMS load shapes. Prior literature indicated that a reasonable CLF for the RCAC end use might be $10-15 \%$. Although improving the load shapes lowered the CLF (from 45\% to 33\% for trial standard level (TSL) 4), the results still appear to be much higher than expected. Berkeley Lab continued investigating this problem and has developed a new approach for future analyses that can clearly track the effects from a proposed energy efficiency standard.

\subsection{Traditional Approach}

The traditional approach to analyzing a proposed energy efficiency appliance standard is to simply reduce the end-use energy consumption of the appliance for each modeled year and by regional census divisions. This subtracted value is calculated exogenously to NEMS-BT and is referred to as the energy decrement. This approach worked well for most end uses recently studied (e.g. residential clothes washers, water heaters, and commercial fluorescent ballasts); however, the RCAC rulemaking being conducted during California's winter of discontent, 20002001, raised concerns because NEMS-BT did not appear to be accurately reflecting the amount of installed generating capacity potentially saved.

Because the relative size of appliance energy efficiency standard savings implemented in NEMSBT is so small compared to the fluctuations in energy use by the whole energy sector, multiple NEMS-BT runs must be performed using larger decrements that are simple multiples of the proposed energy savings. Interpolated values for the NEMS-BT savings are derived from this series of larger-decrement simulations; the savings in each of the runs are based on an appliance energy efficiency TSL, which represents a certain combination of energy efficiency improvements to the appliance that are considered technically feasible by Berkeley Lab engineers.

The electricity generation and capacity output by fuel type for each of the NEMS-BT runs, e.g. 4, 6 , and 8 times the TSL energy savings, are then regressed, and the actual forecast of the impact of the standard is interpolated back to the origin, i.e. to the Reference Case. The linear regression is forced through the origin because a zero change will result if no standard is enacted.

The NEMS-BT analysis reports changes resulting from an appliance standard; these include changes in installed generating capacity and the corresponding equivalent number of power plants avoided, electric generation saved by the power sector, and carbon and NOx emissions saved at electricity generators.

The method described above was recently used for the utility and environmental analysis related to the federal rulemakings for residential clothes washers, water heaters, and commercial fluorescent ballasts. However, unlike these other end uses, the RCAC and CUAC end uses are 
peaky, that is they have a low load factor and their use coincides with system peaks. The CLF is a convenient indicator of the peakiness of the likely energy savings of any end use.

\subsection{What is the Conservation Load Factor?}

Analysis of non-peaky end uses on the power-sector are simpler because their use is not strongly coincident with peak demand times, i.e. the impact of a standard on new power plant construction is limited. The CLF measures how peaky an end use is and, in general, how peaky the load decrement might be resulting from improved efficiency in this end use. Any capacity factor relates actual output to maximum possible output. By, definition the CLF is expressed as follows:

$$
\begin{aligned}
& \text { Average Energy Savings (GWh) } \\
& \text { CLF }=\text { Peak Load Savings }(\mathrm{GW}) * 8760(\mathrm{~h})
\end{aligned}
$$

For an end use like refrigerators, whose load shape is fairly flat, a CLF value of approximately 60 to $70 \%$ is typical. This value indicates that average load of the end use is 60 to $70 \%$ of its peak load, yielding a flatter (baseload) profile. However, for a peaky end use like RCAC and CUAC, the CLF is typically in the range of 10-20\% (Koomey et al. 1990; Treidler and Modera 1994). The high-demand episodes are largely on hot, summer days when air conditioning use is high.

This report uses more than one CLF to help understand the results from a proposed CUAC standard. The one used most often in this and the previous work is called the National Proxy $\mathrm{CLF}_{\text {out, }}$ which is based on NEMS output. This metric is the ratio of the average year-round energy savings to the peak capacity savings as shown below:

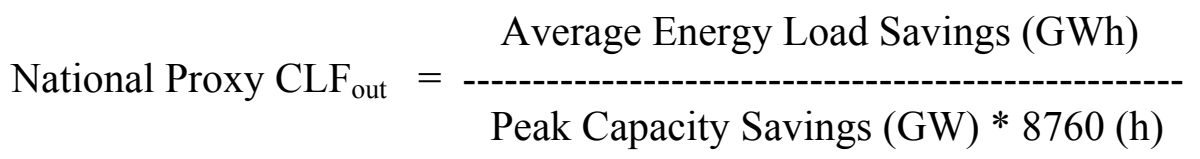

The National Proxy $\mathrm{CLF}_{\text {out }}$ is calculated for the U.S. from the NEMS-BT output due to limitations in the parameters NEMS outputs and is referred to in this report herein as the National $\mathrm{CLF}_{\text {out }}$ NEMS-BT does not calculate a national value for load so installed capacity is therefore used as a proxy and regional CLF's are used to accommodate the regional load data provided in the model.

Because CUAC and RCAC are peak-coincident end uses, the energy efficiency standard will usually result in large peak demand savings relative to the energy saved. For example, using the established end-use decrement or traditional approach, the proposed CUAC TSL 4 (roughly equivalent to a seasonal energy efficiency ratio, or SEER, of 13), which saves an estimated 31.9 TWh of site energy in 2020, results in a reduction of only $14.5 \mathrm{GW}$ of installed generating capacity, translating to a National $\mathrm{CLF}_{\text {out }}$ of roughly $25 \%$. That is, the peak reduction result from AEO2001 is at least 10 to $20 \mathrm{GW}$ lower than expected and the corresponding National $\mathrm{CLF}_{\text {out }}$ is substantially higher, i.e. capacity reduction would be closer to $25 \mathrm{GW}$ with a typical National $\mathrm{CLF}_{\text {out }}$ of $15 \%$. Because the CUAC rulemaking is still in its early stages, all CUAC runs use the 
energy savings from the RCAC rulemaking as a general approximation for the energy savings from this end use.

Table 1 below briefly describes each metric used in this analysis. The $L_{\text {in }}$ refers to the load factor estimated from the input end use load shape, which is important because the degree of coincidence between the system load and end-use load shape has a significant influence on the National $C_{\text {out }}$, which reflects capacity savings. In order to relate $L_{\text {in }}$, which is an input to the model and estimated by region, to the National $C_{L F}$ out, which is based on changes to installed capacity and only easily estimated for the U.S., we found an intermediate estimate of the CLF, called the Regional $\mathrm{CLF}_{\text {out }}$, which is based on the hourly load output and can be calculated by region, to help us compare how the load factor evolves through NEMS-BT. The Regional $\mathrm{CLF}_{\text {out }}$ is somewhat different than the definition for the National $\mathrm{CLF}_{\text {out }}$ in that the regional calculation uses load data while the national estimate uses capacity as a proxy for load. The Regional CLF $_{\text {out }}$ is explained in more detail in Section 6.

Table 1. Description of CLF Metrics

\begin{tabular}{|c|l|c|}
\hline Name & \multicolumn{1}{|c|}{ Description of Metric } & Formula \\
\hline $\mathrm{LF}_{\text {in }}$ & $\begin{array}{l}\text { Implicit load factor by EMM } \\
\text { region based on fraction of peak } \\
\text { load to total annual demand that } \\
\text { characterizes the end use or system } \\
\text { load shape }\end{array}$ & Average End-Use or System Load \\
\cline { 2 - 3 } $\mathrm{CLF}_{\text {in }}$ & $\begin{array}{l}\text { The CLF of the load decrement by } \\
\text { EMM region and equal to the LF in } \\
\text { if the decrement is proportional } \\
\text { across all regions }\end{array}$ & Peak End-Use or System Load \\
\cline { 2 - 3 } Regional CLF & $\begin{array}{l}\text { The CLF of the decrement to the } \\
\text { system load by EMM region }\end{array}$ & Peak End-Use Load Savings \\
\hline National (Proxy) & $\begin{array}{l}\text { The national result based on } \\
\text { electricity generation and peak } \\
\text { CLF }\end{array}$ & Average System Load \\
\cline { 2 - 3 } & &
\end{tabular}

Berkeley Lab relies heavily on the CLF to gauge how well NEMS-BT represents the CUAC end use and to compare how modifications to the approach represent the CUAC peak coincidence.

\subsection{Results Using Traditional Approach}

A summary of the results using the traditional approach described in the previous section is presented in Table 2 below. Results are reported for year 2020 using the AEO2003 version of NEMS-BT. The results only cover CUAC energy savings and ignore savings from ventilation or heat pumps, which are currently not included as part of the CUAC standard. Note that our previous report showed results from both RCAC and heat pumps, which are not directly comparable. 
Table 2. CUAC Cooling-Only Results in Year 2020 Using the Traditional Approach in the 2003 Version of NEMS-BT

\begin{tabular}{|c|c|c|c|}
\hline $\begin{array}{c}\text { Trial Standard } \\
\text { Level }\end{array}$ & $\begin{array}{c}\text { Energy Sales } \\
\text { Change (TWh) }\end{array}$ & $\begin{array}{c}\text { Peak Capacity } \\
\text { Change (GW) }\end{array}$ & $\begin{array}{c}\text { National CLF } \\
\text { out }\end{array}$ \\
\hline TSL 1 & -12.7 & -4.5 & $32 \%$ \\
\hline TSL 2 & -21.3 & -9.7 & $25 \%$ \\
\hline TSL 3 & -24.7 & -11.2 & $25 \%$ \\
\hline TSL 4 & -31.9 & -14.5 & $25 \%$ \\
\hline TSL 5 & -62.3 & -24.6 & $29 \%$ \\
\hline
\end{tabular}

As will be discussed further in subsection 6.4, varying the multipliers can influence the range in magnitude of the National $\mathrm{CLF}_{\text {out }}$ in this table. In general, the higher the multipliers that are chosen, the higher the National CLF $_{\text {out }}$ tends to be. Table 3 shows the sets of multipliers used for each of the CUAC TSLs. For the traditional approach results, TSLs 1 and 5 use higher sets of multipliers, resulting in higher National CLF $_{\text {out }}$ values as seen in Table 2. For this reason, the results in this report, with the exception of the Table 2 results, use the lower set of multipliers presented in Table 3. In general, the use of lower multipliers lowers the CLF roughly 2-5\%. Table 4 shows the results for CUAC TSL 4 using both the higher and lower multipliers to perform our analysis. The effect of the multipliers is discussed further in Section 6.3.2.

Table 3. Comparison of Multipliers used for each CUAC TSL

\begin{tabular}{|c|c|c|}
\hline $\begin{array}{c}\text { Trial Standard } \\
\text { Level }\end{array}$ & Higher Multipliers & Lower Multipliers \\
\hline TSL 1 & $12,24,36$ & $5,8,10$ \\
\hline TSL 2 & $6,8,10$ & $3,4,5$ \\
\hline TSL 3 & $6,8,10$ & $3,4,5$ \\
\hline TSL 4 & $4,6,8$ & $2,3,4$ \\
\hline TSL 5 & $2,4,6$ & $1,1.5,2$ \\
\hline
\end{tabular}

Table 4. Impact of Results for CUAC TSL 4 Due to Multipliers

\begin{tabular}{|c|c|c|}
\hline & $\begin{array}{c}\text { Peak Capacity } \\
\text { Change (GW) }\end{array}$ & National CLF out \\
\hline $\begin{array}{c}\text { Higher } \\
\text { Multipliers }\end{array}$ & 14.5 & $25 \%$ \\
\hline $\begin{array}{c}\text { Lower } \\
\text { Multipliers }\end{array}$ & 16.5 & $22 \%$ \\
\hline
\end{tabular}





\section{Validating the Load Shapes in NEMS}

This section compares NEMS commercial space cooling end-use and system load shapes to those from an external simulation. Also, NEMS system loads are compared to historic system load data. The purpose is to ensure that the load shapes in NEMS are credible and to identify any significant differences. Section 3.1 presents the end use space cooling and ventilation load shapes. Section 3.2 compares those NEMS end-use load shapes to ones developed exogenously by building simulations. Section 3.3 makes a similar comparison for the system loads among three sources - NEMS, historic 1999 data, and TMY weather normalized data. Finally, section 3.4 compares the end-use space cooling load shape in NEMS to the system load shape in NEMS to gauge the degree of peak coincidence or non-coincidence.

Throughout this section, comparisons of the various load shapes are illustrated by focusing on the ECAR (East Central Area Reliability) EMM region. All regions were similarly analyzed but this region should provide enough representative information to satisfy the reader. ECAR amounts to roughly $15 \%$ of the total U.S. load so is a significant contributor to the overall impact from a proposed CUAC standard. Figure 1 shows a map of the 13 EMM regions and Table 5 shows the shorthand used in this report for each of these regions.

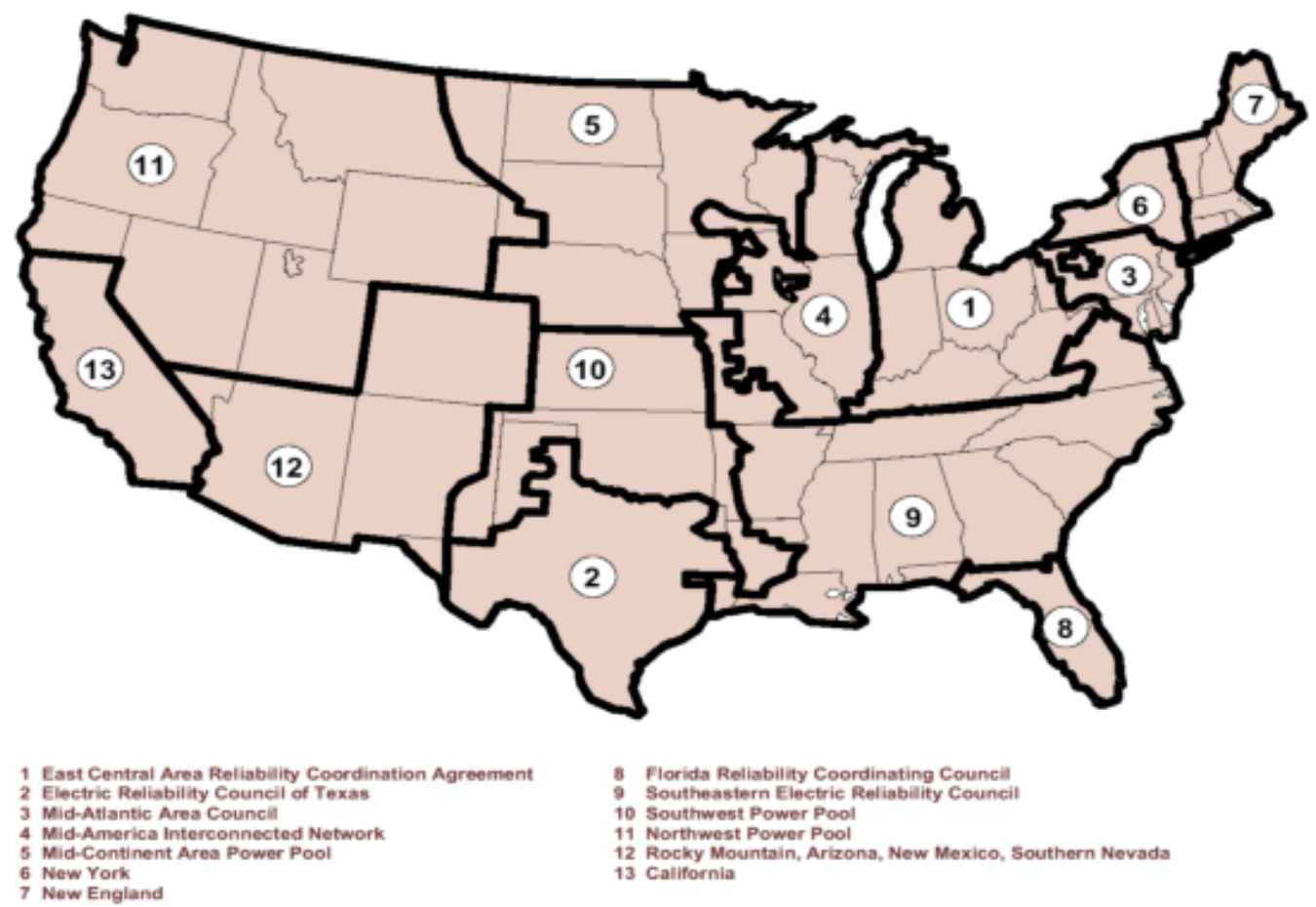

Figure 1. Map of EMM Regions 
Table 5. Definition of EMM Regions

\begin{tabular}{|c|c|c|}
\hline$\#$ & EMM Region & Definition \\
\hline 1 & ECAR & $\begin{array}{c}\text { East Central Area Reliability Coordination } \\
\text { Agreement }\end{array}$ \\
\hline 2 & ERCOT & Electric Reliability Council of Texas \\
\hline 3 & MAAC & Mid-Atlantic Area Council \\
\hline 4 & MAIN & Mid-America Interconnected Network \\
\hline 5 & MAPP & Mid-Continent Area Power Pool \\
\hline 6 & NY & New York \\
\hline 7 & NE & Florida Reliability Coordinating Council \\
\hline 8 & FL & Southeastern Electric Reliability Council \\
\hline 9 & STV & Southwest Power Pool \\
\hline 10 & SPP & Northwest Power Pool \\
\hline 11 & NWP & Rocky Mountains, Arizona, New Mexico and \\
southern Nevada
\end{tabular}

\subsection{End-Use Space Cooling and Ventilation Load Shapes in NEMS}

Although still in the early stages of the rulemaking analysis, it is estimated that over $55 \%$ of the energy savings estimated from this standard will come from commercial space cooling, which is highly peak coincident, with the remaining $45 \%$ derived from ventilation savings. The space cooling load shape is more peak coincident than the ventilation load shape so it is important that it be accurately represented in this CUAC analysis. For more detailed illustration of the space cooling load profiles for the months of January, April, July and October for four EMM regions ECAR, NE, SERC, and CNV please see Appendix C. This appendix of figures also includes hourly profiles from simulated loads that will be discussed in more detail in the next section. The commercial space cooling end use is represented by 13 different load shapes, one for each of the 13 EMM regions. Table 6 below shows the $\mathrm{LF}_{\text {in }}$ and peak hour of the input commercial space cooling load shapes for each region. With the exception of EMM region 13, the load shape peaks at $3 \mathrm{pm}$ in July. 
Table 6. Commercial Space Cooling LF in and Peak Hour from Input Load Shape of AEO2003 Version

\begin{tabular}{|c|c|c|}
\hline EMM Region & $\mathbf{L F}_{\text {in }}(\mathbf{\%})$ & Month and Hour of Peak \\
\hline 1 & $10 \%$ & July $3 \mathrm{pm}$ \\
\hline 2 & $15 \%$ & July $3 \mathrm{pm}$ \\
\hline 3 & $11 \%$ & July $3 \mathrm{pm}$ \\
\hline 4 & $10 \%$ & July $3 \mathrm{pm}$ \\
\hline 5 & $10 \%$ & July $3 \mathrm{pm}$ \\
\hline 6 & $9 \%$ & July $3 \mathrm{pm}$ \\
\hline 7 & $8 \%$ & July $3 \mathrm{pm}$ \\
\hline 8 & $16 \%$ & July $3 \mathrm{pm}$ \\
\hline 9 & $15 \%$ & July $3 \mathrm{pm}$ \\
\hline 10 & $12 \%$ & July $3 \mathrm{pm}$ \\
\hline 11 & $12 \%$ & July $3 \mathrm{pm}$ \\
\hline 12 & $12 \%$ & July $3 \mathrm{pm}$ \\
\hline 13 & $12 \%$ & August $3 \mathrm{pm}$ \\
\hline
\end{tabular}

Figure 2 illustrates the commercial space cooling load profile for ECAR. This figure shows the normalized hourly load for three day types - weekday, weekend and the peak day for the month of July assuming an annual energy demand of $1000 \mathrm{kWh}$. All load curves are expressed as fractions of annual energy use, making them very readily compared by applying a consistent annual consumption value. In Figure 2, the ECAR space cooling load profile shows a clear apex on the peak day at $3 \mathrm{pm}$, consistent with Table 6 . This strong peak is characteristic of the demand from this end use in regions with warmer, drier climates in the summer. For most other regions, this shape is similar during the month of July, although varying in the magnitude of the hourly load. The commercial space cooling load profile is essentially zero during the winter months from November through March.

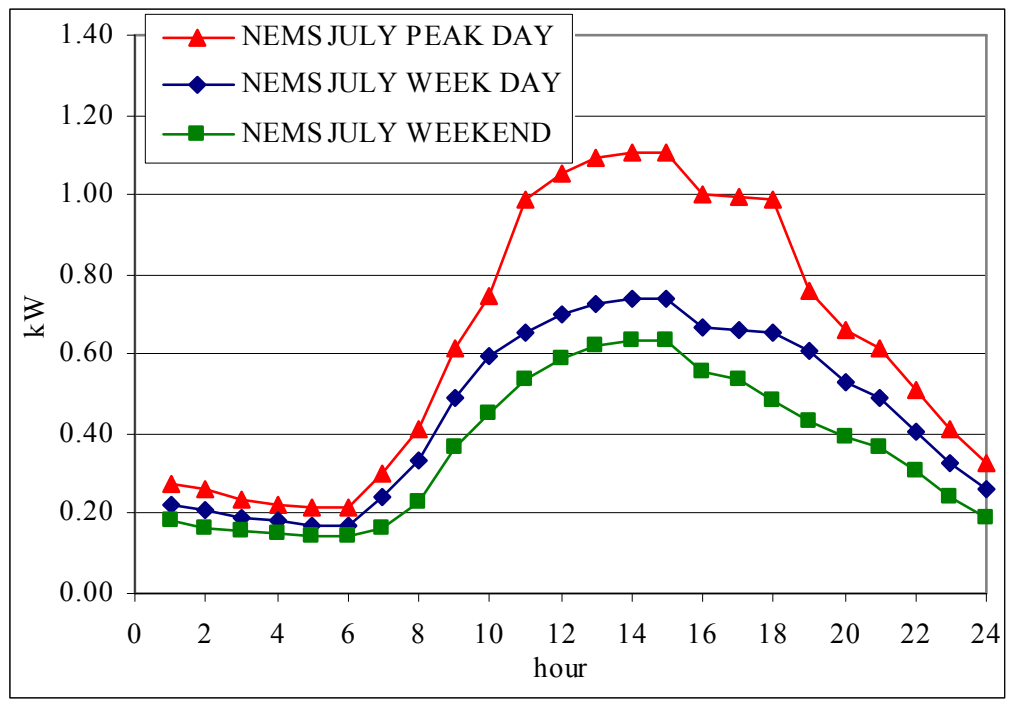

Figure 2. NEMS July Space Cooling Load Shapes for ECAR

Figure 3 shows the commercial ventilation load profile for ECAR for the month of July. Unlike the commercial space cooling load profile, the ventilation shape in NEMS is characteristically 
flat throughout both the day and the year. Note that ventilation is in use during all seasons irrespective of the need for heating or cooling. The CUAC rulemaking covers energy savings from this end use, where savings are largely during the non-peak hours of the day.

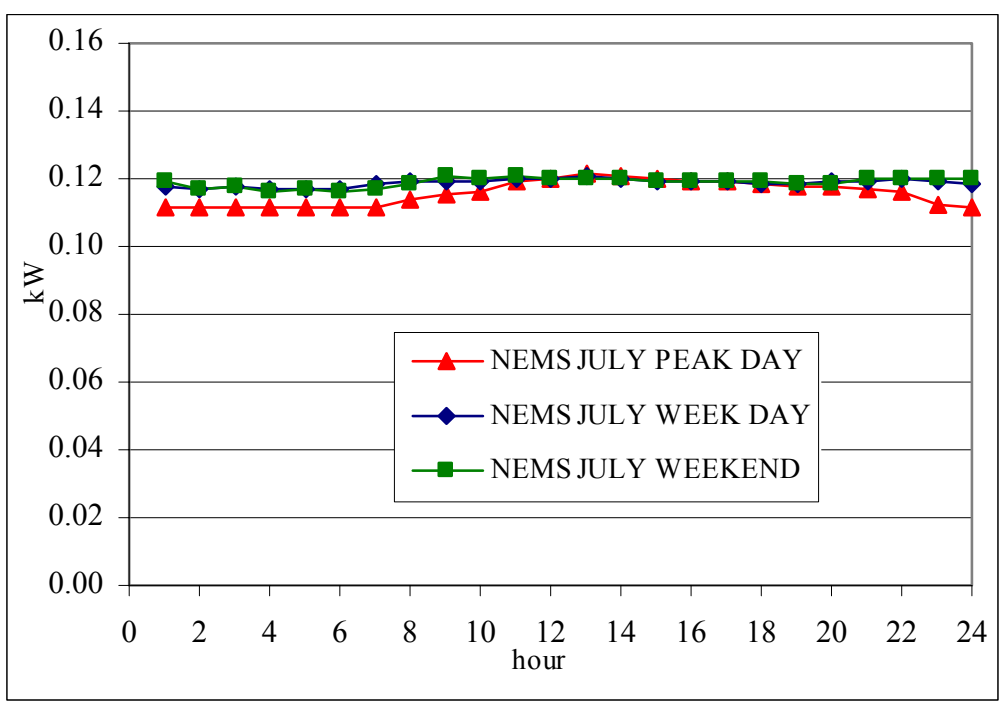

Figure 3. NEMS July Ventilation Load Shapes for ECAR

In general, the space cooling and ventilation load shapes in NEMS cover a broader range of technology types than under consideration for the CUAC rulemaking. The NEMS end uses that are covered under the proposed CUAC energy efficiency standard roughly cover only commercial sector space cooling and ventilation. The space cooling end use in NEMS covers a variety of cooling technology types, including heat pumps, chillers, and rooftop, residential-style and window unit air conditioners. The CUAC rulemaking, however, only considers a subset of these: air-cooled single package and split system unitary air conditioners with cooling capacities of $\geq 69,000 \mathrm{~kJ} / \mathrm{h}(65,000 \mathrm{Btu} / \mathrm{h})$ to $<250,000 \mathrm{~kJ} / \mathrm{h}(240,000 \mathrm{Btu} / \mathrm{h})$. This is roughly equivalent to 20-70 kW sized units. The ventilation load shape in NEMS covers the circulation of air through a building to provide fresh air to the occupants and to deliver heating and cooling to the occupied spaces. Again, this is a broader spectrum than is considered in the rulemaking.

Heat pumps are not currently included under the CUAC rulemaking.

\subsection{Comparison of End-Use Load Shapes with Simulations}

Berkeley Lab compared the NEMS end use space cooling and ventilation load shapes to simulated CUAC and ventilation load shapes developed by Pacific Northwest National Laboratory (PNNL). Section 3.2.1 provides detailed information about the simulated load shapes. Section 3.2.2 then presents the comparison of the NEMS space cooling and simulated AC load shapes to the PNNL simulated shapes, hereafter called typical meteorological year (TMY) CUAC load shapes. 


\subsubsection{Simulation of Load Shapes}

PNNL used commercial building simulations to generate TMY CUAC load shapes. The simulations consider how CUAC energy-use varies according to efficiency level and a number of factors including climate, building-type, building occupancy and function. The simulations yield hourly estimates of the buildings' electric loads, including CUAC and ventilation. These are subsequently used in the Life Cycle Cost (LCC) analysis portion of the CUAC rulemaking process to assess the operating cost-savings that the CUAC equipment provides at each of the efficiency levels analyzed.

The simulations produced results for a variety of building types in different climate locations to represent the diversity of use and performance of unitary air conditioning equipment. The 1995 Commercial Buildings Energy Consumption Survey (CBECS 95) was the primary source of data used to develop a data set consisting of 1033 buildings. Only buildings that are air conditioned over $70 \%$ of their floor space with unitary air conditioning equipment were included. Six building types were considered: assembly, education, food service, office, retail, and warehouse. These six building types account for $73 \%$ of the annual cooling energy use and $67 \%$ of the floor space of commercial buildings that reported having unitary air-conditioning equipment. The meteorological data is represented by TMY data to represent each of the 1,033 buildings represented in the simulation analysis. Using TMY data removes the influence of abnormal weather phenomena and therefore removes any association to a specific year.

Each building in the set was modeled using the Building Loads and System Thermodynamics (BLAST) software and the simulations were performed using a generic building model. The prototype building is a three-story $4,500 \mathrm{~m}^{2}\left(48,000 \mathrm{ft}^{2}\right)$ building situated in 15 separate climate zones. The result is an estimated hourly end-use energy profile for CUAC equipment. ${ }^{1}$

\subsubsection{Comparison of NEMS Commercial Space Cooling Load Shape with Simulated TMY CUAC Load Shape}

NEMS defines only 13 different commercial space-cooling load shapes, one for each of the 13 EMM regions, making no distinction among the various commercial building types. For purposes of making direct comparisons between the load shapes in NEMS and those that were simulated, a single representative simulated load shape was determined for each EMM region. This was accomplished by assigning each of the 1,033 buildings to an EMM region, and then aggregating building CUAC loads to a single load shape using CBECS based weighting.

Similar to Figure 2, Figure 4 illustrates the NEMS ECAR July hourly load profile for commercial space cooling, this time in conjunction with the corresponding TMY simulated load for the CUAC end use. Both shapes are normalized to an annual energy use of $1,000 \mathrm{kWh}$. The purpose of this comparison is to illustrate what, if any, differences exist between these two data sources. The ECAR EMM region is shown for illustrative purposes as generally representative of the variation between the NEMS space cooling and simulated TMY CUAC load shapes seen in other EMM regions and day types. For the most part, the NEMS and simulated load profiles both

\footnotetext{
${ }^{1}$ For more detailed information on the commercial building end use load characterizations, a PowerPoint presentation is available at the following website: http://www.eere.energy.gov/buildings/appliance_standards/commercial/ac_hp.html
} 
capture the shape of the peak for this region's July cooling load. The simulated TMY CUAC load profile peaks around $4 \mathrm{pm}$, while the NEMS cooling shape peaks at $3 \mathrm{pm}$. In general, the simulated TMY load shape is smaller than the NEMS shape with the TMY peak roughly $30 \%$ lower than the NEMS peak. This is similar to what is seen in other regions, with the shape of the profile well captured, yet somewhat significant differences in the magnitude of the peak. During the summer months, NEMS is generally higher than the TMY simulated peak, although in winter the TMY shows more use than the NEMS profile.

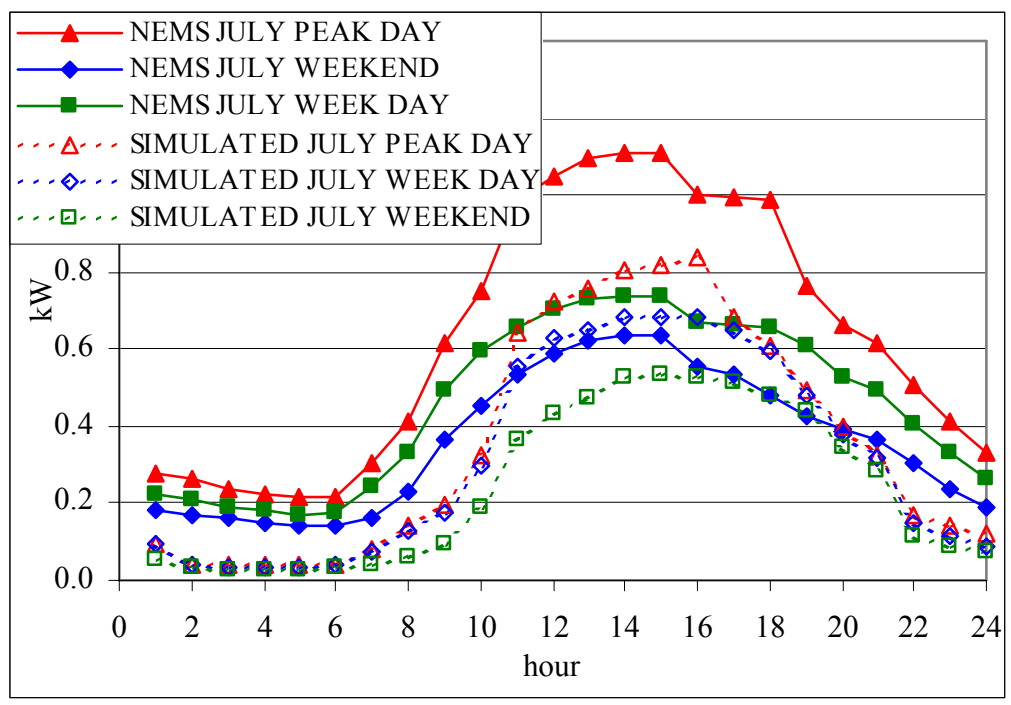

Figure 4. Comparison of NEMS Space Cooling and Simulated TMY CUAC Load Shapes

The NEMS space cooling load shape that was updated in the AEO2001 version and that is still used in the AEO2003 version is based on a large database of end use load shapes called the RELOAD database. This database is a large collection of 1,486 load profiles compiled by EPRI with the original development of the load shapes performed by ICF Resources, Inc.

Unfortunately not much is known about the specifics regarding the RELOAD database, as EPRI no longer maintains this file nor possesses any detailed documentation for it (Holte 2001b).

The updated space cooling load shape is a composite of space cooling end use load shapes from different building types taken from the RELOAD database. Table 7 shows the commercial space cooling end use load shape composition. Interestingly, the commercial space cooling load shape is based entirely on air conditioning load shapes for the city of Chicago, with over one-third coming from a load shape for a commercial large retail building. 
Table 7. Composition of Commercial Space Cooling Load Shape in NEMS

\begin{tabular}{|c|c|}
\hline $\begin{array}{c}\text { Share of } \\
\text { Load Shape }\end{array}$ & $\begin{array}{c}\text { Commercial Building Type } \\
\text { in Chicago }\end{array}$ \\
\hline $35.0 \%$ & Large office \\
\hline $15.9 \%$ & Shopping center \\
\hline $11.6 \%$ & Large retail \\
\hline $14.6 \%$ & School \\
\hline $6.4 \%$ & Restaurant \\
\hline $6.4 \%$ & Fast Food \\
\hline $3.1 \%$ & Grocery \\
\hline $3.1 \%$ & Hospital \\
\hline $4.0 \%$ & Warehouse \\
\hline
\end{tabular}

Source: OnLocation, Inc., Alternative Sectoral Load Shapes for NEMS, August 2001.

However, this was only done for the weekday and weekend load shapes. The space cooling peak day load shape from the RELOAD database was not deemed acceptable so was constructed from the weekday load shape using reasonable assumptions. OnLocation, Inc. assumed that the peak day load shape was $50 \%$ higher than the weekday load shape for 12 hours out of the peak day and $25 \%$ higher than the weekday load shape for the remaining 12 non-peak hours. Therefore the peak hours are essentially the highest hours of the weekday load shape (Holte 2001a).

Regional load shapes were constructed using weather information by Census Division region. Monthly normal temperature data from the Short Term Energy Outlook was used to calculate the cooling degree days, which were then applied to each region's space cooling load shape. The percentage of cooling degree days in each month were used to adjust the monthly loads to reflect the regional influence of climate.

Figure 5 shows a comparison of the implicit $\mathrm{LF}_{\text {in }}$ based on the load profile from the NEMS input space cooling load shape and the simulated TMY CUAC load shape. In general, the simulated TMY CLF is higher, i.e. the NEMS space cooling load shape is peakier. The PNNL TMY CUAC load shape is based on simulations of more than 1,033 commercial buildings and is adjusted to be weather-neutral. 


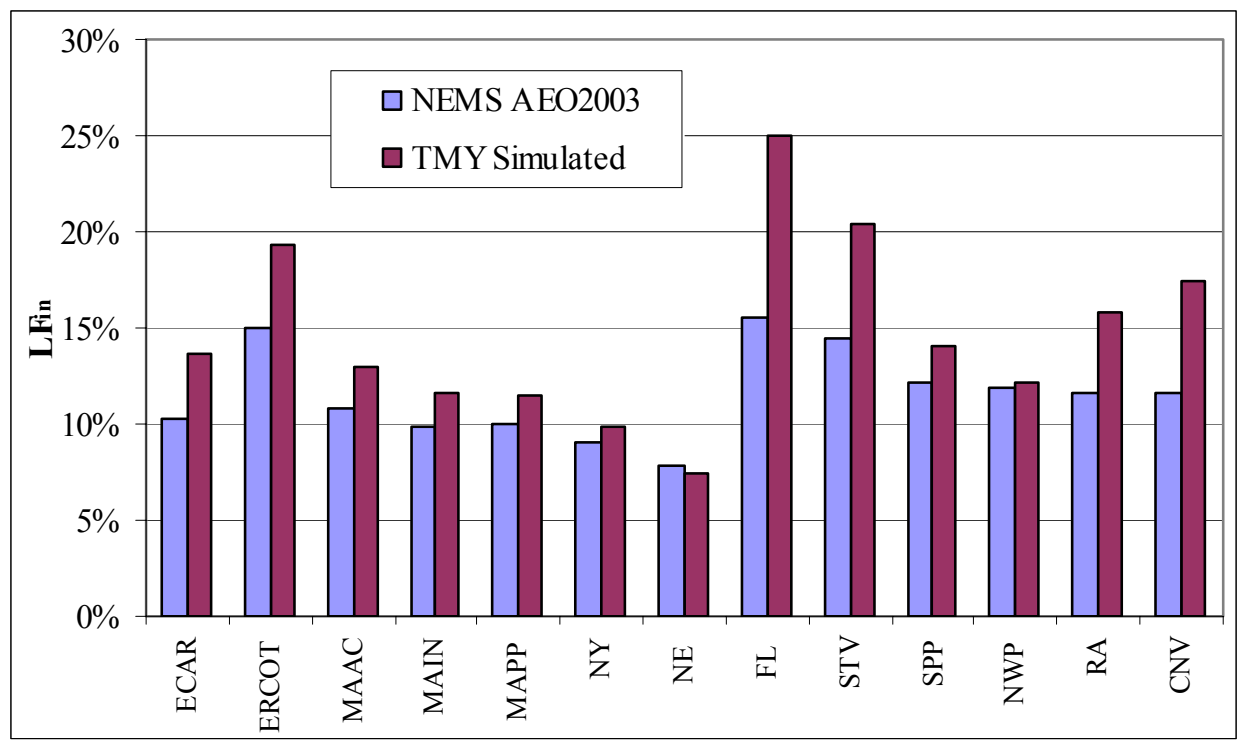

Figure 5. Comparison of NEMS and TMY Simulated Cooling Load Shape LF in

Figure 6 shows a similar comparison except this time for ventilation, and noticeable differences exist between the NEMS and TMY load shapes. The NEMS load profile is simply flat throughout the day, whereas the simulated load shape indicates a higher-level usage from 10am to $6 \mathrm{pm}$ compared to the nighttime hours. The flat shape in the NEMS ventilation load shape is likely due to an oversimplified use assumption that does not account for typical commercial building operating schedules. The building simulations show lower usage at night and high flat usage during the day. Because real buildings are often not ventilated when the building is unoccupied, the PNNL shapes appear prima facie more credible.

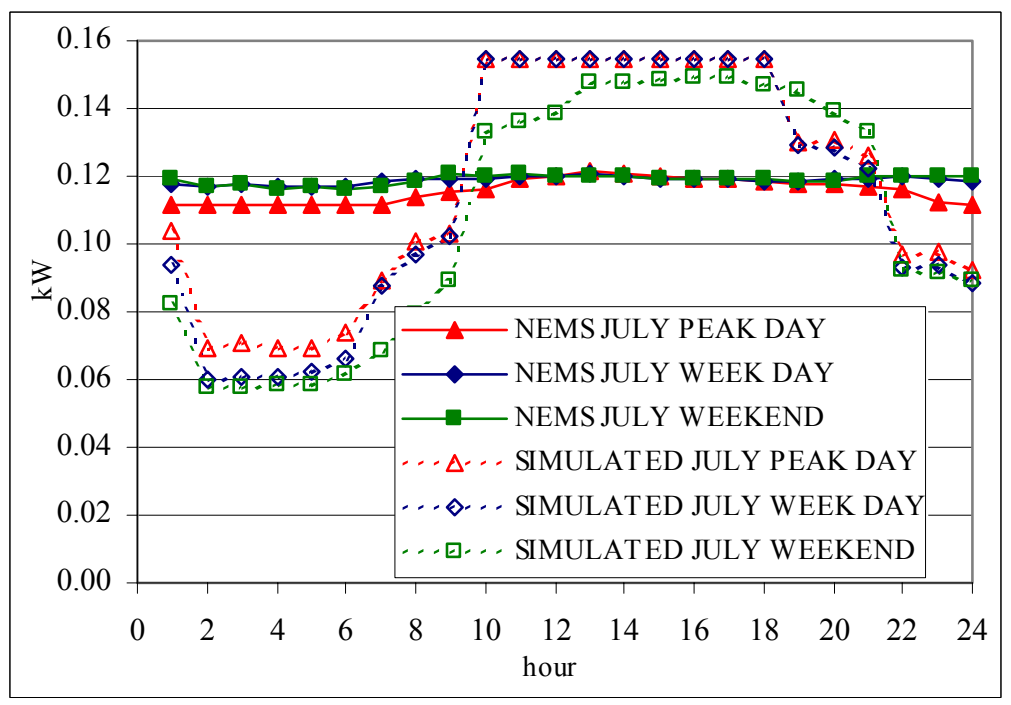

Figure 6. Comparison of NEMS Ventilation and Simulated TMY Ventilation Load Shapes 
A more complete display of the comparisons appears in Appendix C, showing the hourly profiles for four months, January, April, July, and October, and four EMM regions, ECAR, NE, STV, and $\mathrm{CNV}$.

\subsection{Comparison of NEMS System Load Shape with Historical Data and TMY System Load}

This section compares NEMS system load shapes to historical 1999 data and to weather normalized load data. Because coincidence of end use load decrements with system load is a major determinant of the National CLF $_{\text {out }}$, it is important to validate the NEMS system load shapes as well as to improve on its end use load shapes.

The historical data on hourly system loads was taken from the U.S. Federal Energy Regulatory Commission (FERC) Form 714 filings. Every utility in the country with an annual peak load above $200 \mathrm{MW}$ for its planning area must report a time series of hourly load each year. The analysis used market data from year 1999 for California, and from 2000 for New York, PJM, and New England.

The TMY system load shapes were developed at Berkeley Lab based on historical 1999 system load data and collected TMY temperature data. For each EMM region and for every hour, including an index for day/night, and day type, a least-squares third-order-polynomial fit is used to express load as a function of TMY temperature. Experimentation with different models showed the best fit was from a third-order polynomial. This polynomial is used to compute the TMY loads as a function of TMY temperature. A correction is then made to the TMY loads to represent fluctuations around the mean value computed with a polynomial fit. This variation is calculated as the difference between the historical load and the predicted load to develop a frequency distribution that is then used to generate a set of random corrections to the TMY predicted loads. The values of the fluctuations range from $-15 \%$ to $+20 \%$ and are randomly applied to the predicted loads in order to account for the degree of random fluctuation around the fitted value predicted by the model. ${ }^{2}$

Figure 7 illustrates a comparison of the ECAR June to September system load shapes from NEMS with the TMY system loads. All three profiles are normalized to an annual demand of $1,000 \mathrm{kWh}$. Because the TMY system load shape is derived based on the historical 1999 data, it makes sense that both the TMY and historical system loads would have similar characteristic shapes. The main difference between these two shapes is the influence of extreme weather, which is removed from the TMY load profile. As was seen in Figure 4 with the NEMS space cooling and TMY CUAC load shape comparison, the NEMS system load is slightly higher in magnitude compared to the simulation or historical 1999 system loads. However, this is not evident in most other regions. Overall, the shape of the peak day system load is comparable across all three sources.

\footnotetext{
${ }^{2}$ For more information on how the TMY system loads were developed, please see Appendix N: Modeling TMY Prices of the CUAC Rulemaking TSD.
} 


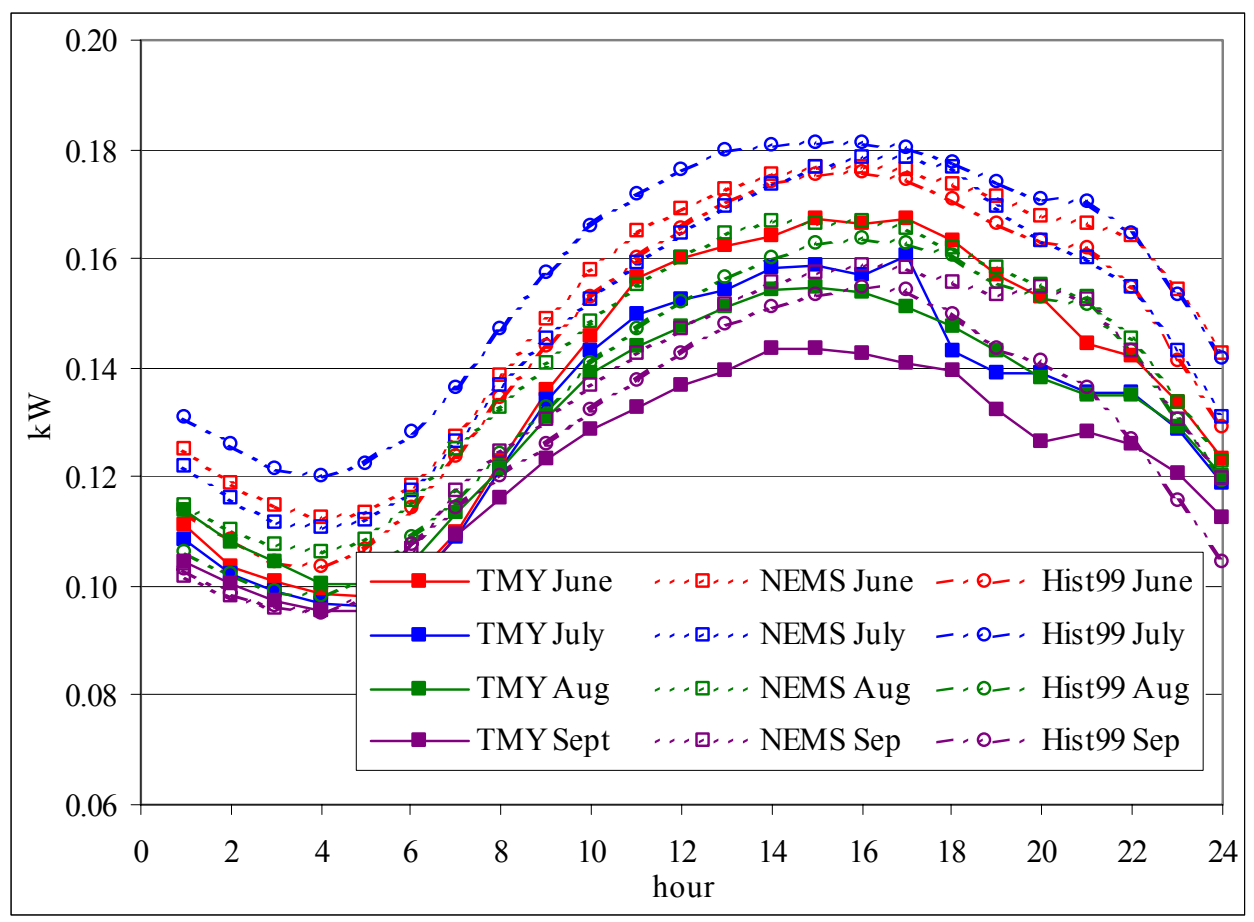

Figure 7. Comparison of System Load Peak Day in ECAR from NEMS, TMY, and Historical 1999 Data

Berkeley Lab also calculated the root mean square (RMS) difference to identify the degree of variability among the NEMS, TMY, and historical 1999 system load shapes. The RMS difference is expressed as follows,

$$
\text { RMSDifference }=\sqrt{\frac{\sum_{n=1}^{24}\left(X_{N E M S}-X_{T M Y}\right)^{2}}{n-1}}
$$

where $X_{N E M S}$ and $X_{T M Y}$ are the energy demanded for a given hour of each day type, month and region and $n$ is the number of hours in the day. The differences are calculated for each day type and each month for all 13 EMM regions.

Figure 8 illustrates the RMS difference for each day type and month of the year for the ECAR region. Both the difference between the NEMS and TMY system load and between the historical 1999 and TMY system loads are shown. Although there is some noticeable variability in the difference, there is no consistent trend error that would suggest a discrepancy between these data sources. The same is true of the remaining EMM regions with the exception of the MAPP region, where the NEMS system load is significantly higher than the other two sources. Berkeley Lab has yet to conclude why this one EMM region appears to be behaving anomalously. 


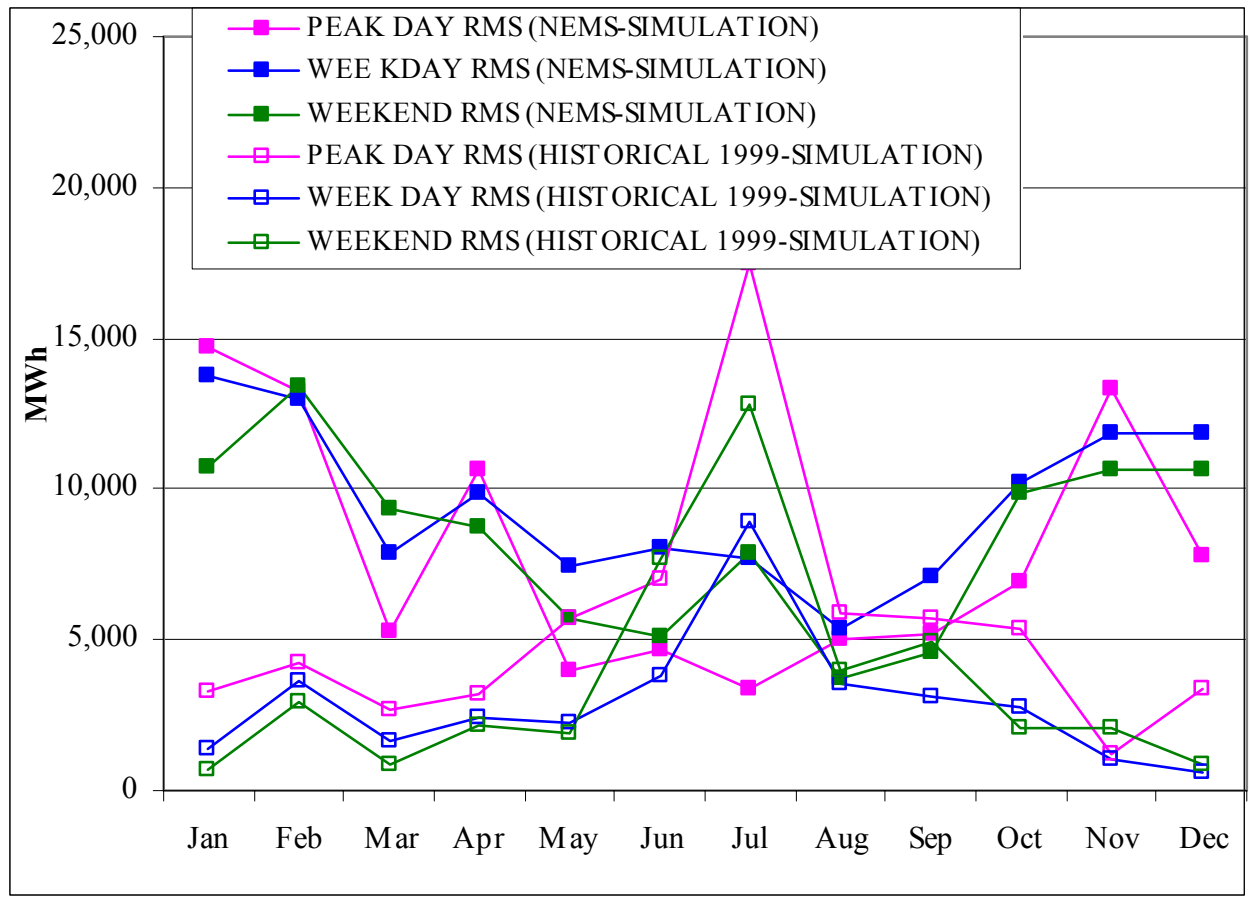

Figure 8. Root Mean Square Difference of ECAR System Load

Expressed as a percentage of the average daily demand in Figure 9, the RMS difference represents less than $1 \%$ of the daily energy demanded. The difference in the peak day is higher than for the weekday or weekend day types, and again, this is true of the other EMM regions. However, compared to the total usage for the day, the overall impact is small, indicating that the differences in the system loads do not exhibit a systematic bias. This is not to say that the system load shapes are not different, just that the differences don't look systematic. For more information on an exercise performed by Berkeley Lab of what it takes to restore the substituted TMY system load shape in NEMS-BT back to the Reference Case, please see Appendix G. 


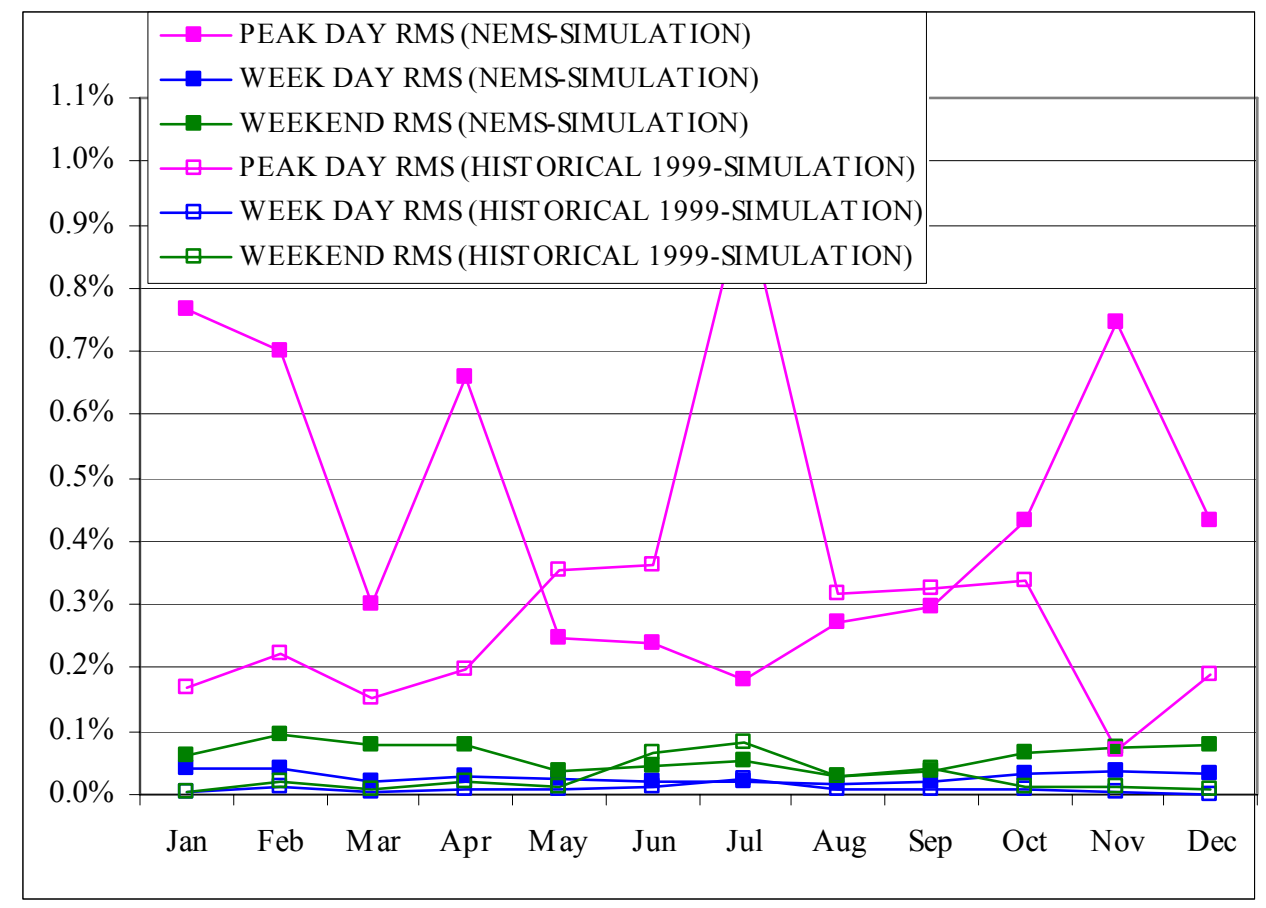

Figure 9. Root Mean Square Difference of System Load for ECAR as Percentage of Daily Load

Additionally, Berkeley Lab also plotted a series of scatter plots that compare the peak hour from the NEMS, TMY, and historical 1999 data sources. Figure 10 compares the TMY and NEMS system loads when the total annual energy is set equal for both sources. With the total energy equal in both cases, the peak load is plotted as a percentage of each month and region's total energy demand. The diagonal line represents equivalent peak hours. Figure 11 shows a similar plot for NEMS and historical 1999 system loads. In both cases, the scatter of points is evenly distributed around the diagonal, with no indication of a bias by month or region. That is, the 13 points for any month of the year (representing each of the 13 EMM regions) do not appear to be systematically skewed to one side of the 45-degree line. This test shows that the relative size of the peak to total energy is consistent across the three data sources. 


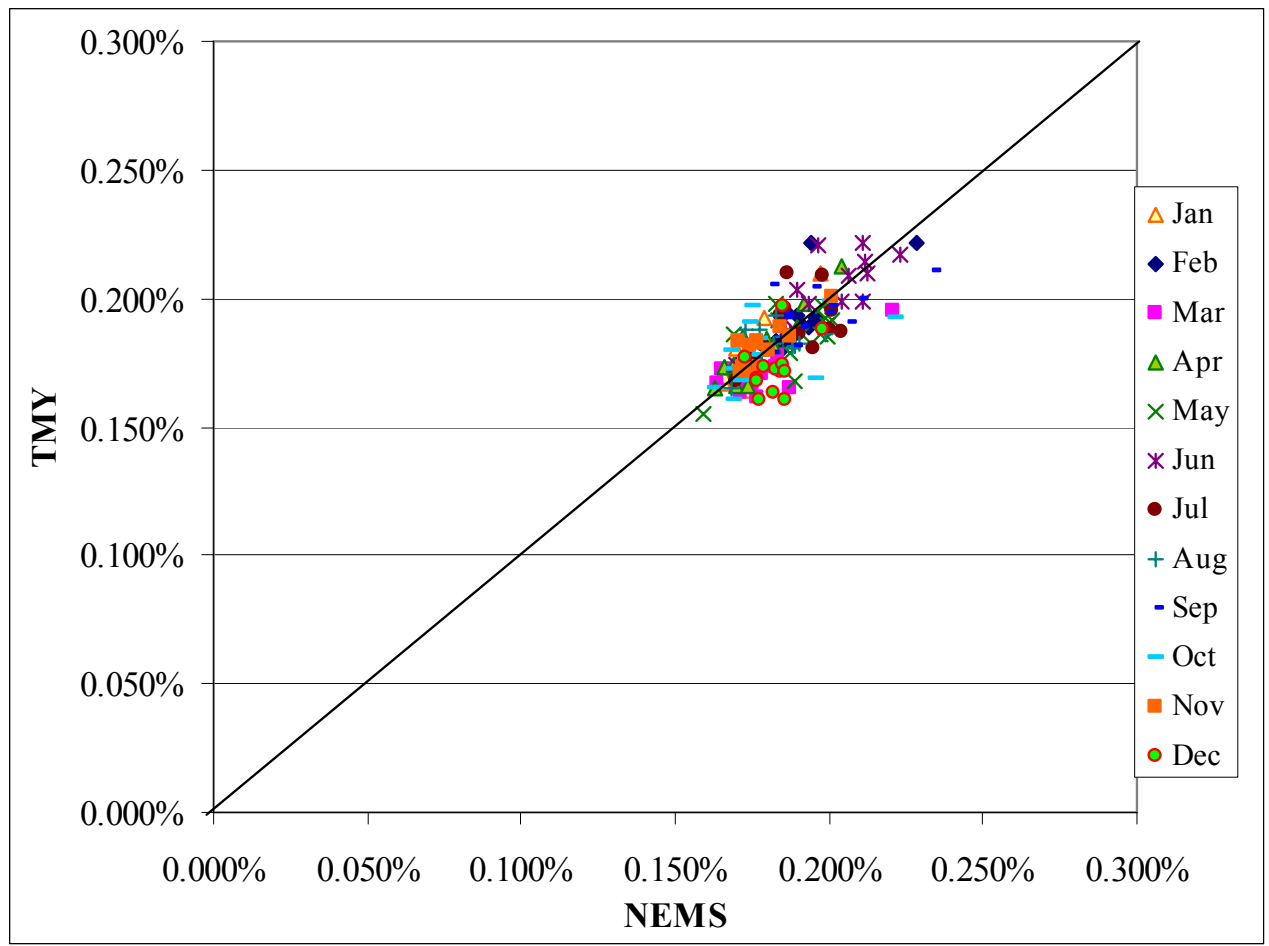

Figure 10. Peak Hour Energy as a Percentage of Total Demand by Month and EMM Region: NEMS vs. TMY System Loads

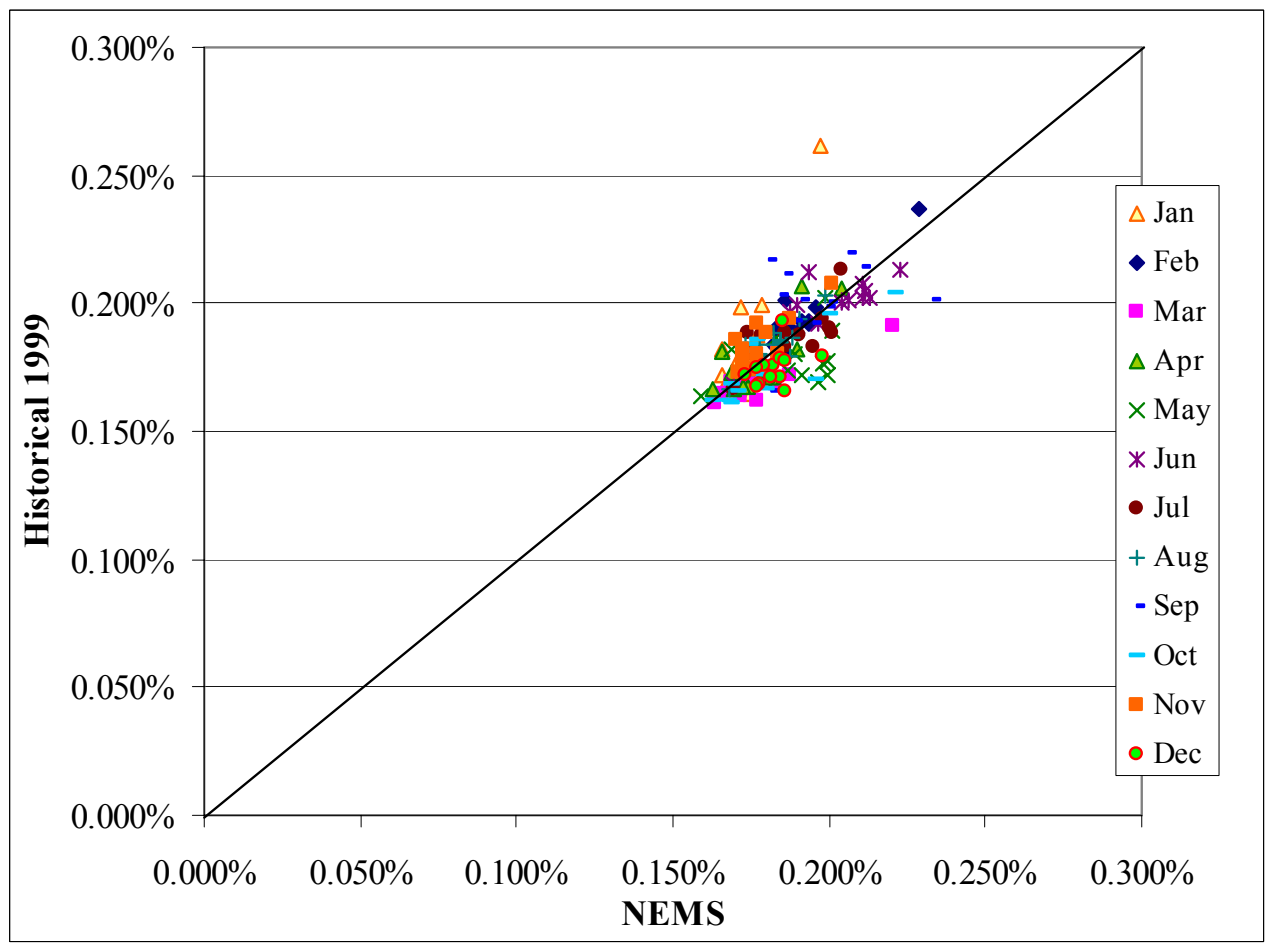

Figure 11. Peak Hour Energy as a Percentage of Total Demand by Month and EMM Region: NEMS vs. Historical 1999 System Loads 
A comparison of the total energy when the peak hours are set equal was also performed. In this exercise each hour's demand is transformed relative to the peak hour such that the share of the peak hour is maintained, but the magnitude of the demand changes. Figure 12 shows the scatter plot of the total energy in GWh for each month and region compared between the NEMS and TMY system loads. Figure 13 shows a similar figure comparing the NEMS and historical 1999 data sets. In both figures, the scatter of points is evenly distributed around the diagonal. Again, no bias for time of year is detectable in these figures.

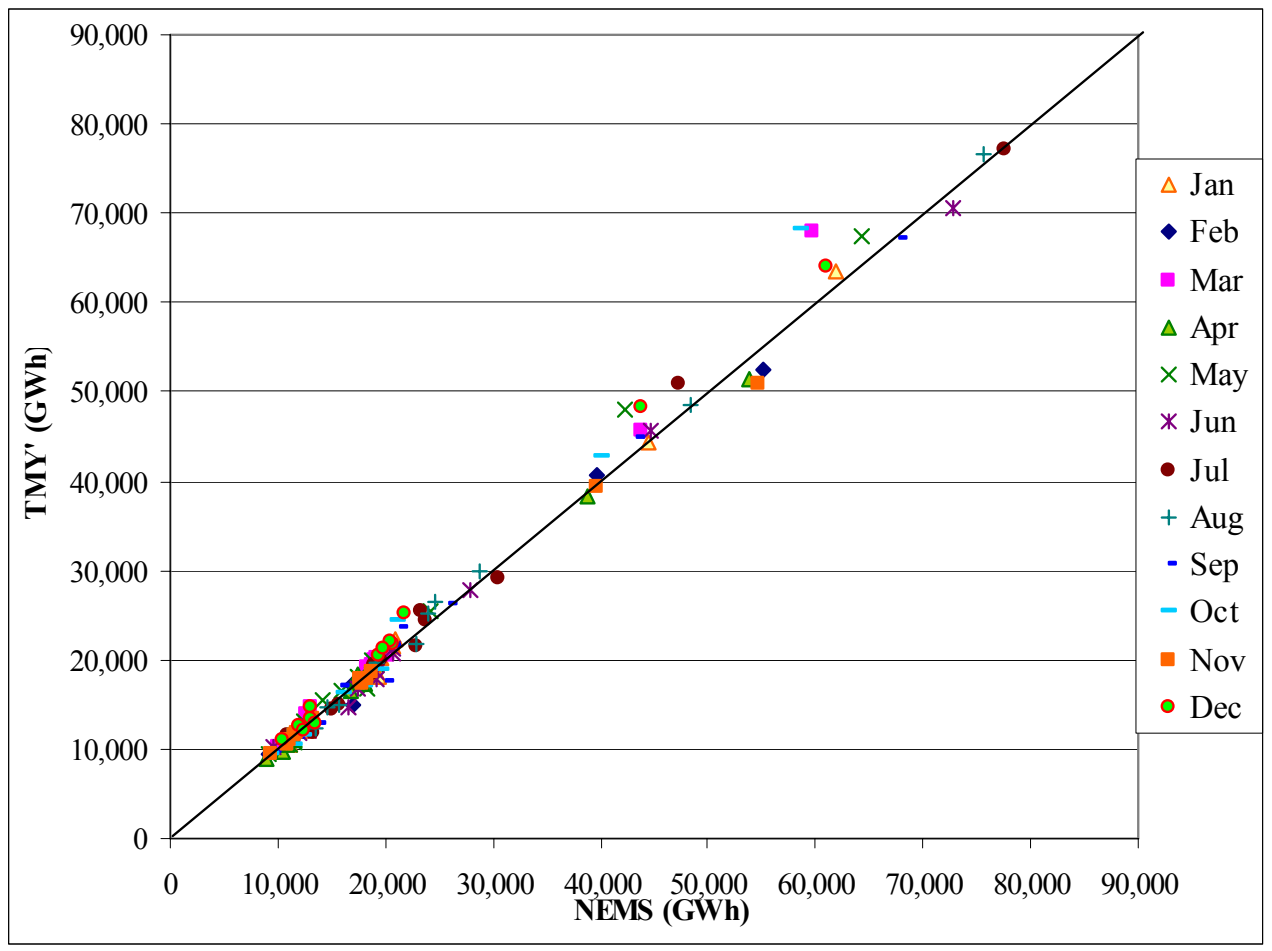

Figure 12. Total Energy by Month and EMM Region: NEMS vs. TMY System Loads 


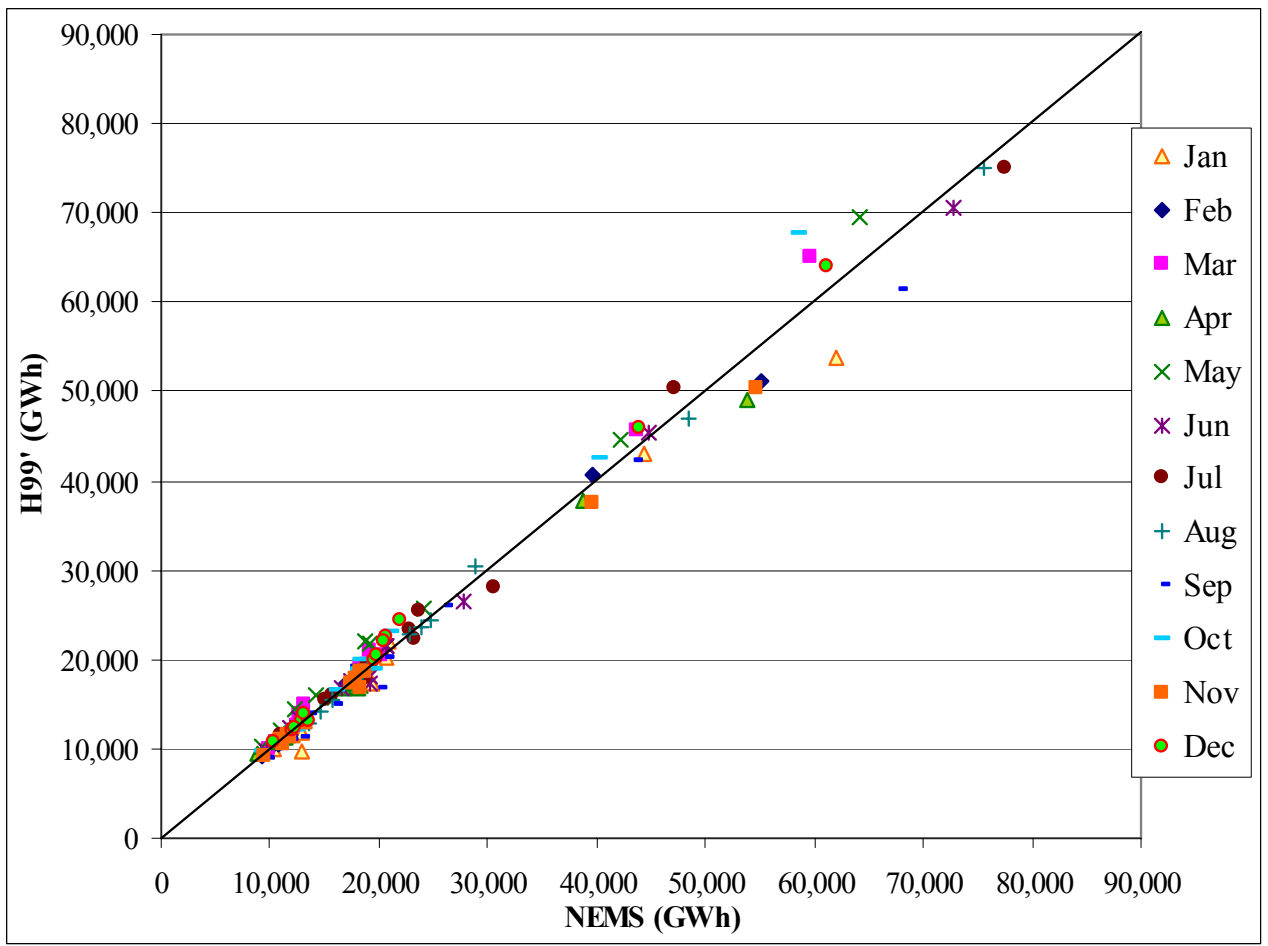

Figure 13. Total Energy by Month and EMM Region: NEMS vs. Historical 1999 System Loads

\subsection{Comparison of Space Cooling Load Shape with System Load Shape in NEMS}

This section compares the end-use space cooling and CUAC load shapes with the NEMS system load shape to illustrate the degree of non-coincidence inherent between these two loads. Berkeley Lab's new approach models the effects from a CUAC standard by modifying the system load so it is important to understand any differences between them.

Figure 14 below illustrates the comparison of the NEMS July 2000 ECAR system load with the simulated AC load. The y-axis shows the load normalized to an annual demand of $1000 \mathrm{kWh}$ for ease of comparison. As expected the system load shape is more flat than the AC load shape. Again, we see the AC load shape peaking around 4pm while the system peak for this month is flat during the afternoon. 


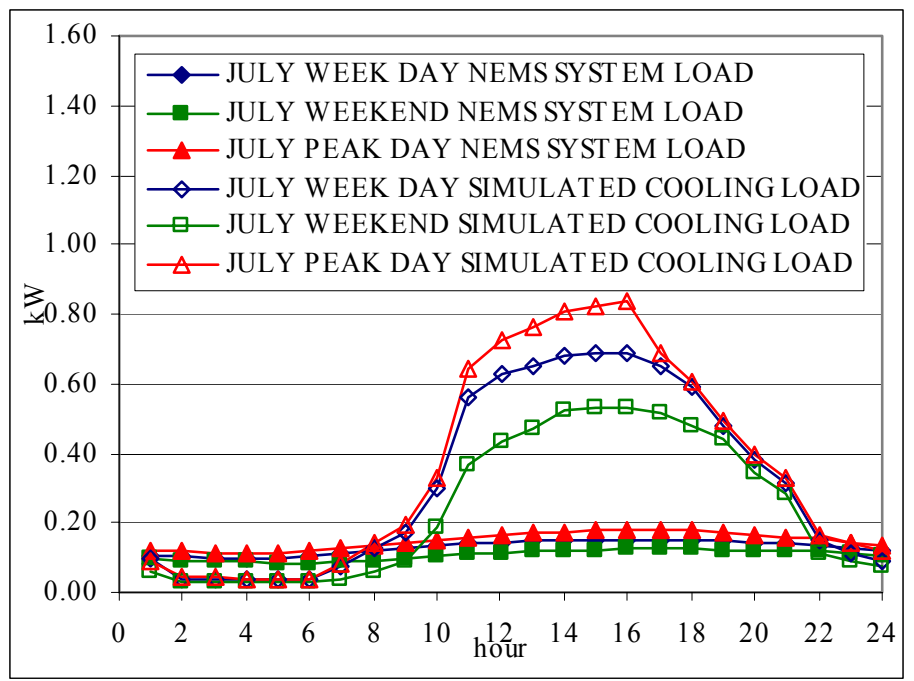

Figure 14. July NEMS System Load with Simulated AC Load Shape in ECAR

Figure 15 shows a similar illustration, except this time displaying the NEMS space cooling load shape instead of the simulated one. Here we see slightly less coincidence between the end-use space-cooling load (which peaks at 3pm) and the NEMS system load, illustrating the difference in the timing of the energy demanded. Again, both load profiles are normalized to an annual demand of $1,000 \mathrm{kWh}$. When focusing on the peak hour of the day, Figures 14 and 15 illustrate a slight difference in the coincidence of the NEMS space cooling load and the NEMS system load versus the TMY CUAC load with the NEMS system load. Although this section focuses on the ECAR region and the month of July, the comparisons are largely consistent with other EMM regions during the summer months.

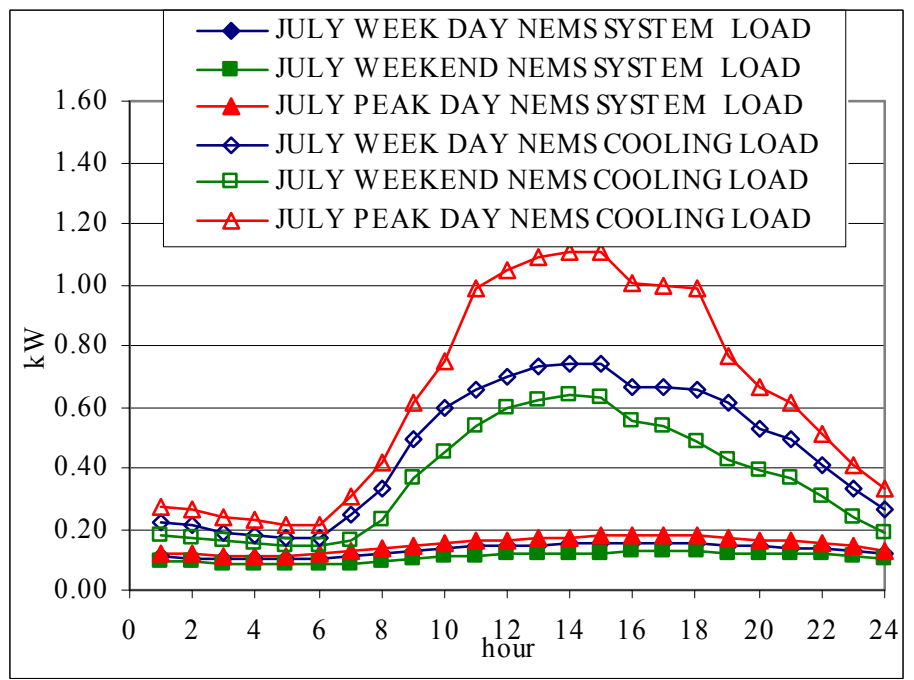

Figure 15. July NEMS System Load with NEMS Space Cooling Load Shape in ECAR

The issue of non-coincidence is an important one and will be discussed in more detail later in this report. Table 8 below shows the peak hour of the system load and the space-cooling loads for each EMM region. For the NEMS system and space cooling load shapes, the peaks are based 
on the year 2000. The simulated TMY CUAC load shape is weather-adjusted so does not correspond to any particular year.

In the ECAR region, the NEMS system load peaks at $5 \mathrm{pm}$ in July, while the NEMS space cooling and the simulated TMY CUAC loads peak at $3 \mathrm{pm}$ and $4 \mathrm{pm}$ in July, respectively. The ECAR TMY system load peaks at 5pm in June. But not all EMM regions follow a similar pattern. For example, in ERCOT, both the NEMS space cooling and simulated TMY CUAC loads peak at $3 \mathrm{pm}$ in July, while the NEMS system load peaks in August at 4pm and the TMY system load peaks in July at 4pm. The NWP region depicts the greatest amount of noncoincidence between the cooling and system load shapes. For the NWP region, the NEMS space cooling and simulated TMY CUAC loads peak at 3 and 4pm in July, respectively, while both the NEMS and TMY system loads are winter peaking.

Table 8. Month and Time of Peak Hour from End Use and System Loads

\begin{tabular}{|c|c|c|c|c|c|}
\hline EMM \# & EMM Region & $\begin{array}{l}\text { NEMS Commercial } \\
\text { Space Cooling }\end{array}$ & $\begin{array}{c}\text { Simulated TMY } \\
\text { CUAC }\end{array}$ & NEMS System Load & TMY System Load \\
\hline 1 & ECAR & July $3 \mathrm{pm}$ & July $4 \mathrm{pm}$ & July $5 \mathrm{pm}$ & June $5 \mathrm{pm}$ \\
\hline 2 & ERCOT & July $3 \mathrm{pm}$ & July $3 \mathrm{pm}$ & August 4pm & July $4 \mathrm{pm}$ \\
\hline 3 & MAAC & July $3 \mathrm{pm}$ & June 4pm & July $5 \mathrm{pm}$ & July $3 \mathrm{pm}$ \\
\hline 4 & MAIN & July $3 \mathrm{pm}$ & July $12 \mathrm{pm}$ & July $2 \mathrm{pm}$ & July $1 \mathrm{pm}$ \\
\hline 5 & MAPP & July $3 \mathrm{pm}$ & July $3 \mathrm{pm}$ & July $3 \mathrm{pm}$ & July $4 \mathrm{pm}$ \\
\hline 6 & NY & July 3pm & July 4pm & June $3 \mathrm{pm}$ & July 4pm \\
\hline 7 & $\mathrm{NE}$ & July $3 \mathrm{pm}$ & August 2pm & July $5 \mathrm{pm}$ & July $2 \mathrm{pm}$ \\
\hline 8 & FL & July 3pm & August $12 \mathrm{pm}$ & June $5 \mathrm{pm}$ & June $3 \mathrm{pm}$ \\
\hline 9 & STV & July $3 \mathrm{pm}$ & July $3 \mathrm{pm}$ & July $3 \mathrm{pm}$ & July $2 \mathrm{pm}$ \\
\hline 10 & SPP & July 3pm & August 3pm & July $5 \mathrm{pm}$ & June 4pm \\
\hline 11 & NWP & July $3 \mathrm{pm}$ & July $4 \mathrm{pm}$ & December $7 \mathrm{pm}$ & January $6 \mathrm{pm}$ \\
\hline 12 & RA & July 3pm & June $4 \mathrm{pm}$ & July 4pm & June $3 \mathrm{pm}$ \\
\hline 13 & $\mathrm{CNV}$ & August $3 \mathrm{pm}$ & July $3 \mathrm{pm}$ & September 4pm & September $12 \mathrm{pm}$ \\
\hline
\end{tabular}

\subsection{Summary of Load Shape Comparisons}

A comparison of the system load shapes in NEMS with those developed for TMY data and with historical data show that differences exist, although these differences do not seem to be overly concerning. The end use space cooling and TMY CUAC load shapes appear to be highly coincident overall. Although the NEMS ventilation load shape appears flat compared with the TMY simulated ventilation load shape, the amount of savings during these off peak hours is small and therefore not likely to significantly impact the results. The system loads appear similar among the three data sources and further examination using the RMS difference does not indicate any consistent trend in the differences. All differences are less than one percent of the energy demanded. Normalizing the system loads of these three sources by setting the peak hour equivalent and then total energy equivalent to identify potential inconsistencies also showed no persistent identifiable differences. A comparison of the end use NEMS space cooling load shapes with the NEMS system load shows a contrast in the peak hour, providing a first indication of the degree of non-coincidence apparent between the cooling and system load profiles. 



\section{The New Double Decrement Approach}

This section details the approach that Berkeley Lab has developed to model the utility impacts associated with a proposed appliance standard. The method is demonstrated using the CUAC energy efficiency standard. Previous experience with modeling a peaky end use using NEMS-BT resulted in inaccurate peak impacts, raising the need to model peak-coincident end uses using an alternative method. Despite the fact that NEMS-BT does represent the commercial space cooling end use, this approach decrements the hourly system load directly from the system load.

However, to ensure that the energy balance is correct throughout NEMS, equivalent amounts of energy must be decremented from the end use and system load shape sides. Hence, this method has been called the double decrement approach.

The approach is summarized into three different parts, each run sequentially in a single NEMSBT run:

\section{Part 1 - End-Use Consumption Decrement}

The energy savings are decremented from the NEMS-BT space cooling end use to model the effect on the demand-side of NEMS-BT.

\section{Part 2 - Restoration of the System Load}

Coding changes are then made to restore the effect that decrementing the end use demand has on the supply side. This ensures that the hourly decrement to the system load is not duplicating the effects from changes made to the demand side.

\section{Part 3 - Decrement Hourly System Load}

The hourly system load is decremented to match the savings decremented on the demand side, ensuring the peak reductions are properly modeled.

Figure 16 illustrates how all three parts are performed as one NEMS-BT run. Part 1 essentially describes the traditional approach explained in section 2.2 where the energy savings estimated from a proposed CUAC standard are decremented from the commercial module space cooling end use. This change reduces the annual end-use consumption for commercial sector space cooling in the comm. $f$ commercial demand module. Modifications are also made to read in a created savings. dat input file that decrements the "EndUseConsump" parameter and weights the savings by Census Division based on the share of consumption in each region. This decrement is made in the "COMConsumption" sub-module of the commercial sector demand module.

For each forecast year in NEMS-BT, the "Restoration" restores any changes that may have affected the system load as a result of changes made by performing the traditional end-use decrement approach on the demand side. Because this approach modifies both the demand and supply sides, a restoration is required to isolate the impacts between the commercial sector and Electricity Market Module (EMM). A code change restores the system load back to its Reference Case value in the "DSMNWS" subroutine of the Load Demand Side Management module. The estimated restoration is applied to the end of each forecast year after the decrement to the demand side occurs, facilitating the need for only one run to implement this approach.

Finally, the hourly system load is decremented according to the energy savings dictated by the proposed standard level. The hourly decrement is made to each region to each of the three day types - weekday, weekend, and peak day, each of the 24 hours in a day type, and to each of the 
12 months. The savings are decremented in this way for every year that the standard applies, beginning in 2007 and ending in 2025, the final year of the forecast, and by EMM region. The 864 hours are decremented in energy units based on estimates of the annual energy savings and on the simulated TMY CUAC load shapes. In this way, the annual energy savings are proportional to the characteristic shape of this end use. The code changes are made in the "DSMHLM" subroutine of the Load and Demand Side Management (LDSM) sub-module with the decrement made to the "SYLOAD" hourly system load parameter.

For a more detailed mathematical description of the code modifications made in this approach, please see Appendix B.

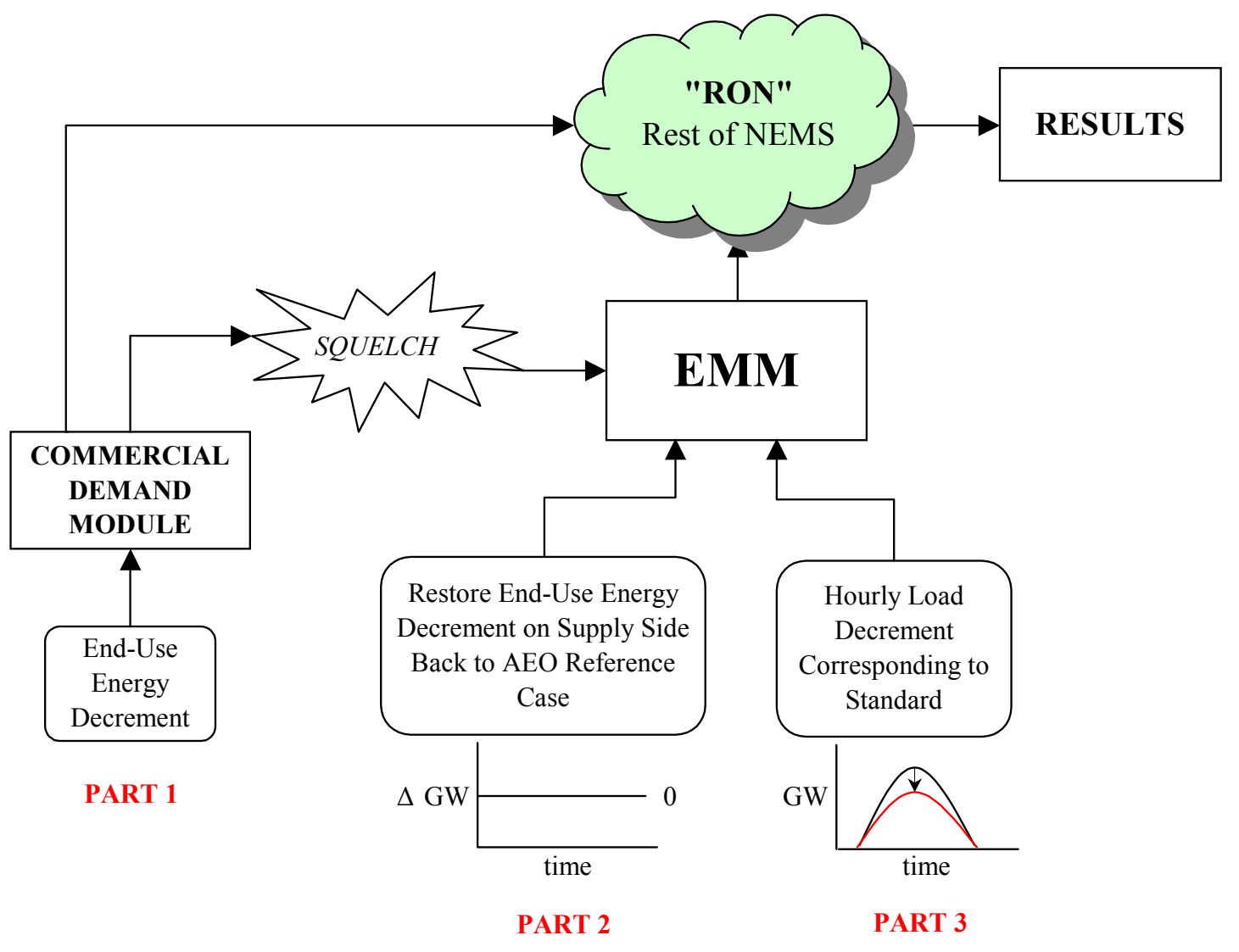

Figure 16. Flowchart of Double Decrement Approach in NEMS-BT

Because the size of the energy savings is small compared to the magnitude of the electricity sector, higher decrement runs are required, consistent with the traditional approach. A series of multipliers are chosen based on experience to inflate the energy savings enough to see a clear effect. Typically three multipliers are used per TSL and the impacts from these three runs are interpolated and linearly regressed to determine the impact from the actual standard. This technique has worked well in the past using the traditional approach. However, one concern that has arisen from the current work is the chance of changes to the shape of the load duration curve (LDC) when the decremented savings are too high. This phenomenon is understandable as 
larger decrements lead to greater impacts to the LDC. Subsection 2.4 briefly addressed this concern of using higher multipliers and subsection 6.3.2 illustrates how significant an effect higher multipliers can have on the peak impacts. 



\section{Results Using Double Decrement Approach}

This section presents results from implementing the new double decrement approach. Section 5.1 provides some preliminary results from experimenting with the hourly decrement as a way of validating how peak end uses behave. Section 5.2 then presents the results using the double decrement approach to model a proposed CUAC standard using energy savings from the prior RCAC rulemaking. Section 5.3 then discusses an experiment Berkeley Lab conducted to switch out the system load shape with a TMY normalized one. Section 5.4 then summarizes our results. All results are presented using the AEO2003 version of NEMS.

Throughout this work, the analysis uses the RCAC forecasted energy savings because the CUAC rulemaking is still in the early stages of analysis and no quantitative results are yet available. According to the current state of the CUAC rulemaking, heat pumps are not included, unlike the RCAC rulemaking where they were included; therefore, the results in this section only reflect effects from the cooling energy savings.

The double decrement approach allows the energy savings to be modeled consistently with the CUAC energy savings development; that is, the savings are modeled hourly by decrementing the system load for all three-day types (weekday, weekend and peak day), and all 12 months.

\subsection{Early Stage Runs}

Initially, a series of experimental runs were performed to better understand peak load behavior, including decrementing the LDC during the top 500 peak hours of the year or just during the peak summer hours. The results are assessed using the CLF of the resulting effects from these sensitivity runs.

\subsubsection{Decrementing the Top 500 Hours}

This exercise sought to understand how NEMS-BT responds to reductions that are almost perfectly coincident with the system peak to ensure that NEMS-BT properly handles modifications to the peak load. The top 500 hours of the annual LDC were identified and a load decrement equal to the energy savings from the proposed CUAC standard was dispersed across the top 500 hours. $^{3}$ This experimental run used a 3x TSL 4 level of forecasted energy savings and the implicit $\mathrm{CLF}_{\text {in }}$ is an estimated $6 \%$ in 2025. The code changes were made in the LDSM sub-module of NEMS-BT (uldsm. $f$ ).

The results from this sensitivity run are promising. Decrementing the top 500 hours in the year results in a very peak coincident National $\mathrm{CLF}_{\text {out }}$ of $7 \%$ in 2025 . The closeness of the CLF in to the National CLF $_{\text {out }}$ indicates the nearly perfect coincidence between the input savings and resulting decrement. Total installed generating capacity is reduced $129.6 \mathrm{GW}$ by 2025 , with total electricity generation down $94 \mathrm{TWh}$ in the same year. This experimental run indicates that hourly peak loads can be reduced directly to model energy savings from a peak-coincident end use.

3 This run is saved on the NEMS server, “amichai”, under D:/Home/ptc/runs/AEO2003/aps/ccac/std4/AEO_sysld/d012004a 


\subsubsection{Decrementing 20\% of the Topmost Summer Peak Hours}

This exercise reduces only the highest summer peak hours. A $20 \%$ decrement is taken from as many top peak summer hours necessary to match the same total energy savings and the corresponding CLF in estimated at 6\%. ${ }^{4}$ The code changes are made in the same LDSM submodule where the previous exercise was performed.

The results from this run indicate that a focused summer peak hour decrement produces the very peak coincident National $\mathrm{CLF}_{\text {out }}$ of $9 \%$. Compared to our previous experimental run, the summer only peak decrement is not as coincident with the system peak which leads to the larger discrepancy between the CLF in and the National $C_{2 L}$ out. Total installed generating capacity is reduced $106 \mathrm{GW}$ in year 2025 with total electricity generation down $101 \mathrm{TWh}$ in the same year.

\subsubsection{Summary of the Preliminary Runs}

The initial results indicate that Berkeley Lab was successful in targeting decrements from the peak hours. Both exercises show CLFs below 10\%, which provides a useful lower bound on the CLFs. This is lower than would be expected from a CUAC standard because of the lower peak coincidence.

\subsection{Double Decrement Approach Results}

Based on the preliminary runs, it was concluded that peak-coincident end uses could be properly modeled in NEMS-BT. Taking a decrement during the highest load hours results in changes to the installed generating capacity inline with what we would expect, i.e. a CLF $<10 \%$. This section presents the initial results from using the double decrement approach. Two sets of results are presented in this section, one assuming the NEMS space cooling end use load shape and the other using the simulated TMY CUAC load shape.

\subsubsection{Results Using Double Decrement Approach with NEMS Space Cooling Load Shape}

The results for a proposed CUAC TSL 4 standard using the double decrement approach and leaving the NEMS space cooling load shape in place are presented as an example in Table 9. ${ }^{5}$ The CLF results for other TSLs are similar. This example uses 2, 3, and 4 as the multipliers, lower than was used in the traditional approach results presented in subsection 2.4 or in the previous report. The choice of multipliers in not inconsequential, but has a potentially significant effect on the ordering of peak hours that could change the CLF. This was discussed in subsection 2.4 and subsection 6.3.2 will also address this issue. Again, the results are based on modeling only the cooling energy savings from a proposed CUAC standard.

\footnotetext{
4 This run is saved on the NEMS server, "amichai”, under D:/Home/ptc/runs/AEO2003/aps/ccac/std4/AEO_sysld/d012004c

5 This run is saved on the NEMS server, "amichai”, under D:/nems/AEO2003/output/aps/cuac/Ddvalid/CcoolDD/NEMSeu/
} 
Table 9. TSL 4 Cooling-Only Results Using Double Decrement Approach with NEMS Space Cooling Load Shape

\begin{tabular}{|l|c|c|c|}
\hline & 2015 & 2020 & 2025 \\
\hline Change in Capacity (GW) & -9.0 & -16.9 & -19.1 \\
\hline Change in Energy Sales (TWh) & -21.5 & -31.9 & -38.8 \\
\hline National CLF out $_{\text {ou }}$ (\%) & $27 \%$ & $21 \%$ & $23 \%$ \\
\hline
\end{tabular}

The results indicate that the National $\mathrm{CLF}_{\text {out }}$ of $21 \%$ in 2020 is higher than the implicit $\mathrm{LF}_{\text {in }}$ estimated from the input load profiles. Figure 5 shows that the $\mathrm{LF}_{\text {in }}$ is typically $10-20 \%$ for most EMM regions and likely around $15 \%$ for the U.S. As will be discussed in more detail in section 6 , non-coincidence plays a significant role in explaining the discrepancy between the $\mathrm{LF}_{\text {in }}$ and the National $\mathrm{CLF}_{\text {out }}$ the results.

Compared to the traditional approach results presented in Table 2, the National CLF out of TSL 4 shows a slight decrease from $25 \%$ to $21 \%$ in year 2020 ; the difference in the National CLF $_{\text {out }}$ is largely due to the use of different multipliers. The traditional approach results in Table 2 use higher multipliers to be more consistent with our previous report, whereas the double decrement results use lower multipliers to be more consistent with our proposed approach for the upcoming CUAC rulemaking. Using smaller multipliers with the traditional approach would have reduced the National $\mathrm{CLF}_{\text {out }}$ from $25 \%$ to $22 \%$ for CUAC TSL 4 , re-emphasizing the importance of careful multiplier choice.

\subsubsection{Results Using Double Decrement Approach with TMY CUAC Load Shape}

Berkeley Lab also applied the double decrement approach, but replacing the NEMS space cooling end-use load shape with the TMY simulated CUAC load shape. ${ }^{6}$ Based on the current status of the CUAC rulemaking, this is the most likely shape that will be used. That is, each proposed CUAC standard analysis will decrement from the system load hourly to match the energy savings dictated by the NES model and follow the shape of the simulated TMY CUAC load shape. The analysis will also decrement the commercial demand-side energy savings using the simulated TMY CUAC load shape rather than keeping the end use space cooling load shape in NEMS-BT. The PNNL simulated load shapes are believed to be more representative of the CUAC load profile than the NEMS space cooling shape. The results are presented for all five TSLs in Table 10 for completeness.

Using a different space cooling load shape to the one used in the AEO2003 Reference Case poses a concern. The analysis for previous appliance standard rulemakings has avoided any modifications that would alter the AEO2003 Reference Case because it provides such a convenient and widely accepted baseline for energy policy analysis. Changing the commercial space cooling load shape has a significant effect on the Reference Case, resulting in a $13 \mathrm{GW}$ (17 GW) or $1.2 \%(1.4 \%)$ increase in total U.S. generating capacity in 2020 (2025). Because of this change, the results are presented relative to this new Reference Case with TMY CUAC Load Shape.

\footnotetext{
6 This run is saved on the NEMS server, "amichai”, under D:/nems/AEO2003/output/aps/cuac/Ddvalid/CcoolDD/TMYeu/
} 
Comparing the TSL 4 results in Table 10 with the results in Table 9, the CLF is further reduced because the simulated TMY CUAC load shape is more coincident with the system load. The CUAC load shape has some cooling load, albeit small, during the winter months while the winter NEMS space-cooling load is essentially zero.This tends to flatten the simulated CUAC load shape and lead to a $1-10 \%$ higher input CLF, which is reflected in the results.

Table 10 shows that the National $\mathrm{CLF}_{\text {out }}$ ranges from $17 \%$ to $19 \%$ and saves between $8 \mathrm{GW}$ and $41 \mathrm{GW}$ in year 2020. Again, the results are based on runs using a set of lower multipliers for each TSL run. Table 3 shows the multipliers used for each of the TSLs and subsection 6.3.2 discusses the reason for using the lower multipliers in this analysis.

Table 10. Cooling-Only Results for Year 2020 Using Double Decrement Approach with TMY CUAC Load Shape

\begin{tabular}{|c|c|c|c|}
\hline & $\begin{array}{c}\text { Change in } \\
\text { Energy Sales } \\
(\text { TWh })\end{array}$ & $\begin{array}{c}\text { Peak Capacity } \\
\text { Change (GW) }\end{array}$ & $\begin{array}{c}\text { National CLF } \\
\text { out } \\
(\%)\end{array}$ \\
\hline TSL 1 & -12.7 & -7.9 & $18 \%$ \\
\hline TSL 2 & -21.3 & -14.0 & $17 \%$ \\
\hline TSL 3 & -24.7 & -16.3 & $17 \%$ \\
\hline TSL 4 & -31.9 & -18.7 & $19 \%$ \\
\hline TSL 5 & -62.3 & -40.9 & $17 \%$ \\
\hline
\end{tabular}

\subsubsection{Comparing the Results from the Traditional and Double Decrement Approaches}

In general, the double decrement approach using the simulated TMY CUAC load shapes result in a lower National CLF $_{\text {out }}$ compared to the analysis using the traditional approach. Comparing the results in Table 10 with those in Table 2 , the installed generating capacity reduction is $3 \mathrm{GW}$ to $16 \mathrm{GW}$ greater using the new double decrement approach and the National $\mathrm{CLF}_{\text {out }}$ is $6 \%$ to $14 \%$ points lower. Again, this difference is because the simulated CUAC load shape is more coincident with the system load.

\subsection{Substitution of TMY System Load and TMY CUAC Load Shape}

In addition to substituting the end use CUAC load shape into NEMS, Berkeley Lab also experimented with substitution of the NEMS system load shape for the TMY normalized system load shape. ${ }^{7}$ The main potential benefit of this combination is that the weather pattern embodied in the CUAC shape is identical to that on which the TMY system shape is based. This should result in the most accurate representation of coincidence between CUAC and system loads. The comparison of system load shapes in sub-section 3.3 revealed that the difference between the NEMS and TMY system loads does not appear significant. Sub-section 5.3.1 shows results of

7 This run is saved on the NEMS server, "amichai”, under D:/nems/AEO2003/output/aps/cuac/Ddvalid/CcoolDD/TMYsl/ 
this substitution compared to the AEO2003 Reference Case and sub-section 5.3.2 highlights results with the system load substitution in conjunction with the double decrement approach.

\subsubsection{Results from Substituting the TMY System Load into NEMS Reference Case}

To substitute the system load shape, the system load shapes as well as the end-use load shapes are read into NEMS from the file pointed to by the LDSMDAFN parameter in the scedes setup file. The scedes file is user-defined and contains any modifications to the NEMS Reference Case. In this case, NEMS-BT reads in the system load. ${ }^{8}$ To replace the default NEMS system load shapes with the TMY system load shapes, Berkeley Lab created a new ldsmdaf input file, a binary file requiring a special preprocessor to convert from ascii to binary format. A preprocessor provided by John Holte of OnLocation, Inc. performed the task. It reads in the Reference Case ldsmdaf file and allows the user to delete or add system or end-use load shapes to generate a new ldsmdaf file. The 13 modified EMM regional system load shapes are: ecarLD, erctLD, maacLD, mainLD, mappLD, ny00LD, ne00LD, f100LD, str0LD, spp0LD, nwppLD, ra00LD, cnv0LD. After the new ldsmdaf is created, the LDSMDAFN parameter in the scedes file is modified to point to the location of the newly created ldsmdaf file. ${ }^{9}$

Changing out the system load shape in NEMS has a significant effect, resulting in a reduction of the forecast installed capacity of $48 \mathrm{GW}$ by year 2020 and through 2025 . So despite the fact that the comparison of the NEMS and TMY system load do not show any consistent trends as shown in subsection 3.3, using the TMY system load does result in a 4\% reduction of the peak load forecast.

Changing out both the system and end use load shapes with TMY ones results in a $35 \mathrm{GW}$ (33 $\mathrm{GW})$ decrease in total installed generating capacity by 2020 (2025), with $35 \mathrm{GW}(30 \mathrm{GW})$ from fossil-generating capacity, but almost none $(3 \mathrm{GW})$ from coal. This is roughly a $3 \%$ difference from the AEO2003 Reference Case total installed generating capacity of $1085 \mathrm{GW}$ (1182 GW) in 2020 (2025). This implies that the simulated load shape is not quite as peaky as the NEMS system load.

The next section shows some TSL 4 results from simultaneously substituting the system and end use load shapes and using the double decrement approach.

\subsubsection{Results from Substituting the TMY System and CUAC Load Shapes into NEMS Using the Double Decrement Approach}

Berkeley Lab experimented with replacing the system load and space cooling end use load shape in NEMS with the TMY system and CUAC end use load shapes using the lower multipliers. The results for TSL 4 are shown in Table 11 and indicate that the National CLF out increases from $19 \%$ (from Table 10) to $22 \%$ when the TMY system load is substituted. This suggests that the TMY system load is less peaky than the system load shape in the NEMS Reference Case. Although the differences between the NEMS and TMY system load shapes were not significant,

\footnotetext{
${ }^{8}$ The default location of this input file is on the NEMS server, "amichai", under D:/nems2003/input/ldsmdaf.v1.4.daf

9 This run is saved on the NEMS server, "amichai”, under D:/nems/AEO2003/output/aps/cuac/Ddvalid/CcoolDD/TMYs1/reference1/
} 
the peak utility results from the proposed CUAC standard can be significant, as evidenced by the 2.1 GW difference the installed capacity reduction from TSL 4 in year 2020.

Table 11. TSL 4 Cooling-Only Results Using Double Decrement Approach with TMY System Load Shape and TMY CUAC Load Shape

\begin{tabular}{|l|c|c|c|}
\hline & 2015 & 2020 & 2025 \\
\hline Change in Capacity (GW) & -8.7 & -16.6 & -21.1 \\
\hline Change in Energy Sales (TWh) & -21.5 & -31.9 & -38.8 \\
\hline National CLF out $_{(\%)}(28 \%$ & $22 \%$ & $21 \%$ \\
\hline
\end{tabular}

\subsection{Summary of Results}

The results from this section indicate reductions in the National CLF $_{\text {out }}$ going from the traditional approach to the double decrement approach using lower multipliers and substituting out the NEMS end use space cooling load shape with a simulated TMY one. Table 12 summarizes the National $\mathrm{CLF}_{\text {out }}$ for each approach we considered. The National CLF out for TSL 4 decreases from $25 \%$ to $19 \%$ in year 2020. Almost all of this reduction is due to the use of lower multipliers to model each TSL, which drops the National CLF $_{\text {out }}$ from $25 \%$ to $21 \%$ in 2020 . Substituting in the end use space cooling load shape with the simulated TMY CUAC load shape also reduces the National $\mathrm{CLF}_{\text {out }}$ further from $21 \%$ to $19 \%$.

Table 12. Summary of TSL 4 Cooling-Only Results for Year 2020

\begin{tabular}{|c|c|c|c|}
\hline Case & $\begin{array}{c}\text { Change in } \\
\text { Energy Sales } \\
\text { (TWh) }\end{array}$ & $\begin{array}{c}\text { Peak Capacity } \\
\text { Change (GW) }\end{array}$ & $\begin{array}{c}\text { National } \\
\text { CLF }_{\text {out }}(\%)\end{array}$ \\
\hline Traditional Approach & -31.9 & -14.5 & $25 \%$ \\
\hline $\begin{array}{c}\text { DD with NEMS Cooling } \\
\text { Load Shape }\end{array}$ & -31.9 & -16.9 & $21 \%$ \\
\hline $\begin{array}{c}\text { DD with TMY CUAC Load } \\
\text { Shape }\end{array}$ & -31.9 & -18.7 & $19 \%$ \\
\hline $\begin{array}{c}\text { DD with TMY CUAC and } \\
\text { TMY System Load Shape }\end{array}$ & -31.9 & -16.6 & $22 \%$ \\
\hline
\end{tabular}

Section 6 compares input CLFs with output CLFs and attempts to identify the causes of discrepancy. 


\section{Explaining the Peak Impacts}

In the process of developing the double decrement approach to modeling a proposed CUAC standard, a wealth of knowledge was uncovered in our understanding of how discrepancies between input CLFs and output CLFs propagate. This section highlights some of our improved understanding. Subsection 6.1 discusses Berkeley Lab's newfound ability to output the hourly system load. Subsection 6.2 introduces a variation to the CLF used to help understand how the $\mathrm{LF}_{\text {in }}$ of the end use load shape correlates to the output CLF based on the results of the CUAC NEMS run further discussed in subsection 6.3. Subsection 6.4 then shows how the hourly system load is aggregated into blocks that make up the NEMS LDC and how this output helps our understanding of the peak effects from a proposed CUAC standard NEMS-BT run.

\subsection{Output Hourly System Load by EMM Region and Year}

In order to verify whether the double decrement approach was properly working, Berkeley Lab output the NEMS-BT hourly system load shape by forecast year and EMM region. Comparing the hourly load between the NEMS Reference Case and a CUAC NEMS-BT run revealed the shape and size of the energy decrement. Doing this comparison assured us that the double decrement approach was properly decrementing the system load at the appropriate hours of the year. Although this comparison was developed for CUAC standard runs, the output hourly system load can be used for any NEMS run. For a more detailed description of the code modifications please see Appendix E. This method has become an invaluable, although still somewhat unrefined, tool in our energy efficiency standards tool chest.

This tool makes analyzing the hourly system load shape very easy for any given run, not just for analysis of a proposed CUAC standard and prints out the hourly system load, hour number (1-864), EMM region, iteration, and forecast year. A total of 864 unique hours represent the entire year in NEMS; this comes from 24 hours per day times three day types per month times 12 months per year. Each month in NEMS is characterized by three different day types - peak day, weekday, or weekend day. The peak day is represented as one day of the month that corresponds to the day with the highest load for the month. Every other day is either a weekday or weekend day where all weekend days and weekdays in a given month are characterized by the same load profile. The hourly output is transferred to a spreadsheet to analyze the variation between regional peak hours, measure the hourly effect of the decrement, compare the change in load shapes across regions, and compute what we call the Regional CLF out by EMM region.

Figure 17 illustrates an example year 2025 LDC for the ECAR EMM region for 6x TSL 4 standard. The two lines represent the NEMS Reference Case and the proposed CUAC standard case using the simulated TMY CUAC load shape. All 8,760 hours of the year are shown, expanded from the 864 hour LDC. This figure illustrates the size and nature of the decrement that results from a 6x TSL 4. The decrement appears greater during the highest peak hours and less at the base load. Including ECAR, six of the EMM regions show a needle-like peak at the peak hours of the year, MAAC, MAIN, NY, NE, and 
NWP, with the remaining regions showing less of a vertical orientation at the highest load hours.

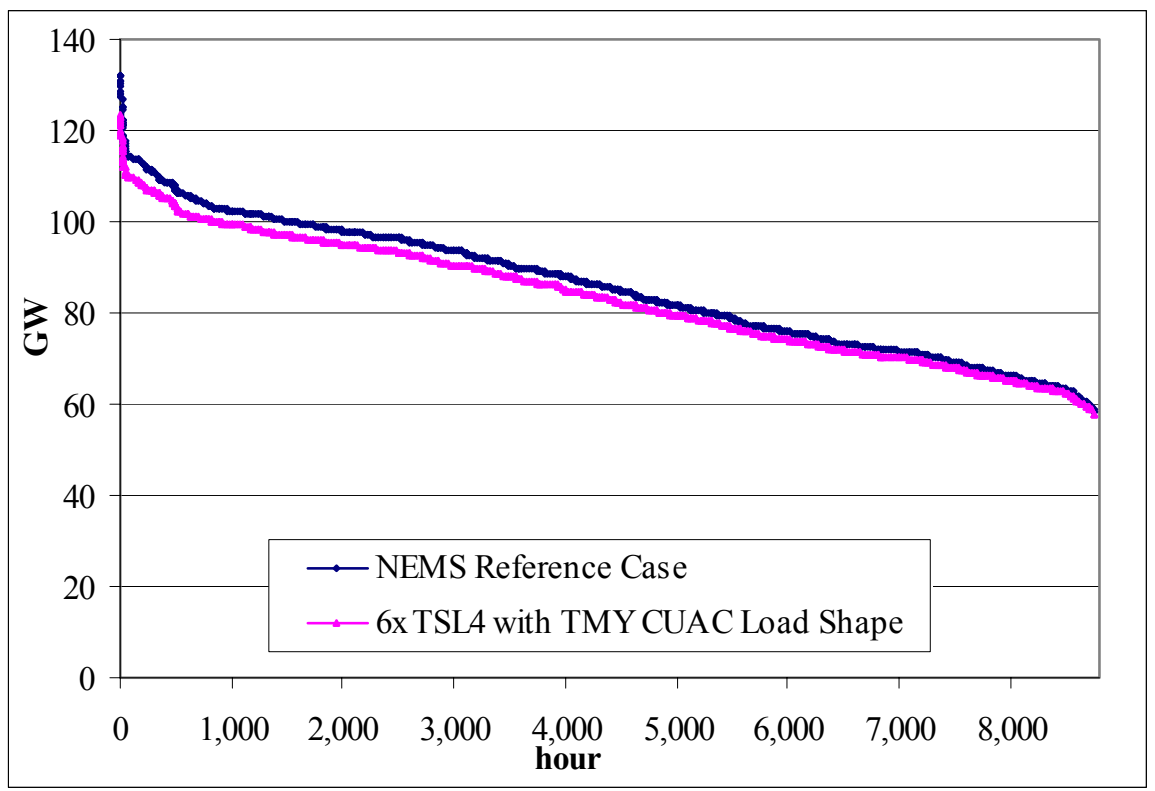

Figure 17. The LDC from 6x TSL 4 for ECAR Region in Year 2025

\subsection{The Regional CLF $_{\text {out }}$}

The Regional CLF out $_{\text {is }}$ based on NEMS-BT hourly system load output. Unlike the National $\mathrm{CLF}_{\text {out }}$, which can only be calculated for the U.S. given the data constraints of the NEMS-BT standard output, the Regional $\mathrm{CLF}_{\text {out }}$ can be estimated by EMM region from dumped regional hourly system load data. As was mentioned previously in Section 2 , the Regional $\mathrm{CLF}_{\text {out }}$ is expressed as,

$$
\text { Regional } \mathrm{CLF}_{\text {out }}=\frac{\Delta \text { Average Energy }}{-- \text { Peak Load }^{*} 8760 \mathrm{~h}}
$$

This metric can be used to measure how a CUAC standard is affected by noncoincidence, error introduced by the iterative process, and error introduced by the magnitude of higher multipliers chosen to model each TSL. The Regional $\mathrm{CLF}_{\text {out }}$ helps tie together the $\mathrm{LF}_{\text {in }}$ and the National $\mathrm{CLF}_{\text {out }}$. The next section explains in more detail the difference between the $L F_{\text {in }}$ and the National $C_{L F}$ out.

Unfortunately, Berkeley Lab has yet to fully understand the relationship between the

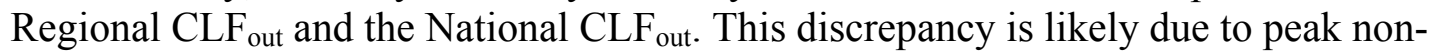
coincidence between regions. NEMS does not estimate a national peak; the model treats each region separately without having to sum the regional peaks and consider noncoincidence among them. NEMS does not calculate a national peak so it is impossible to determine the degree of non-coincidence between the regional system peaks and the 
national system peak. Presumably there are other second-order effects that could also play a role in influencing the transition from Regional $\mathrm{CLF}_{\text {out }}$ to National $\mathrm{CLF}_{\text {out }}$, such as the squelch, changes due to the complex mathematical NEMS solvers, etc.

\subsection{Relating $\mathrm{LF}_{\text {in }}$ and the Regional $\mathrm{CLF}_{\text {out }}$}

This subsection helps explain why the input load factor, $\mathrm{LF}_{\text {in }}$, for CUAC deviates from the estimated Regional CLF $_{\text {out }}$ based on the model output. Table 13 shows the $\mathrm{LF}_{\text {in }}$ and Regional CLF $_{\text {out }}$ values by EMM region for two scenarios that use the CUAC double decrement approach for a 3x TSL 4. One scenario uses the default NEMS-BT space cooling end use load shape and the other substitutes in the simulated TMY CUAC end use load shape.

Table 13. Comparison of $L_{\text {in }}$ and the Regional CLF $_{\text {out }}$ from $3 x$ TSL 4

\begin{tabular}{|c|c|c|c|c|c|}
\hline EMM \# & EMM Region & \multicolumn{2}{|c|}{ NEMS Space Cooling Load Shape } & \multicolumn{2}{c|}{ TMY CUAC Load Shape $^{2}$} \\
\hline 1 & & $\mathrm{LF}_{\text {In }}$ & Regional CLF & $\mathrm{LF}_{\text {In }}$ & Regional $\mathrm{CLF}_{\text {out }}$ \\
\hline 2 & ECAR & $10 \%$ & $18 \%$ & $14 \%$ & $14 \%$ \\
\hline 3 & ERCOT & $15 \%$ & $26 \%$ & $19 \%$ & $19 \%$ \\
\hline 4 & MAAC & $11 \%$ & $22 \%$ & $13 \%$ & $16 \%$ \\
\hline 5 & MAIN & $10 \%$ & $16 \%$ & $12 \%$ & $11 \%$ \\
\hline 6 & MAPP & $10 \%$ & $13 \%$ & $11 \%$ & $9 \%$ \\
\hline 7 & NY & $9 \%$ & $22 \%$ & $10 \%$ & $16 \%$ \\
\hline 8 & NE & $8 \%$ & $26 \%$ & $7 \%$ & $16 \%$ \\
\hline 9 & FL & $16 \%$ & $21 \%$ & $25 \%$ & $28 \%$ \\
\hline 10 & STV & $15 \%$ & $19 \%$ & $20 \%$ & $22 \%$ \\
\hline 11 & SPP & $12 \%$ & $26 \%$ & $14 \%$ & $28 \%$ \\
\hline 12 & NWP & $12 \%$ & $-737 \%$ & $12 \%$ & $-609 \%$ \\
\hline 13 & RA & $12 \%$ & $14 \%$ & $16 \%$ & $12 \%$ \\
\hline & CNV & $12 \%$ & $15 \%$ & $17 \%$ & $17 \%$ \\
\hline & National CLF & & $25 \%$ & & $17 \%$ \\
\hline
\end{tabular}

Two important highlights from Table 13 are:

- Region NWP (located in the Pacific Northwest) is winter peaking so the peak hour is unaffected by a CUAC standard, i.e. denominator of zero. However the iterative nature of NEMS leads to a very small increase in the peak hour load resulting in a large negative value for the Regional $\mathrm{CLF}_{\text {out }}$.

- In general, the NEMS space cooling load shape is more peaky than the simulated TMY CUAC load shape, except in the NE region as seen by comparing the $\mathrm{LF}_{\text {in }}$ in both cases. The lower Regional $\mathrm{CLF}_{\text {out }}$ for the simulated TMY CUAC load shape scenario is due to the closer coincidence between the TMY CUAC peak and the system peak compared to the NEMS cooling load peak in most regions. Peak coincidence will be further explained in section 6.3.1. 
The Regional $\mathrm{CLF}_{\text {out }}$ measures the load factor for the change in the regional system load shape, which should come directly from the $\mathrm{LF}_{\text {in }}$ if coincidence is perfect. The rest of this section explains how the hourly system load decrement of our new approach was verified by tracing the steps from $L_{\text {in }}$ to the Regional $C_{L F}$ out.

$$
\mathrm{LF}_{\text {in }}=\frac{\text { Average End-Use Load }}{- \text { Peak End-Use Load } * 8760 \mathrm{~h}^{-}}
$$

$\mathrm{LF}_{\text {in }}$ characterizes an end-use average load relative to its peak load. $\mathrm{LF}_{\text {in }}$ has an

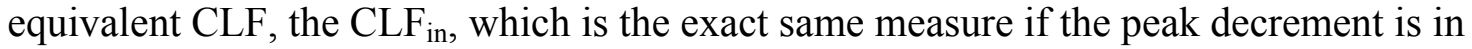
the exact same proportional to the end use peak as the average decrement is to the average load. This is usually the case with efficiency analyses because there is typically little reason to believe that the effect of an efficiency improvement is uneven over the year.

$$
\mathrm{CLF}_{\text {in }}=\underset{\text { Energy Decrement }}{\text { Energy Decrement }} \quad \begin{gathered}
\text { Average End-Use Energy } \\
\text { Eneak End-Use Load } * 8760 \mathrm{~h}
\end{gathered}
$$

which in order to be compared to the Regional $\mathrm{CLF}_{\text {out }}$, can be written as:

$$
\mathrm{CLF}_{\text {in }}=\frac{\Delta \text { End-Use Average Energy }}{\Delta \text { End-Use Peak Load } * 8760 \mathrm{~h}}
$$

The Regional CLF equation is rewritten below to illustrate how it differs from CLF in.

$$
\text { Regional } \mathrm{CLF}_{\text {out }}=\frac{\Delta \text { Total Energy }(\text { Reference Case }- \text { TSL Case })}{\Delta \text { Peak Load (Reference Case }- \text { TSL Case) } * 8760 \mathrm{~h}}
$$

There are two reasons that explain the difference between $C_{L F}$ in and the Regional $C_{\text {L }}$ out. First is peak non-coincidence, which means that the end-use peak load hour and the system load peak hour are different. The second is system load restoration error, or the imperfection of part two of the double decrement approach. System load restoration error is the difference between the numerators of these two equations, the energy decrement and the change in total energy, as well as the difference between the peak energy decrement and the change in peak load. Berkeley Lab identified a simple factor for each of these reasons, which can be measured to show how each cause relates to the translation of $\mathrm{CLF}_{\text {in }}$ to the Regional $\mathrm{CLF}_{\text {out }}$.

$$
\text { Regional } \mathrm{CLF}_{\text {out }}=\mathrm{LF}_{\text {in }} * \mathrm{PNF} * \mathrm{SREF}
$$


In this expression, PNF is Peak Non-coincidence Factor and SREF is System Restoration Error Factor. The following two subsections describe each of these two factors in more detail.

\subsubsection{Peak Non-Coincidence}

Non-coincidence between the end use peak and system peak is a normal phenomenon and not an error. Peak non-coincidence simply means that the peak hour for the end-use and the peak hour for the system load do not occur at the same hour, which is likely to be the case for most end-uses. When calculating capacity savings and the National CLF out $_{\text {, the }}$ end-use decrement at the system peak hour determines the change in system peak, not the maximum decrement from the end use. Table 14 shows three different peak hours that are important in understanding peak non-coincidence and the Regional CLF $_{\text {out }}$ calculation.

Table 14. Identifying Peak Non-Coincidence Between the TMY CUAC End-Use and Reference Case System Load Shapes in Year 2025

\begin{tabular}{|c|c|c|c|c|c|c|c|c|}
\hline $\begin{array}{c}\text { EMM } \\
\text { Region }\end{array}$ & $\begin{array}{c}\text { TMY } \\
\text { CUAC End } \\
\text { Use Peak } \\
\text { Day hour }\end{array}$ & $\begin{array}{l}\text { Reference } \\
\text { Case } \\
\text { System } \\
\text { Peak Hour }\end{array}$ & $\begin{array}{c}\text { 3x TSL } 4 \\
\text { System } \\
\text { Peak Hour }\end{array}$ & $\begin{array}{l}\text { Reference } \\
\text { Case } \\
\text { System } \\
\text { Peak Hour }\end{array}$ & $\begin{array}{c}\text { 3x TSL } 4 \\
\text { System } \\
\text { Peak } \\
\text { Hour }\end{array}$ & $\begin{array}{c}\text { Decrement } \\
\text { at TMY } \\
\text { CUAC } \\
\text { Peak Hour }\end{array}$ & $\begin{array}{c}\text { Change in } \\
\text { System } \\
\text { Peak Hour } \\
\text { (Ref - 3x } \\
\text { TSL 4) } \\
\end{array}$ & PNF \\
\hline & $\mathbf{A}$ & B & $\mathbf{C}$ & D & $\mathbf{E}$ & $\mathbf{F}$ & $\mathbf{G}$ & $\mathbf{H}$ \\
\hline ECAR & July 4 pm & June $3 \mathrm{pm}$ & June $5 \mathrm{pm}$ & 132.3 & 128.2 & 4.27 & 4.09 & $104 \%$ \\
\hline ERCOT $^{\mathrm{a}}$ & July 3 pm & July $5 \mathrm{pm}$ & July $5 \mathrm{pm}$ & 75.5 & 72.3 & 3.39 & 3.13 & $108 \%$ \\
\hline MAAC & June 4 pm & June 5 pm & July 5 pm & 69.8 & 66.6 & 3.92 & 3.24 & $121 \%$ \\
\hline MAIN & July noon & July 5 pm & June 4 pm & 62.1 & 60.2 & 2.31 & 1.87 & $124 \%$ \\
\hline MAPP & July 3 pm & July 1 pm & July 1 pm & 39.3 & 38.2 & 1.20 & 1.08 & $111 \%$ \\
\hline NY & July 4 pm & June 3 pm & June $3 \mathrm{pm}$ & 32.1 & 30.2 & 1.94 & 1.90 & $102 \%$ \\
\hline $\mathrm{NE}$ & August 2 pm & July 5 pm & July 5 pm & 29.3 & 28.2 & 1.53 & 1.13 & $135 \%$ \\
\hline FL & August noon & June 5 pm & June $5 \mathrm{pm}$ & 61.1 & 59.0 & 2.89 & 2.12 & $136 \%$ \\
\hline STV & July 3 pm & June $2 \mathrm{pm}$ & June $5 \mathrm{pm}$ & 216.0 & 208.5 & 9.00 & 7.47 & $120 \%$ \\
\hline SPP & August 3 pm & Sept. 5 pm & Sept. 5 pm & 49.8 & 48.6 & 2.40 & 1.17 & $205 \%$ \\
\hline NWP & July 4 pm & Dec. $11 \mathrm{am}$ & Dec. $11 \mathrm{am}$ & 71.8 & 71.1 & 2.88 & 0.62 & $465 \%$ \\
\hline RA & June 4 pm & July 4 pm & July 4 pm & 47.9 & 46.2 & 1.98 & 1.73 & $114 \%$ \\
\hline $\mathrm{CNV}$ & July 3 pm & Sept. 4 pm & Sept. 4 pm & 95.7 & 92.8 & 3.98 & 2.85 & $140 \%$ \\
\hline
\end{tabular}

${ }^{a}$ ERCOT peak hours in italics are weekday peaks, not peak day peaks. So end-use peak is on July peak day, while system peak hour is on July weekday.

The first column, denoted as A, shows the end-use peak hour by region, column B shows when the Reference Case system peak occurs, and column $\mathrm{C}$ shows the new system peak hour after the energy savings decrement is applied, in this case for a 3x TSL 4. Only three of the 13 EMM regions have the TMY CUAC end-use peak (column A) and system load peak (column B) on the same day, although at different hours: MAAC, MAIN, and MAPP. NWP is the only region where the end-use and system peaks occur in opposite seasons, summer for the end use and winter for the system peak. The remaining regions 
have differing peak hours, although the difference remains in the summer months. Thus, most regions do not share the CUAC end use peak and system peak on the same day.

In general, peak non-coincidence leads to less of a peak hour decrement than expected from the $\mathrm{CLF}_{\text {in }}$ for two reasons. First, the system peak hour may change after a decrement. Regions ECAR, MAAC, MAIN, and STV all fit this profile, which can be seen in Table 14 by comparing columns B and C. Second, the system peak hour is subject to less of a decrement than the end-use peak hour. The CUAC end use load shape, not the system load, dictates the decrement, and non-coincidence between their two peaks diminishes the overall peak reduction. Columns D, E, F, and G of Table 14 provide a quantitative explanation of these two effects. Columns D and E show the peak load for the hours in columns B and C. Column F shows the decrement applied to the hour reported in column one. If the peak hour were the same for columns $\mathrm{A}, \mathrm{B}$, and $\mathrm{C}$ then the difference between columns $\mathrm{D}$ and $\mathrm{E}$ would be equivalent to the value in column $\mathrm{F}$. The last column, column $\mathrm{G}$, shows the actual difference between columns $\mathrm{D}$ and $\mathrm{E}$. The ratio of column $\mathrm{G}$ to column $\mathrm{F}$ is the measure we call PNF in column $\mathrm{H}$, which is defined below.

$$
\begin{gathered}
\Delta \text { EU Peak Hour Load (Reference Case }- \text { TSL Case) } \\
\Delta \text { Peak Hour Energy Load (Reference Case }- \text { TSL Case) }
\end{gathered}
$$

The region with the least coincidence between the TMY CUAC end use and system load is NWP, as shown by the high PNF value, which is due to the seasonal difference between these two loads. The SPP region also exhibits a significant degree of noncoincidence, with NY and ECAR showing the greatest degree of coincidence.

Identifying this PNF has another use as well. The PNF can be used to evaluate how the larger multipliers chosen for each TSL can affect the results. Using the traditional approach, the guiding principal was to use multipliers that provided a generally linear scatter of the generation and capacity variable and were high enough to escape the range of numerical noise in NEMS. The PNF helps indicate when a chosen multiplier becomes problematic, as the next subsection explains.

\subsubsection{Multiplication Error}

The PNF proves a useful metric that shows how higher magnitude multipliers can have a significant effect on increasing the peak non-coincidence. While peak-non-coincidence is normal, changes to it caused by the arbitrary use of multipliers is not. Higher multipliers are more likely to disrupt the ordering of the LDC and the overall magnitude of the load at the peak hour. The linear regression of results cannot correct for this effect. The problem exists when the use of a higher multiplier moves the peak hour. When the peak hour moves as a legitimate result of the decrement, the Regional CLF $_{\text {out }}$ is still valid as defined. If, however, it moves because of the multiplier, which is an arbitrary tool of the analysis, then the Regional CLF $_{\text {out }}$ estimate is less accurate. 
An example that shows both regular non-coincidence and the multiplier error effect is illustrated in Figure 18. This figure shows various multiplier runs for five selected nonconsecutive hours in year 2025 for the MAPP region. The four scenarios are the NEMS Reference Case and the $1 \mathrm{x}, 3 \mathrm{x}$, and $6 \mathrm{x}$ multipliers for TSL 4 using the NEMS space cooling load shape. The reason these five hours are shown is because they illustrate the peak effect among these different scenarios. Hour "b" in this figure represents the Reference Case peak hour at $39.28 \mathrm{GW}$ and hour "c" represents the CUAC end-use peak hour at $39.08 \mathrm{GW}$ in for this region. In this example, the $1 \mathrm{x}$ TSL 4 , or modeling the CUAC standard without inflating the savings, shifts the peak hour from hour "b" to hour "d". However, the 3x TSL 4 and 6x TSL 4 runs each result in different peak hours, hours "a" and "e", respectively. Ideally, multipliers would be chosen to make sure the run results in the same peak hour as the 1x TSL 4 . Of course, looking at the 3x TSL 4 line, the load difference between hour "a" and hour " $\mathrm{d}$ " is trivial. Significant error is introduced in this example when a 6x TSL 4 leads to the difference between hour "e" and hour "d".

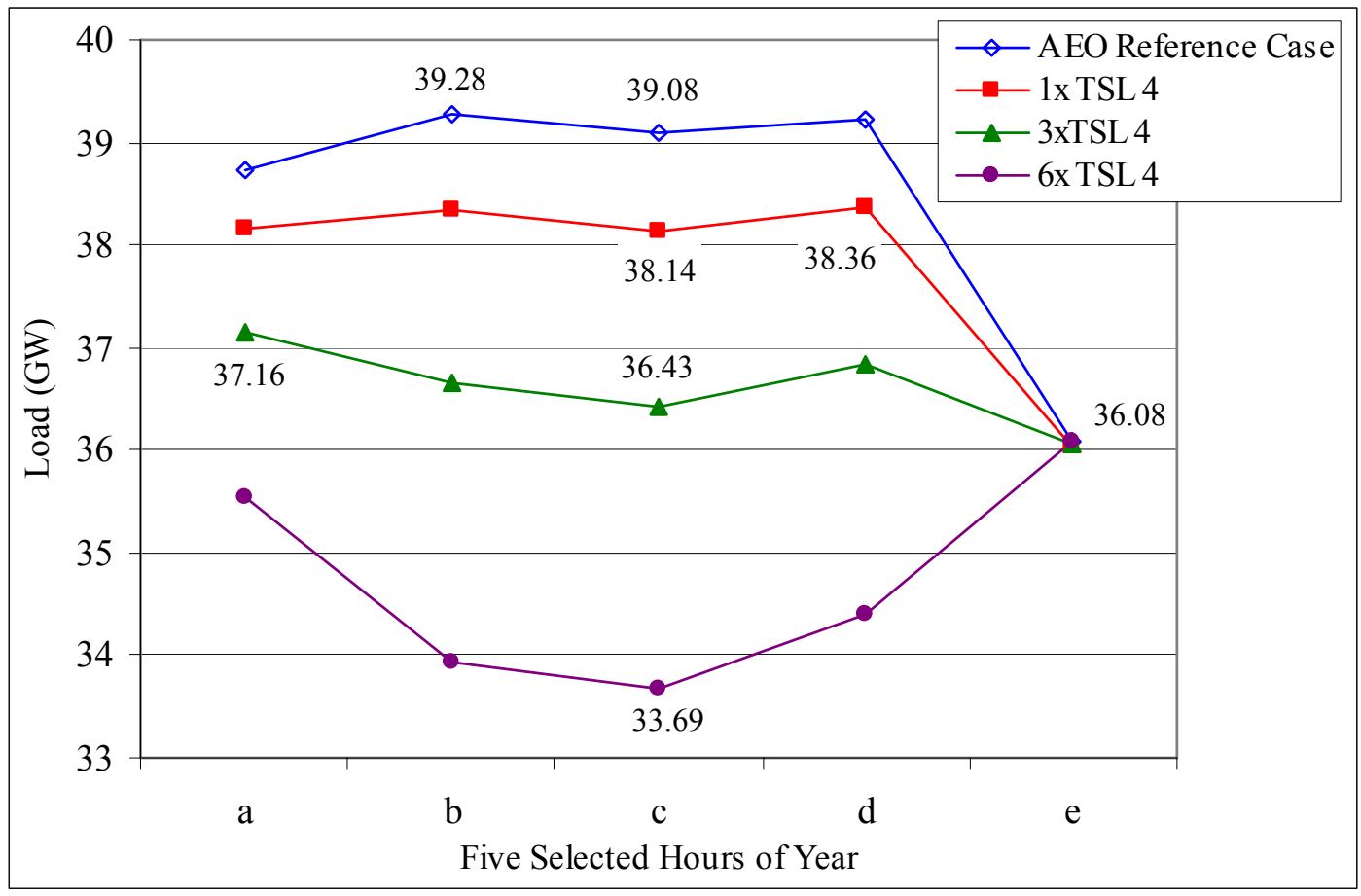

Figure 18. Example of Peak Non-Coincidence in MAPP in 2025 for Selected Multiples of TSL 4

This example can be further demonstrated by comparing the PNF across different multipliers. Table 15 shows that for $1 x$ TSL 4, even though peak non-coincidence exists, it is pretty insignificant. To help explain these percentages, the maximum decrement of the CUAC end use peak in the MAPP region is $0.94 \mathrm{GW}(39.08 \mathrm{GW}-38.14 \mathrm{GW})$, while the change in the peak system load is $0.92 \mathrm{GW}(39.28 \mathrm{GW}-38.36 \mathrm{GW})$. The 1.03 in Table 15 is the result of dividing 0.94 by 0.92 . In general, the table below shows that higher multipliers tend to result in a higher measure of the PNF. As the higher 
multipliers shift the peak hour in the $3 \mathrm{x}$ and especially in the $6 \mathrm{x}$ scenarios, the PNF increases.

The PNF also indicates how peak reductions are dampened. As this work reveals, the use of higher multipliers has a significant impact on the non-coincidence between the CUAC end use and system load shapes. The greater non-coincidence that results from higher multipliers leads to reduced peak utility impacts as a result of the decreased correlation between the end use and system load. This means that a significant error associated with our peak utility impacts is due to the multipliers chosen to model each TSL.

Table 15. Peak Non-coincidence Factor by Region for Selected Multiples of TSL 4 in Year 2025

\begin{tabular}{|c|c|c|c|}
\hline & \multicolumn{3}{|c|}{ Peak Non-Coincidence Factor } \\
\hline EMM Region & $1 \times$ TSL 4 & $3 \times$ TSL 4 & $6 x$ TSL 4 \\
\hline ECAR & 1.52 & 1.62 & 1.62 \\
\hline ERCOT & 1.66 & 1.66 & 1.65 \\
\hline MAAC & 1.75 & 1.80 & 1.79 \\
\hline MAIN & 1.32 & $\mathbf{1 . 5 3}$ & $\mathbf{1 . 5 8}$ \\
\hline MAPP & 1.03 & $\mathbf{1 . 2 5}$ & $\mathbf{1 . 6 9}$ \\
\hline NY & 1.77 & 1.86 & $\mathbf{2 . 1 9}$ \\
\hline NE & 1.49 & $\mathbf{2 . 0 8}$ & $\mathbf{2 . 9 1}$ \\
\hline FL & 1.35 & 1.39 & $\mathbf{1 . 6 5}$ \\
\hline STV & 1.30 & 1.35 & 1.35 \\
\hline SPP & 2.08 & 2.11 & $\mathbf{2 . 2 8}$ \\
\hline NWP & n/a & n/a & n/a \\
\hline RA & 1.11 & 1.13 & $\mathbf{1 . 4 4}$ \\
\hline CNV & 1.42 & 1.41 & 1.45 \\
\hline
\end{tabular}

The PNF values that are in bold indicate when multipliers increase the PNF value by more than an additional $10 \%$ beyond the $1 \mathrm{x}$ scenario PNF, an arbitrary cut off to identify when the multiplier becomes problematic. That said, the $3 \mathrm{x}$ scenario shows a multiplier problem in three EMM regions, MAIN, MAPP and NE, as indicated by the bolded values in Table 15. The 6x scenario shows a problem in seven regions, most of which raise the PNF by 0.20 to 1.42 from the $1 \mathrm{x}$ scenario.

Berkeley Lab will in the future use the PNF to evaluate whether multipliers chosen for each TSL significant risk of further altering the LDC. Berkeley Lab expects to use lower multipliers as a result of this finding that retain the general ordering of the peak system load hours. 


\subsubsection{Restoration Error}

Earlier it was explained that part two (as shown in Figure 16) of the double decrement approach restores the system energy to the Reference Case, thereby correcting for decrements to the demand side of NEMS in part one. If this restoration were not made, the decrement would be double counted, once on the demand side and again by the load shape decrement. The restoration is performed by mathematically restoring the term that is removed by the demand side decrement in part one of the double decrement approach. Appendix B, section III shows the coding modifications for this restoration.

However, by restoring the energy to the load shape without restoring it to the demand, other demand side factors affected by part one of the approach are not corrected for. The main second order effect is the price change induced by a demand reduction. Therefore, beyond the first iteration, perfectly restoring the system load back to the Reference Case is theoretically impossible given that one goal of the restoration process is to leave the demand side effects static.

For example, the reduced commercial sector space cooling energy consumption affects end use electricity and fuel prices that lead to second order effects that also affect the system load. This discrepancy in the system load or second order effect is referred to in this work as the restoration error. Restoration error represents the difference between the Reference Case and Restored Reference Case system load shapes. Berkeley Lab can compare these two loads shapes by using the same method described in subsection 6.1, by outputting the hourly system load for the Restored Reference Case. The magnitude of restoration error is explained for one example scenario in the following two tables.

For CUAC 3x TSL 4, Table 16 shows the regional energy decrement in year 2025. Columns B and $\mathrm{C}$ show the total energy by summing the load across all hours of the year. Column D shows the effective energy decrement relative to the NEMS Reference Case and column E shows the energy decrement input into NEMS-BT relative to the Restored Reference Case. The ratio of the two energy decrements is called the Total Energy correction Factor (TEF), and may be higher or lower than 1.0.

$$
\mathrm{TEF}=\frac{\Delta \text { Total Energy (Reference Case }- \text { TSL Case })}{\Delta \text { Total Energy (Restored Reference Case }- \text { TSL Case) }}
$$


Table 16. Energy Decrement for 3x TSL 4 by Region in Year 2025 (TWh)

\begin{tabular}{|c|c|c|c|c|c|c|}
\hline $\begin{array}{c}\text { EMM } \\
\text { Region }\end{array}$ & $\begin{array}{c}\text { NEMS } \\
\text { Reference } \\
\text { Case }\end{array}$ & $\begin{array}{c}\text { Restored } \\
\text { Reference } \\
\text { Case }\end{array}$ & $\begin{array}{c}\text { 3x TSL 4 } \\
\text { Case }\end{array}$ & $\begin{array}{c}\text { Energy } \\
\text { Decrement } \\
\text { NEMS } \\
\text { Reference } \\
\text { Case }\end{array}$ & $\begin{array}{c}\text { Energy } \\
\text { Decrement } \\
\text { Restored } \\
\text { Reference Case }\end{array}$ & TEF \\
\hline ECAR & 749.0 & 748.7 & 739.4 & 9.60 & E-C B-C & D/E \\
\hline ERCOT & 404.8 & 404.4 & 396.4 & 8.47 & 8.09 & 1.038 \\
\hline MAAC & 355.3 & 354.3 & 346.3 & 8.92 & 7.95 & 1.047 \\
\hline MAIN & 331.8 & 331.7 & 327.3 & 4.50 & 4.43 & 1.015 \\
\hline MAPP & 227.6 & 227.6 & 225.2 & 2.45 & 2.41 & 1.017 \\
\hline NY & 176.4 & 175.3 & 171.9 & 4.55 & 3.46 & 1.313 \\
\hline NE & 159.7 & 158.5 & 156.0 & 3.73 & 2.47 & 1.512 \\
\hline FL & 307.0 & 307.6 & 299.7 & 7.27 & 7.89 & 0.922 \\
\hline STV & $1,204.9$ & $1,207.0$ & 1182.6 & 22.25 & 24.30 & 0.915 \\
\hline SPP & 258.8 & 258.8 & 253.9 & 4.96 & 4.93 & 1.007 \\
\hline NWP & 377.3 & 377.4 & 371.3 & 5.98 & 6.05 & 0.988 \\
\hline RA & 250.0 & 249.5 & 245.1 & 4.87 & 4.36 & 1.117 \\
\hline CNV & 421.1 & 422.6 & 413.2 & 7.95 & 9.42 & 0.844 \\
\hline Total & $5,223.8$ & $5,223.3$ & 5128.3 & 95.50 & 95.00 & \\
\hline
\end{tabular}

Furthermore, the restoration error can also lead to another problem involving differences in peak energy demand. That is, the demand from the Restored Reference Case peak hour varies from the NEMS Reference Case. Table 17 shows the regional peak hour for the NEMS Reference Case compared to the Restored Reference Case. While these values seem similar, a small discrepancy can have a significant effect because the change in peak hour determines the Regional CLF $_{\text {out }}$. The ratio of the two measured differences, the Restored Reference Case minus the standard case and the Reference Case minus the standard case, is referred to in this work as the Peak Discrepancy correction Factor (PDF).

$$
\begin{aligned}
& \Delta \text { Peak Hour Energy Load (Restored Reference Case - TSL Case) } \\
& \mathrm{PDF}=\text { - } \Delta \text { Peak Hour Energy Load (Reference Case - TSL Case) }
\end{aligned}
$$


Table 17. Peak Hour Demand for 3x TSL 4 by Region in Year 2025 (TWh)

\begin{tabular}{|c|c|c|c|c|c|c|}
\hline $\begin{array}{c}\text { EMM } \\
\text { Region }\end{array}$ & $\begin{array}{c}\text { Peak Hour } \\
\text { Demand, NEMS } \\
\text { Reference Case }\end{array}$ & $\begin{array}{c}\text { Peak Hour } \\
\text { Demand, Restored } \\
\text { Reference Case }\end{array}$ & $\begin{array}{c}\text { Peak Hour } \\
\text { Demand, } \\
\text { TSL }\end{array}$ & $\begin{array}{c}\text { NEMS } \\
\text { Reference } \\
- \text { TSL }\end{array}$ & $\begin{array}{c}\text { Restored } \\
\text { Reference - } \\
\text { TSL }\end{array}$ & PDF \\
\hline ECAR & 132.3 & B & C & D = A-C & E= B-C & E/D \\
\hline ERCOT & 75.5 & 732.6 & 126.2 & 6.0 & 6.3 & 1.051 \\
\hline MAAC & 69.8 & 69.8 & 71.7 & 3.7 & 3.7 & 0.989 \\
\hline MAIN & 62.1 & 62.4 & 58.9 & 3.2 & 3.5 & 0.997 \\
\hline MAPP & 39.3 & 39.4 & 37.2 & 2.1 & 2.2 & 1.080 \\
\hline NY & 32.1 & 32.0 & 29.7 & 2.4 & 2.2 & 0.955 \\
\hline NE & 29.3 & 29.5 & 27.7 & 1.7 & 1.8 & 1.086 \\
\hline FL & 61.1 & 61.3 & 57.1 & 4.0 & 4.2 & 1.051 \\
\hline STV & 216.0 & 216.8 & 202.4 & 13.6 & 14.4 & 1.058 \\
\hline SPP & 49.8 & 49.8 & 47.6 & 2.2 & 2.2 & 1.014 \\
\hline NWP & 71.8 & 71.9 & 71.9 & -0.1 & 0.0 & \#DIV/0! \\
\hline RA & 47.9 & 47.9 & 44.1 & 3.8 & 3.8 & 0.984 \\
\hline CNV & 95.7 & 96.2 & 89.6 & 6.1 & 6.6 & 1.089 \\
\hline
\end{tabular}

Table 17 shows that the PDF is variable across the regions and not consistent to either side of one. Four regions (ERCOT, MAAC, NY, and RA) indicate a restoration to a level below the NEMS Reference Case, with eight regions showing an overcorrection for the demand-side decrement on the supply side of NEMS.

Based on analysis of the restoration error portion of the double decrement approach, Berkeley Lab has developed a simple expression that relates the PDF and TEF factors presented in this section with the SREF, or System Restoration Error Factor, previously discussed:

$$
\mathrm{SREF}=\mathrm{TEF} * \mathrm{PDF}
$$

This expression provides a better understanding of the factors that contribute to the overall error associated with the restoration. Both the TEF and PDF metrics show unbiased variability, as evidenced by values both above and below a level of perfect restoration. The PDF appears more variable than the TEF metric, indicating the importance of properly restoring the load at the peak hour.

\subsection{Summarizing our Findings}

This section presents a number of different factors used to help understand the differences between the $\mathrm{LF}_{\text {in }}$ and Regional $\mathrm{CLF}_{\text {out }}$ examined in this work. The PNF identifies the degree of non-coincidence between the NEMS Reference Case and a standard, while proving a useful metric for evaluating the higher multipliers required when modeling each TSL. The TEF and PDF help quantify the restoration error effect. The TEF and PDF result from differences in the total energy decrement and peak hour 
decrement, as calculated by comparing the NEMS Reference Case to the Restored Reference Case. Table 18 shows an example of these factors in MAPP for different multiples of TSL 4. The implicit $\mathrm{LF}_{\text {in }}$ is $10 \%$, yet the resulting Regional CLF $_{\text {out }}$ is $14 \%$, $13 \%$, and $17 \%$, for the $1 \mathrm{x}, 3 \mathrm{x}$, and $6 \mathrm{x}$ TSL 4 cases, respectively. For the $1 \mathrm{x}$ TSL 4 case, there is only a three-percentage point difference due to peak non-coincidence (PNF) and peak discrepancy (PDF) with most of the difference between the input $10 \%$ and output $14 \%$ due to the TEF. For the $3 \times$ TSL 4 case, the largest factor contributing to the difference between $\mathrm{LF}_{\text {in }}$ and the Regional $\mathrm{CLF}_{\text {out }}$ appears to be due to the PNF factor, and in the $6 \mathrm{x}$ TSL 4 case the seven-percentage point difference is largely driven by peak noncoincidence. Thus, the peak non-coincidence is clearly more problematic with higher multipliers, yet the restoration error does indicate a potentially significant factor, especially in the $1 x$ TSL case.

Table 18. Summary of Metrics used to Evaluate Selected Multiples of TSL 4 for MAPP

\begin{tabular}{|c|c|c|c|}
\hline & 1x TSL 4 & 3x TSL 4 & 6x TSL 4 \\
\hline $\mathbf{L F}_{\text {in }} \mathbf{\&}_{\mathbf{C L F}}$ & $10 \%$ & $10 \%$ & $10 \%$ \\
\hline & & & \\
\hline PNF & 1.03 & 1.25 & 1.69 \\
\hline TEF & 1.45 & 1.02 & 0.99 \\
\hline PDF & 0.97 & 1.04 & 1.02 \\
\hline & & & \\
\hline Regional $_{\text {CLF }}$ & $14 \%$ & $13 \%$ & $17 \%$ \\
\hline
\end{tabular}

\subsection{The 11 Blocks that Represent the LDC in NEMS}

Additionally, Berkeley Lab was able to output LDC information from NEMS-BT, which helped clarify how higher decrement CUAC runs affect the LDC. After NEMS computes the hourly system load, the EMM module groups the hours into blocks by season and time of day.

NEMS characterizes the system load into eleven different blocks that represent the 8760 hours of the year. The blocks sort the load for each EMM region by season and time of day. Table 19 shows each of the eleven blocks, the months corresponding to each season, the hours indicating the time of day, and the number of hours corresponding to each block type. 
Table 19. Summary of Load Duration Curve Parameters in NEMS

\begin{tabular}{|c|c|c|c|c|}
\hline Block & Load Group & Months & Hours of the Day & $\begin{array}{c}\text { \# Hours of } \\
\text { the Year }\end{array}$ \\
\hline 1 & summer day peak & June-September & & 67 \\
\hline 2 & winter morning/evening peak & December-March & & 67 \\
\hline 3 & winter day & December-March & $7: 00 \mathrm{am}-6: 00 \mathrm{pm}$ & 968 \\
\hline 4 & summer day non-peak & June-September & $7: 00 \mathrm{am}-6: 00 \mathrm{pm}$ & 1275 \\
\hline 5 & winter morning/evening non-peak & December-March & $5: 00 \mathrm{am}-7: 00 \mathrm{am}, 6: 00 \mathrm{pm}-12: 00 \mathrm{am}$ & 1264 \\
\hline 6 & spring/fall day & April-May, October-November & $7: 00 \mathrm{am}-6: 00 \mathrm{pm}$ & 1220 \\
\hline 7 & summer morning/evening & June-September & $5: 00 \mathrm{am}-7: 00 \mathrm{am}, 6: 00 \mathrm{pm}-12: 00 \mathrm{am}$ & 976 \\
\hline 8 & spring/fall morning/evening & April-May, October-November & $5: 00 \mathrm{am}-7: 00 \mathrm{am}, 6: 00 \mathrm{pm}-12: 00 \mathrm{am}$ & 1098 \\
\hline 9 & winter night & December-March & $12: 00 \mathrm{am}-5: 00 \mathrm{am}$ & 605 \\
\hline 10 & summer night & June-September & $12: 00 \mathrm{am}-5: 00 \mathrm{am}$ & 610 \\
\hline 11 & spring/fall night & April-May, October-November & $12: 00 \mathrm{am}-5: 00 \mathrm{am}$ & 610 \\
\hline
\end{tabular}

Recent work with developing this new approach has provided a greater understanding of how these blocks are used. In an experimental run with 6x TSL 4, we identified a shift in the ordering of these blocks such that a normally summer peaking load in three EMM regions switched to winter peaking as a result of the large decrement from this summer peaking end use. ${ }^{10}$ This run estimated a $225 \mathrm{TWh}$ reduction in electricity sales in 2025 and a $112 \mathrm{GW}$ reduction in total installed generating capacity for the same year. As a result, the winter peak block was superceded by the peak summer block in the MAPP, NE, and NY regions. This is a concern because the peak load is no longer dictated by summer demand, potentially altering the behavior of capacity planning in each EMM region. Berkeley Lab is still working on resolving this problem.

The nine seasonal and time of day blocks are: (1) spring/fall night, (2) spring/fall morning and evening, (3) spring/fall day, (4) winter night, (5) winter morning and evening, (6) winter day, (7) summer night, (8) summer morning and evening, and (9) summer day. Within each of the blocks, the hourly loads are sorted in descending order as can be seen in Figure 19. The summer day and winter morning/evening block are further subdivided into non-peak and peak blocks. A fixed percentage of $5 \%$ or 67 hours out of the year (as specified in the ldsmstr.txt file) from the highest load end of summer day and winter morning/evening blocks is designated as peak blocks. The 11 blocks are then sorted in descending order to provide a compact representation of the load duration curve.

The 11 LDC blocks by the 13 EMM regions were output. Comparing the block information from the NEMS Reference Case to runs modeling the impact from a proposed CUAC standard, this output helped identify an interesting phenomena: decrementing the system load in the standards case can cause the peak to switch from summer season to winter season. By noting the decrease in the peak blocks versus the annual saving, the CLF can be computed for each EMM region. Berkeley Lab also

\footnotetext{
10 This run is located on the "amichai" server used for running NEMS under

D:/nems/AEO2003/output/aps/cuac/Ddvalid/CcoolDD/NEMSeu/6xstd4/d121503b
} 
output the entire (864 hours) system load shape for the NEMS reference and the CUAC standard cases in order to compute the Regional CLF $_{\text {out }}$ based on the peak hours.

Comparison of this output revealed that the Regional CLF $_{\text {out }}$ computed from the LDC blocks are in close agreement with those calculated from the hourly system load itself.

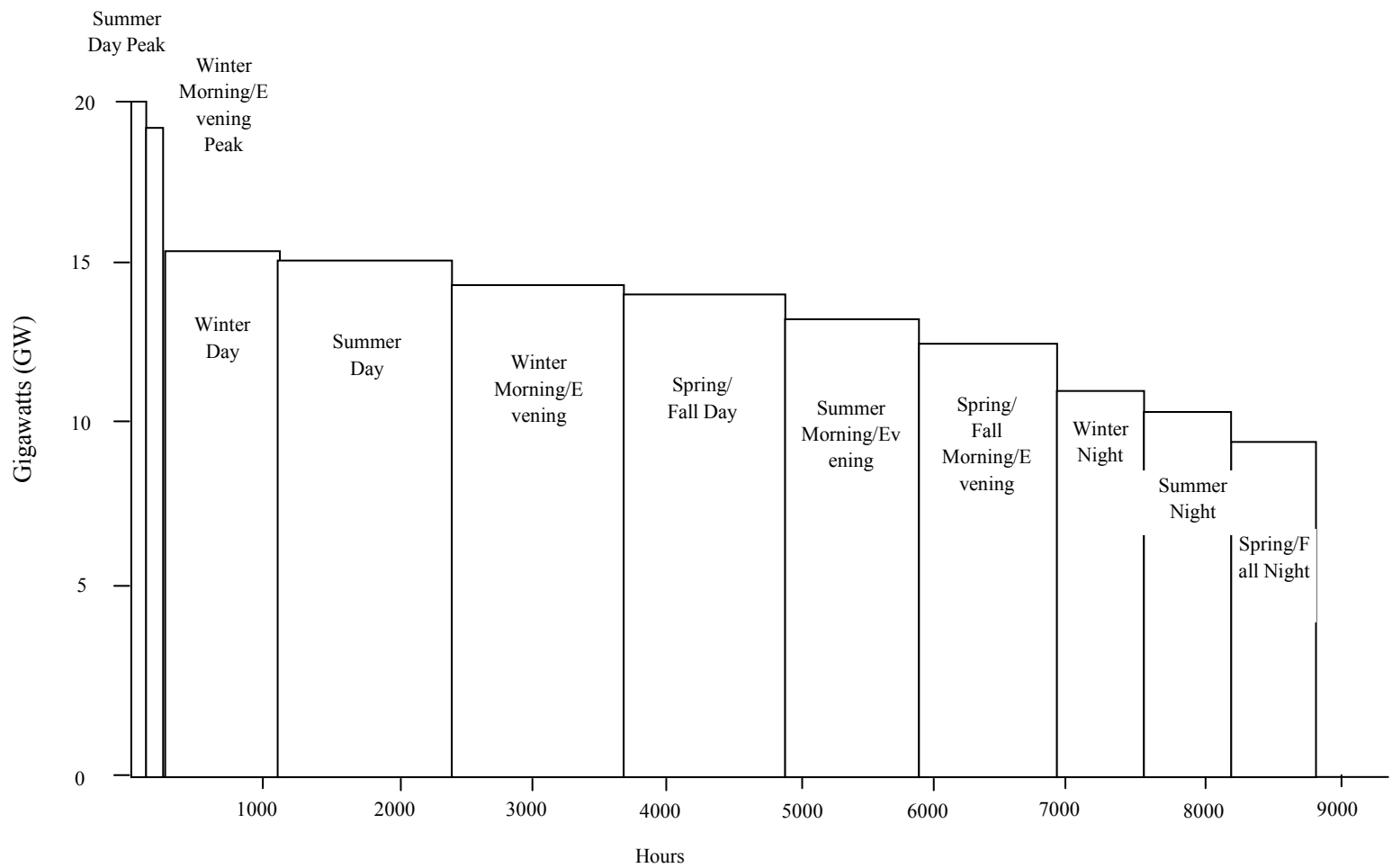

Figure 19. An Example of the Load Duration Curve in NEMS

The transition from a summer to winter peaking system load only occurs with higher multipliers. Lowering the magnitude of the multiplier yet still ensuring that the impacts are safely out of the range of numerical noise minimized the risk of this phenomenon occurring. 


\section{Summary of Findings and Conclusions}

Because of previous unsuccessful modeling of the utility effects from an appliance standard on a peaky end use in NEMS-BT, Berkeley Lab has developed the new double decrement approach for modeling the effects from a proposed CUAC standard.

The following summarizes the key findings and conclusions from this work:

- The double decrement approach reduces the hourly system load shape directly to ensure the effects from a proposed CUAC standard are properly lowering the peak and properly accounting for changes on the supply side of the model. The approach also decrements the commercial space cooling consumption to account for changes on the demand side of the model, with a restoration step designed to eliminate any potential double counting of the energy savings.

- Although Berkeley Lab believes the simulated TMY CUAC load shape developed by PNNL are more representative of the CUAC load profile, this simulated load shape is characteristically less peaky than the end use space cooling load shape currently used in NEMS, approximately 1-10 percentage points higher in the input CLF, $\mathrm{LF}_{\text {in }}$.

- A comparison of the standard system load shape in NEMS and the TMY system load shows no significant identifiable differences between these two sources.

- Berkeley Lab was successful at targeting decrements from the highest system load peak hours in a preliminary NEMS-BT run, resulting in National CLF out $_{\text {values that }}$ are very peak coincident, i.e. less than $10 \%$ by 2020 .

- The use of lower magnitude multipliers for our higher decrement runs increases our peak impacts equivalent to roughly 2-5 percentage points in the National CLF out. This work revealed that higher multipliers alter the shape of the LDC such that capacity planning results are no longer representative of a proposed CUAC standard.

- The National CLF $_{\text {out }}$ using the double decrement approach is not significantly different than the National $\mathrm{CLF}_{\text {out }}$ using the traditional approach.

- The non-coincidence between the end-use CUAC load profile and the NEMS-BT system load account for nearly all of the discrepancy between the input CLF of the space cooling or CUAC simulated TMY load shape input to NEMS-BT and the National $\mathrm{CLF}_{\text {out }}$ based on the results of implementing a proposed CUAC standard.

- Using the simulated TMY CUAC load shape in place of the NEMS space cooling end use load shape increases the peak utility effects, amounting to a 2 percentage-point

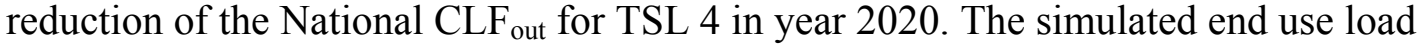
shape is more coincident with the system load with somewhat more usage during the off-peak periods of the day.

- Berkeley Lab proposes using the double decrement approach in conjunction with switching out the NEMS space cooling end use load shape with the simulated CUAC load shape. 



\section{References}

Holte, J. 2001a. Alternative Sectoral Load Shapes for NEMS. Vienna, VA: OnLocation, Inc., August. 61 pp.

Holte, J. 2001b. RELOAD Database Documentation and Evaluation and Use in NEMS. Vienna, VA: OnLocation, Inc. July 9. 155 pp.

Koomey, J., A. Rosenfeld, and A. Gadgil. 1990. "Conservation Screening Curves to Compare Efficiency Investments to Power Plants." Energy Policy, 18 (No. 8).

LaCommare, K. H., C. Marnay, E. Gumerman, P. Chan, G. Rosenquist, and J. Osborn. 2002. Investigation of Residential Central Air Conditioning Load Shapes in NEMS. Berkeley: Lawrence Berkeley National Laboratory. LBNL-52235. May. 41 pp.

Treidler, B., and M. Modera. 1994. Peak Demand Impacts of Residential Air Conditioning Conservation Measures. Berkeley: Lawrence Berkeley National Laboratory. LBNL-35532. August. 



\section{Appendix A. Mathematical Representation of Load Demand in NEMS}

\section{Calculation of System Load in NEMS}

This section describes the differences between two mathematical representations of the system load. One representation corresponds to what is shown in the model documentation of NEMS. We call this the Original Delta Approach. It should be noted that there are lines of code for the Original Delta Approach in the NEMS source code, but the lines have been commented out and the code is thus inactive. The other representation is what is actually implemented in NEMS. This second representation is a modification to the Original Delta Approach involving a scaling factor. We call this representation the Current Delta Approach because that is currently used in NEMS to calculate hourly system loads.

The mathematical representation of the hourly system load using the Original Delta Approach as shown in the model documentation is:

$$
\text { SysLoad }_{-} O^{y r}(h)=p_{s}(h) \cdot T E^{2001}+\sum_{e}^{\text {all e }} p_{e}(h) \cdot\left(E U_{e}^{y r}-E U_{e}^{2001}\right)
$$

where

\begin{tabular}{|c|c|c|}
\hline$e$ & $=$ & end-uses index \\
\hline$y r$ & $=$ & year index \\
\hline SysLoad ${ }^{y r}(h)$ & $=$ & system load at hour $h$ in year $y r$ (SYLOAD in documentation) \\
\hline $\begin{array}{l}T E^{2001} \\
\text { NEMS }\end{array}$ & $=$ & total system load in the base year, which is 2001 in AEO2001 version of \\
\hline $\begin{array}{l}p_{s}(h) \\
\text { documentation) }\end{array}$ & $=$ & historical hourly load shape for the system at hour $h\left(\right.$ DistLo $_{\mathrm{s}}$ in \\
\hline $\begin{array}{l}p_{e}(h) \\
\text { documentation) }\end{array}$ & $=$ & normalized load shape of end use $e$ at hour $h\left(\right.$ DistLo $_{\mathrm{e}}$ in \\
\hline$E U_{e}^{y r}$ & $=$ & Annual end-use load for end-use $e$ in year $y r$ ( $\operatorname{load} 1_{\mathrm{e}}$ in documentation) \\
\hline$E U_{e}^{2001}$ & $=$ & Annual End-use load for end-use $e$ in base year (2001) \\
\hline
\end{tabular}

The Current Delta Approach as shown below calculates the hourly system load using a slightly modified form of the Original Delta Approach:

$$
\text { SysLoad_C } C^{y r}(h)=p_{s}(h) \cdot T E^{y r}+\sum_{e}^{\text {all } e} p_{e}(h) \cdot\left(E U_{e}^{y r}-\frac{T E^{y r}}{T E^{2001}} \cdot E U_{e}^{2001}\right)
$$

where $T E^{y r} \quad=\quad$ total system load in year $y r$

In (2), $p_{s}(h)$ is multiplied by the total system load of the current year, $T E^{y r}$, instead of $T E^{2001}$ as in (1). Also $E U_{e}^{2001}$ is multiplied by a scaling factor $\frac{T E^{y r}}{T E^{2001}}$. 


\section{Comparison to the Bottom-up Approach}

The bottom-up approach calculates the system hourly load for each hour $h$ as follow:

$$
\text { SysLoad_ }_{-} B^{y r}(h)=\sum_{e}^{\text {all } e} p_{e}(h) \cdot E U_{e}^{y r}
$$

Rearranging equation (1), the hourly system load using the Original Delta Approach becomes

$$
\begin{aligned}
\text { SysLoad_O }_{-}{ }^{y r}(h) & =\sum_{e}^{\text {all } e} p_{e}(h) \cdot E U_{e}^{y r}+\left(p_{s}(h) \cdot T E^{2001}-\sum_{e}^{\text {all } e} p_{e}(h) \cdot E U_{e}^{2001}\right) \\
& =\text { SysLoad_ }_{-} B^{y r}(h)+\operatorname{diff}(h)
\end{aligned}
$$

where

$$
\operatorname{diff}(h)=\left(p_{s}(h) \cdot T E^{2001}-\sum_{e}^{\text {all } e} p_{e}(h) \cdot E U_{e}^{2001}\right)
$$

Note: $\operatorname{diff}(h)$ represents how much the historical system load shape in the base year 2001 differs from the sum of all the NEMS end-use load shapes at hour $h$.

By rearranging equation (2), the hourly system load using the Current Delta Approach becomes

$$
\begin{aligned}
\text { SysLoad } C_{-}^{y r}(h) & =\sum_{e}^{\text {all } e} p_{e}(h) \cdot E U_{e}^{y r}+\frac{T E^{y r}}{T E^{2001}} \cdot\left(p_{s}(h) \cdot T E^{2001}-\sum_{e}^{\text {all e }} p_{e}(h) \cdot E U_{e}^{2001}\right) \\
& =\text { SysLoad }_{-} B^{y r}(h)+\frac{T E^{y r}}{T E^{2001}} \cdot \operatorname{diff}(h) \ldots \ldots \ldots \ldots \ldots \ldots \ldots \ldots \ldots \ldots \ldots
\end{aligned}
$$

For the Original Delta Approach, diff( $h$ ) is added to the bottom-up system load. For the Current Delta Approach, diff(h) is multiplied by the factor $T E^{y r} / T E^{2001}$ (which EIA calls the load balancing factor) before added to the bottom-up system load. In fact, both the Original Delta Approach and the Current Delta Approach squelch the bottom-up sum of the end-use hourly loads. The hourly system load using the Original Delta Approach squelches the system load at hour $h$ by a constant amount $\operatorname{diff}(h)$ every year while the Current Delta Approach squelches the bottom-up sum according to the growth of total annual energy. 


\section{Impact on Conservation Load Fact with Current Delta Approach}

Suppose the only end-use that we are varying in the Standards Case is AC. Let TE1 and $T E 2$ be the total annual energy, $E U 1_{A C}$ and $E U 2_{A C}$ be the annual AC energy use for the Base Case and the Standards Case respectively.

Using the Bottom-up Approach, the system hourly load for the Base Case and the Standards Case are given by:

$$
\begin{aligned}
& \text { SysLoad_B } B_{\text {Base }}^{y r}(h)=\sum_{e}^{\text {all }} p_{e}(h) \cdot E U_{e}^{y r}+p_{A C}(h) \cdot E U 1_{A C}^{y r} \\
& \text { SysLoad_B } B_{\text {Stds }}^{y r}(h)=\sum_{e}^{\text {all }} p_{e}^{e \neq A C}(h) \cdot E U_{e}^{y r}+p_{A C}(h) \cdot E U 2_{A C}^{y r}
\end{aligned}
$$

Using the Current Delta Approach, the system hourly load for the Base Case and the Standards Case are:

$$
\begin{aligned}
& \text { SysLoad_C } C_{\text {Base }}^{y r}(h)=\sum_{e}^{\text {all }} \sum_{e}^{e \neq A C} p_{e}(h) \cdot E U_{e}^{y r}+p_{A C}(h) \cdot E U 1_{A C}^{y r}+\frac{T E 1^{y r}}{T E^{2001}} \cdot \operatorname{diff}(h) \\
& \text { SysLoad_C } C_{\text {Stds }}^{y r}(h)=\sum_{e}^{\text {all }} \sum_{e}^{e \neq A C} p_{e}(h) \cdot E U_{e}^{y r}+p_{A C}(h) \cdot E U 2_{A C}^{y r}+\frac{T E 2^{y r}}{T E^{2001}} \cdot \operatorname{diff}(h)
\end{aligned}
$$

Since the only end-use that we are decrementing in the Standards Case is AC, the total annual system energy saving is the same as the annual energy saving for the end-use AC.

$$
\begin{aligned}
& T E 2^{y r}=T E 1^{y r}-D^{y r} \quad \text { and } D^{y r} \text { is decrement in year } y r \\
& E U 2_{A C}^{y r}=E U 1_{A C}^{y r}-D^{y r}
\end{aligned}
$$

The Conservation Load Factor, CLF, is defined as the ratio of the average hourly saving to the peak energy saving.

$$
\begin{aligned}
C L F & =\frac{\left(T E 1^{y r}-T E 2^{y r}\right)}{8760 \times(\text { difference in peak energy })} \\
& =\frac{D^{y r}}{8760 \times(\text { difference in peak energy })}
\end{aligned}
$$


If the system peak hour, $p k h r$, in the Base Case remains the same in the Standards Case, then from $(6)-(6 a)$

$$
\begin{aligned}
& \text { difference in peak energy }(\text { Bottom-up })=\text { Sysload }_{-} B_{\text {Base }}^{y r}(p k h r)-S_{y s l o a d} B_{\text {Stds }}^{y r}(p k h r) \\
& =p_{A C}(p k h r) \cdot D^{y r}
\end{aligned}
$$

Again, if this system peak hour, pkhr, is the same for the Base Case and the Standards Case using the Current Delta Approach, then from (7) - (7a)

$$
\begin{gathered}
\text { difference in peak energy }(\text { Current Delta })=\text { Sysload } C_{\text {Base }}^{y r}(p k h r)-S_{y s l o a d} C_{\text {Stds }}^{y r}(p k h r) \\
=p_{A C}(p k h r) \cdot D^{y r}+\frac{\left(T E 1^{y r}-T E 2^{y r}\right)}{T E^{2001}} \cdot \operatorname{diff}(p k h r) \\
=p_{A C}(p k h r) \cdot D^{y r}+\frac{D^{y r}}{T E^{2001}} \cdot \operatorname{diff}(p k h r) \\
=\left(p_{A C}(p k h r)+\frac{1}{T E^{2001}} \cdot \operatorname{diff}(p k h r)\right) \cdot D^{y r} \ldots(10)
\end{gathered}
$$

Calculating the CFL using (8),

$$
\begin{aligned}
C L F_{\text {Bottom-up }}= & \frac{D^{y r}}{8760 \times\left(p_{A C}(p k h r) \cdot D^{y r}\right)}=\frac{1}{8760 \times p_{A C}(p k h r)} \\
C L F_{\text {Current Delta }} & =\frac{1}{8760 \times\left(p_{A C}(p k h r)+\frac{1}{T E^{2001}} \cdot \operatorname{diff}(p k h r)\right)} \ldots \ldots \ldots
\end{aligned}
$$

From equation (11) and (12), the difference between $C L F_{\text {Bottom-up }}$ and $C L F_{\text {Current Delta }}$ depends on the term $\frac{1}{T E^{2001}} \cdot \operatorname{diff}(p k h r)$. This term is comparatively much smaller than $p_{A C}(p k y r)$ and the effect on the CLF calculated is insignificant.

e.g. For EMM region 9, STV, the system peak hour is at the $17^{\text {th }}$ hour of the June peak day, 
$p_{A C}(p k h r)$ is $0.58 \times 10^{-3}$ and $C L F_{\text {Bottom-up }}$ would be $20 \%$. With the Current Delta Approach, $\frac{1}{T E^{2001}} \cdot \operatorname{diff}(p k h r)$ is $-0.000029 \times 10^{-3}$ and $C L F_{\text {Current Delta }}$ is almost identical to $C L F_{\text {Bottom-up }}$.

This illustrates that in the case where the peak hour does not change from Base Case to Standards Case, the Current Delta Approach does not significantly impact the CLF calculation. However, in reality, the peak hour does change in the Standards Case. This is due to the non-coincidence of the AC load shape and the system load shape. Further more, the peak hours using the Bottom-up Approach and the Current Delta Approach can be different because of the adjustment made in the latter. It is this non-coincidence of system peak hours that is a major factor affecting the outcome of the CLF calculation. 



\section{Appendix B. Code Modifications for Implementing the Double Decrement Approach}

Code additions/changes were made to four subroutines, one in the commercial demand module and three in the LDSM module. The subroutine modified in the commercial module is COMConsumption and in the LDSM module they are DSMACM, DSMNWS and DSMHLM.

The following shows the steps taken to implement the decrement to the hourly system load.

\section{SUBROUTINE COMConsumption:}

1. Read in annual national energy saving for Commercial $\mathrm{A} / \mathrm{C}-$ LBLSavingsCool (yr)

2 . Read in Commercial A/C hourly load shape by NERC region CCACfr (i, reg) , $i=1,864$

3. Read in fraction of national total by Census region to distribution total saving to Census regions $-r C(C R)$

The above 3 steps are done when year $=13$

After year 13, the total cooling electricity use for each Census region $C R$, totC, is calculated using the following equation.

$$
\text { totC }=\sum_{\text {bldg }} \text { EndUseConsump }(1,2, \mathrm{bldg}, \mathrm{CR}, \text { year })
$$

where EndUseConsump $(1,2, \ldots)$ is the electricity consumption for commercial cooling by building type bldg, census region $\mathrm{CR}$ and year.

The energy saving for Census region $\mathrm{CR}$ is calculated by distributing the national annual energy saving, i.e. LBLSavingsCool (year) * rC (CR)

The ratio of the energy saving in $\mathrm{CR}$ to the total cooling electricity use in $\mathrm{CR}$, $\mathrm{drC}(\mathrm{CR}$, year), is calculated as follow.

$$
\operatorname{drC}(\mathrm{CR}, \text { year })=\text { LBLSavingsCool (year }) * r C(\mathrm{CR}) / \operatorname{totC}
$$

Then we assume that the cooling energy for all building types in the Census region $\mathrm{CR}$ are reduced equally by the same ratio $\operatorname{drC}(C R$, year $)$, i.e. for every building type bldg

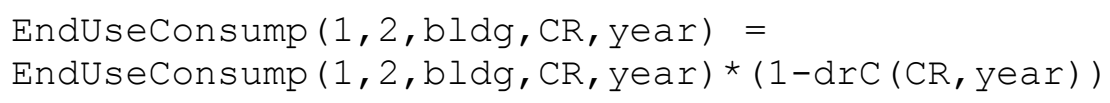




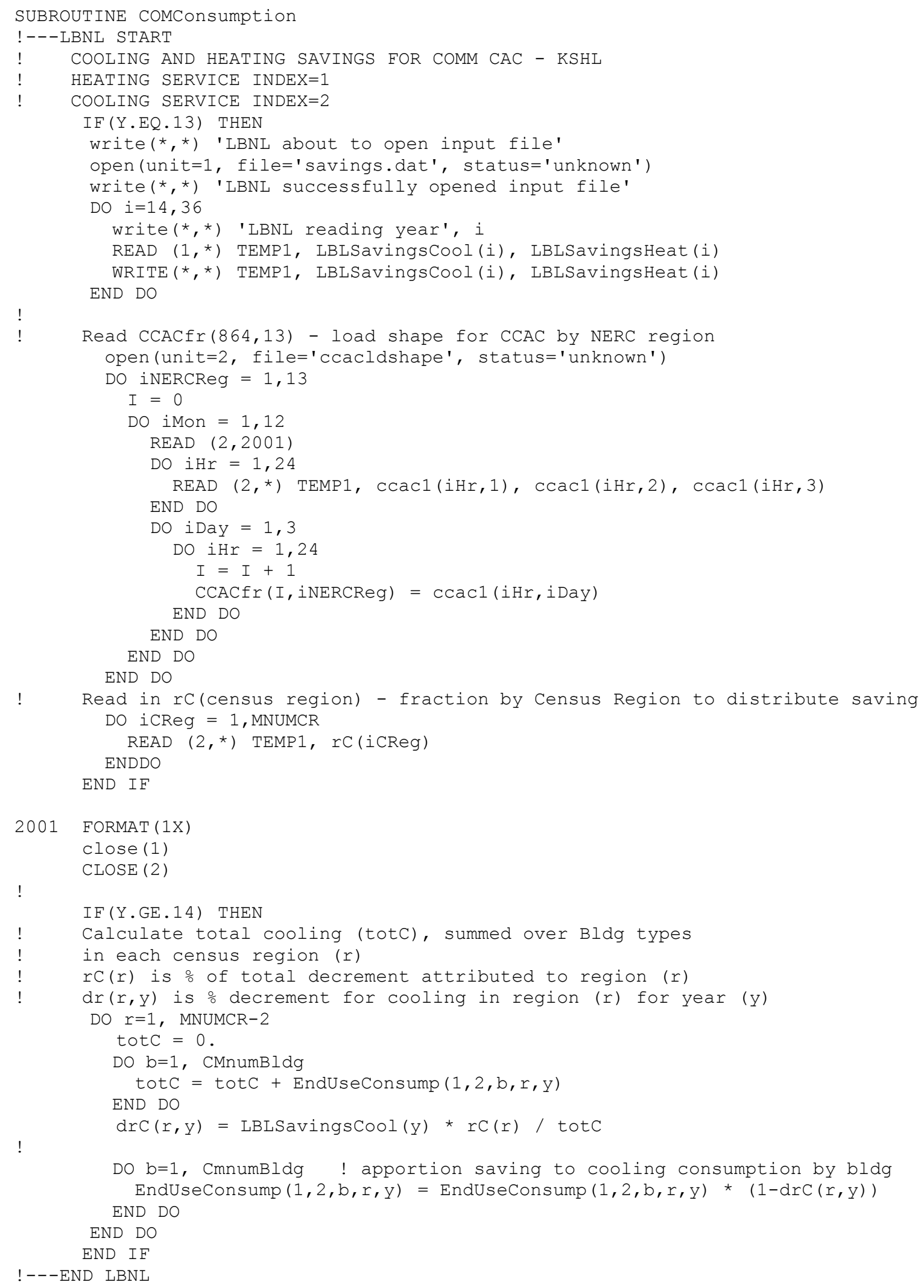


Subroutine DSMACM maps Census region level commercial sector energy use to energy use by NERC region.

We need to calculate the decrement by end use (commercial $\mathrm{A} / \mathrm{C}$ by building type) by NERC region, to be stored in the variable LBLdel (LFinum). This will be used in the restoring to the Reference Case load shape. The cooling energy by Census region is in the variable CENSUSvalues $(k)$ where $k$ is the Census region number. Note that CENSUSValues $(\mathrm{k})$ already has the saving decremented.

The saving tmpSavC $(k)$ can be calculated by

tmpSavC $(\mathrm{k})=$ CENSUSValues $(\mathrm{k}) /(1-\mathrm{drC}(\mathrm{k}$, year $)) * \mathrm{drC}(\mathrm{k}$, year $)$

Then SUBROUTINE DSMEMMV is called and it maps tmpSavC $(k)$ from Census region to NERC region, which is then stored in the variable LBLdel (LFinum) .

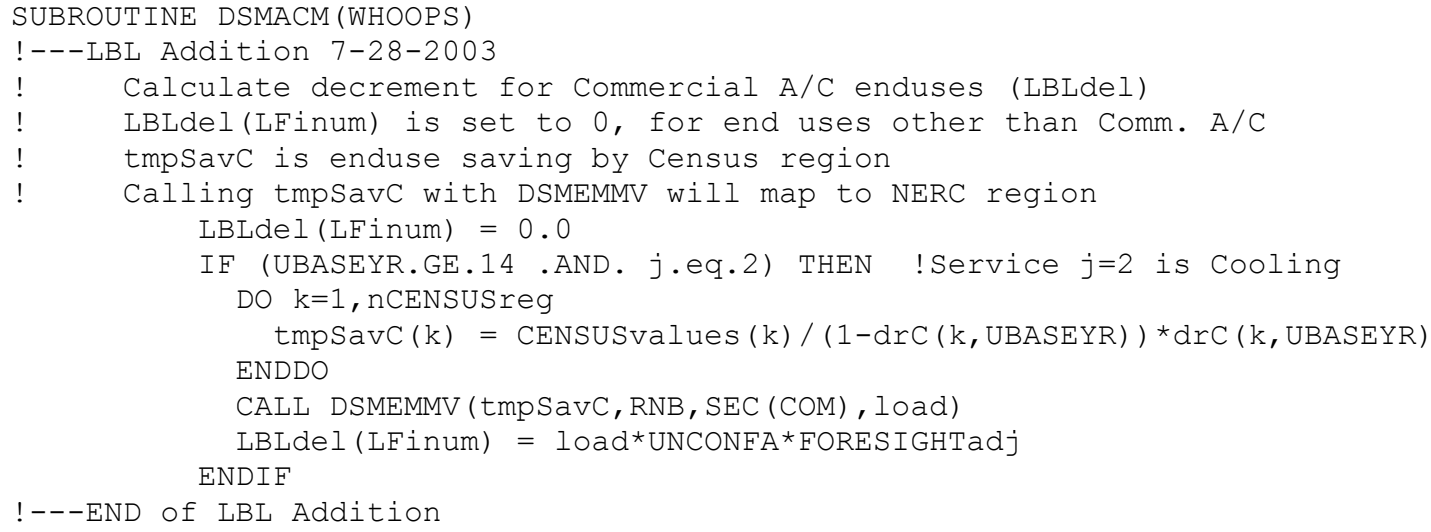




\section{SUBROUTINE DSMNWS:}

\section{In subroutine DSMNWS, the calculations to generate the hourly system load is modified to restore it to the Reference case, i.e. before the energy decrement.}

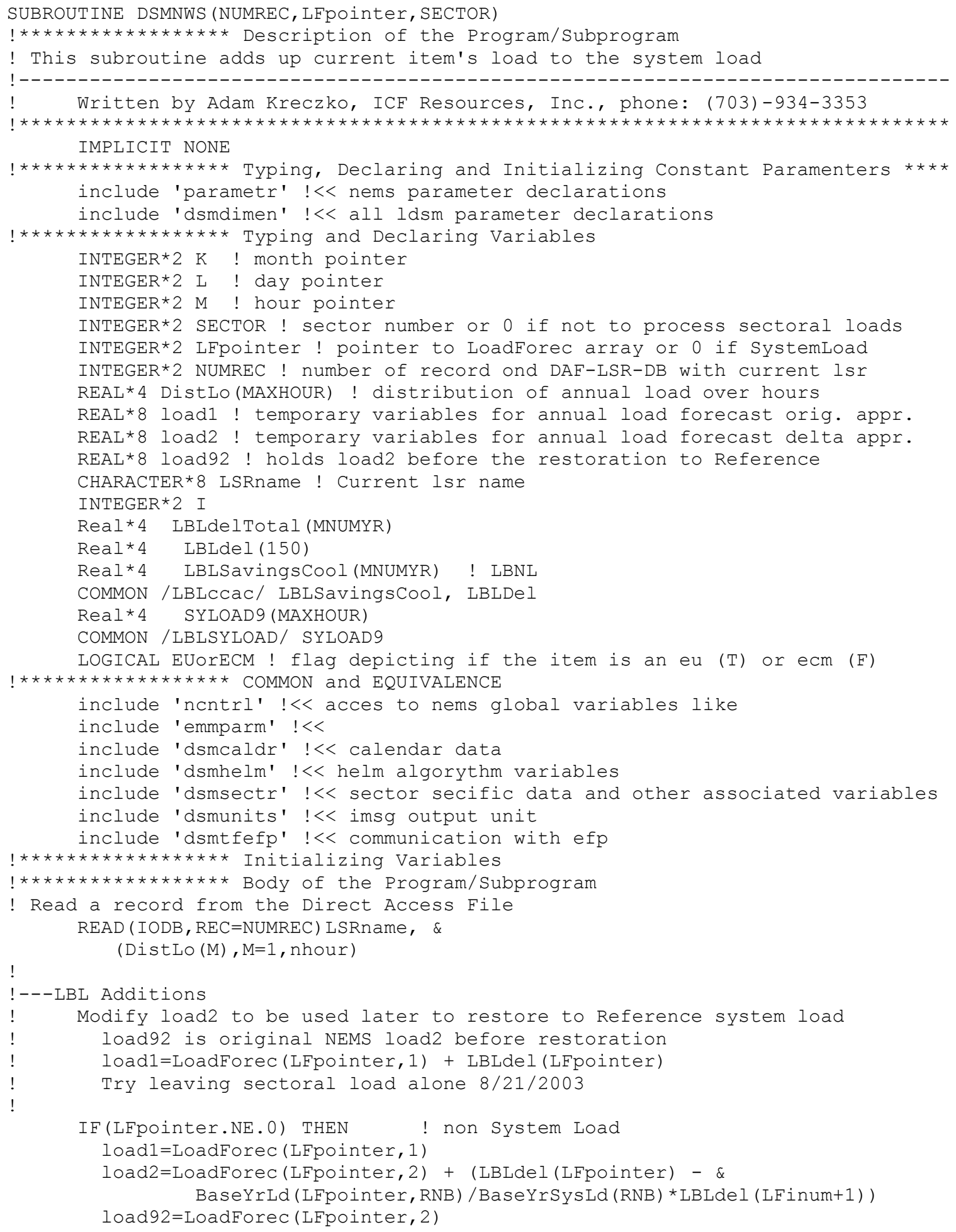




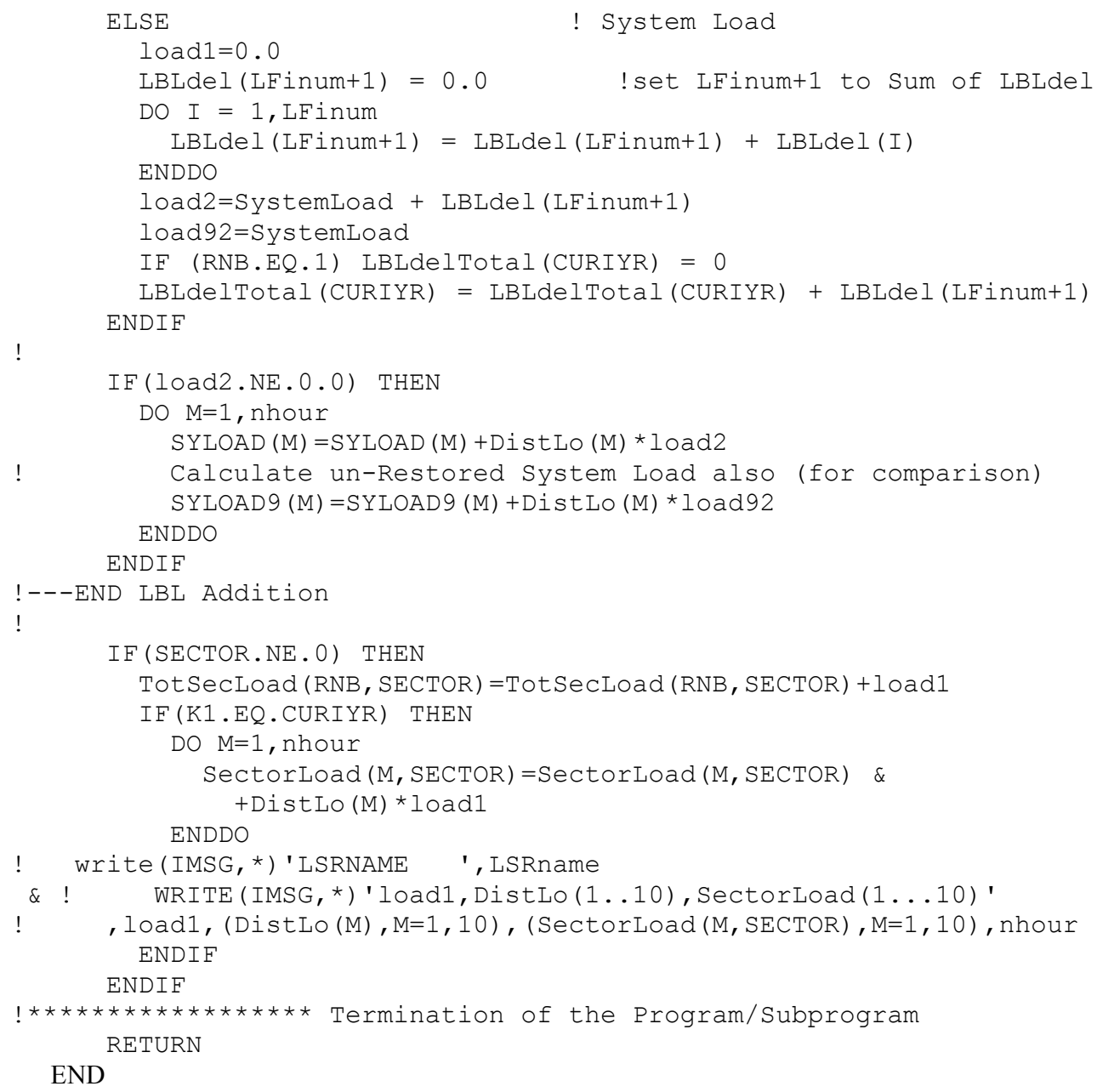

END 


\section{SUBROUTINE DSMHLM:}

\section{In subroutine DSMHLM, the restored hourly System Load is again decremented based on the Commercial A/C load shape and the NERC regional energy savings.}

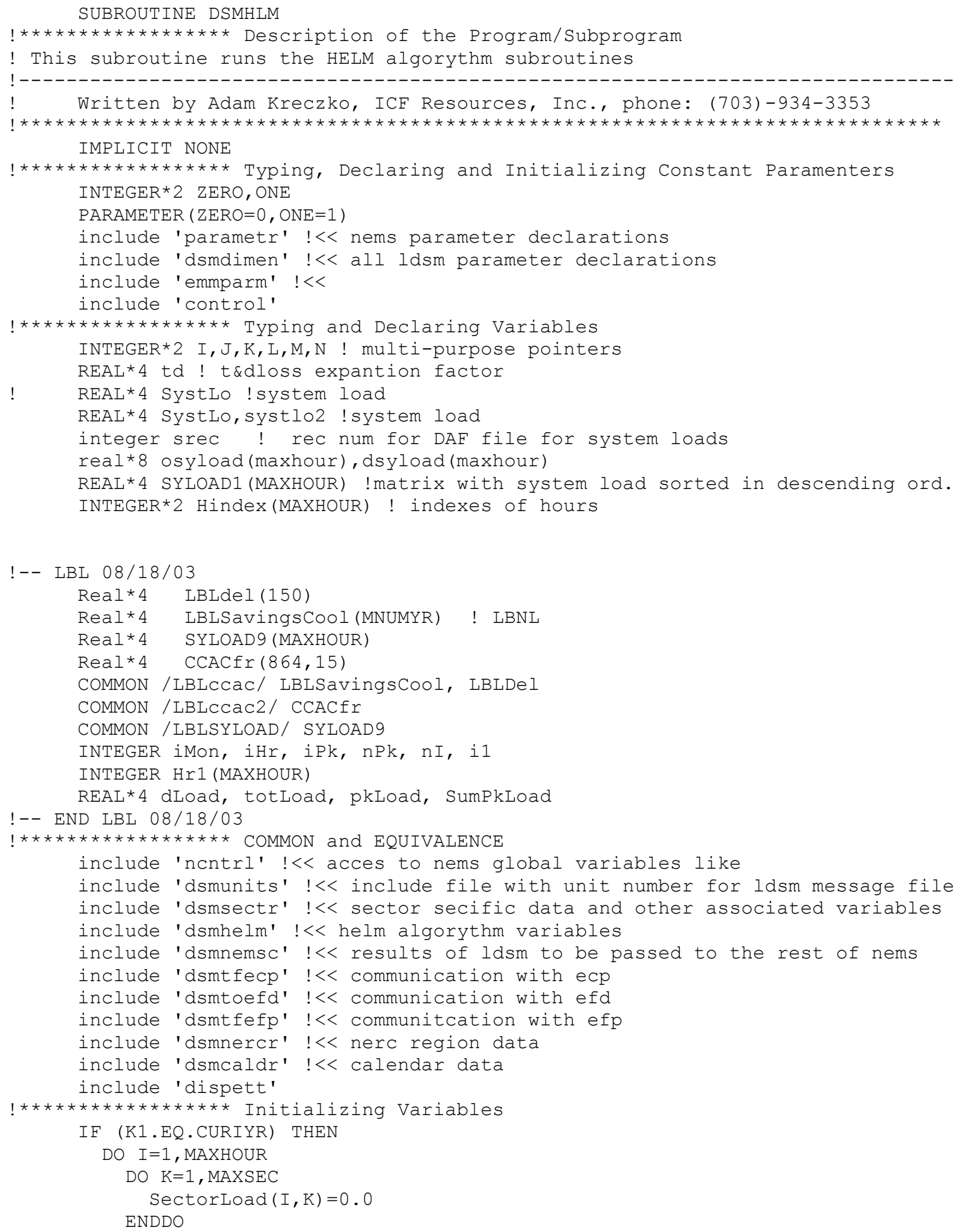




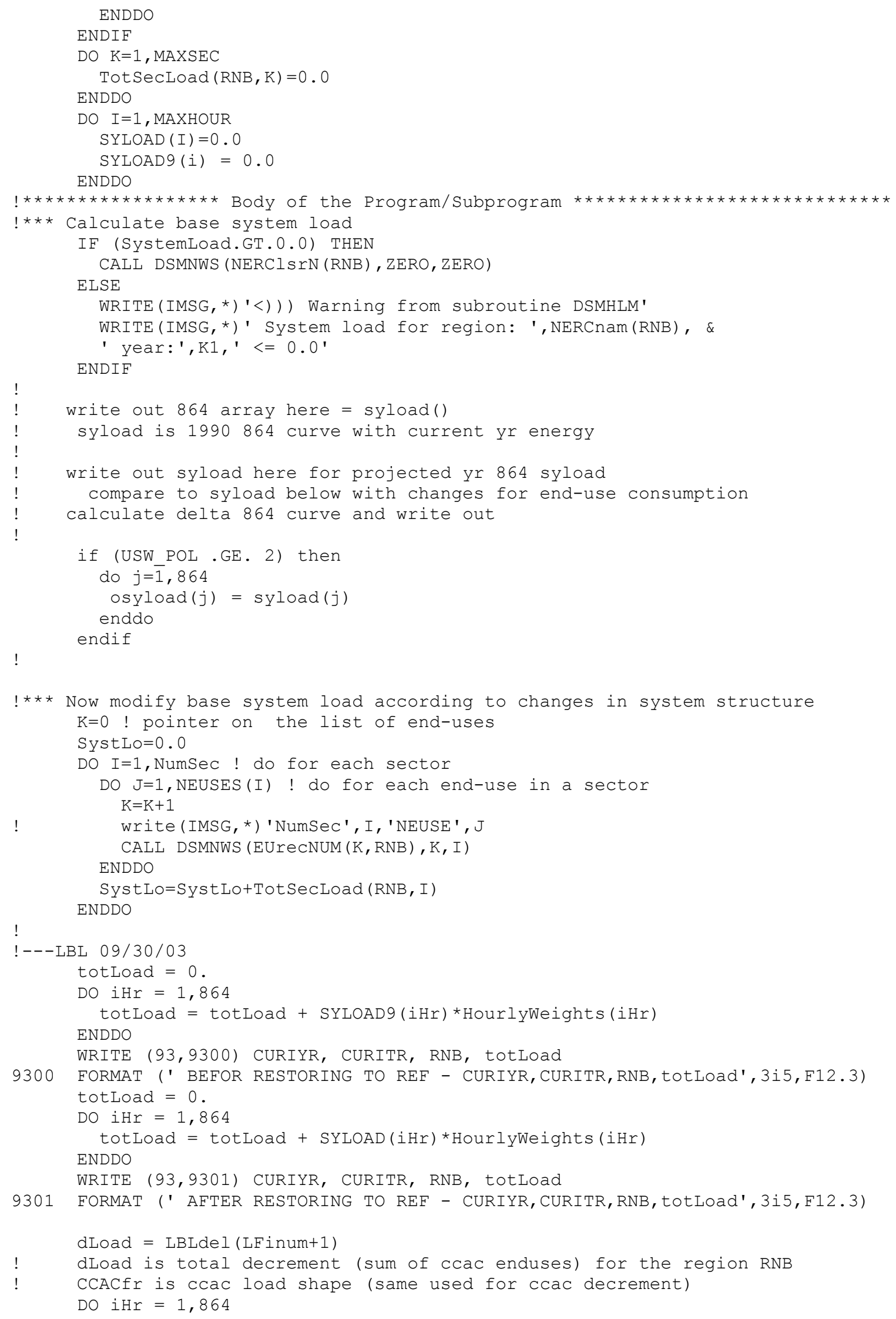




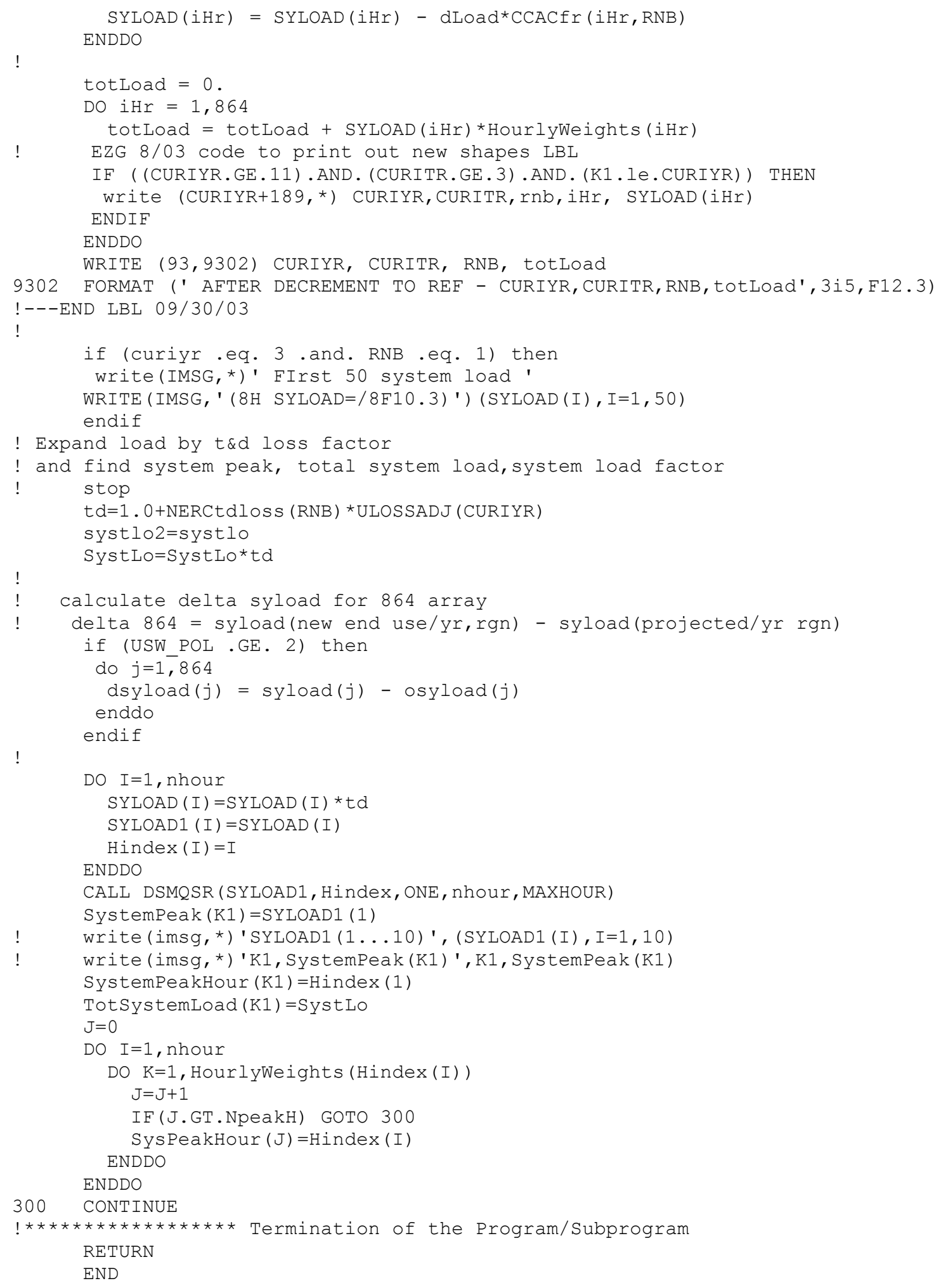



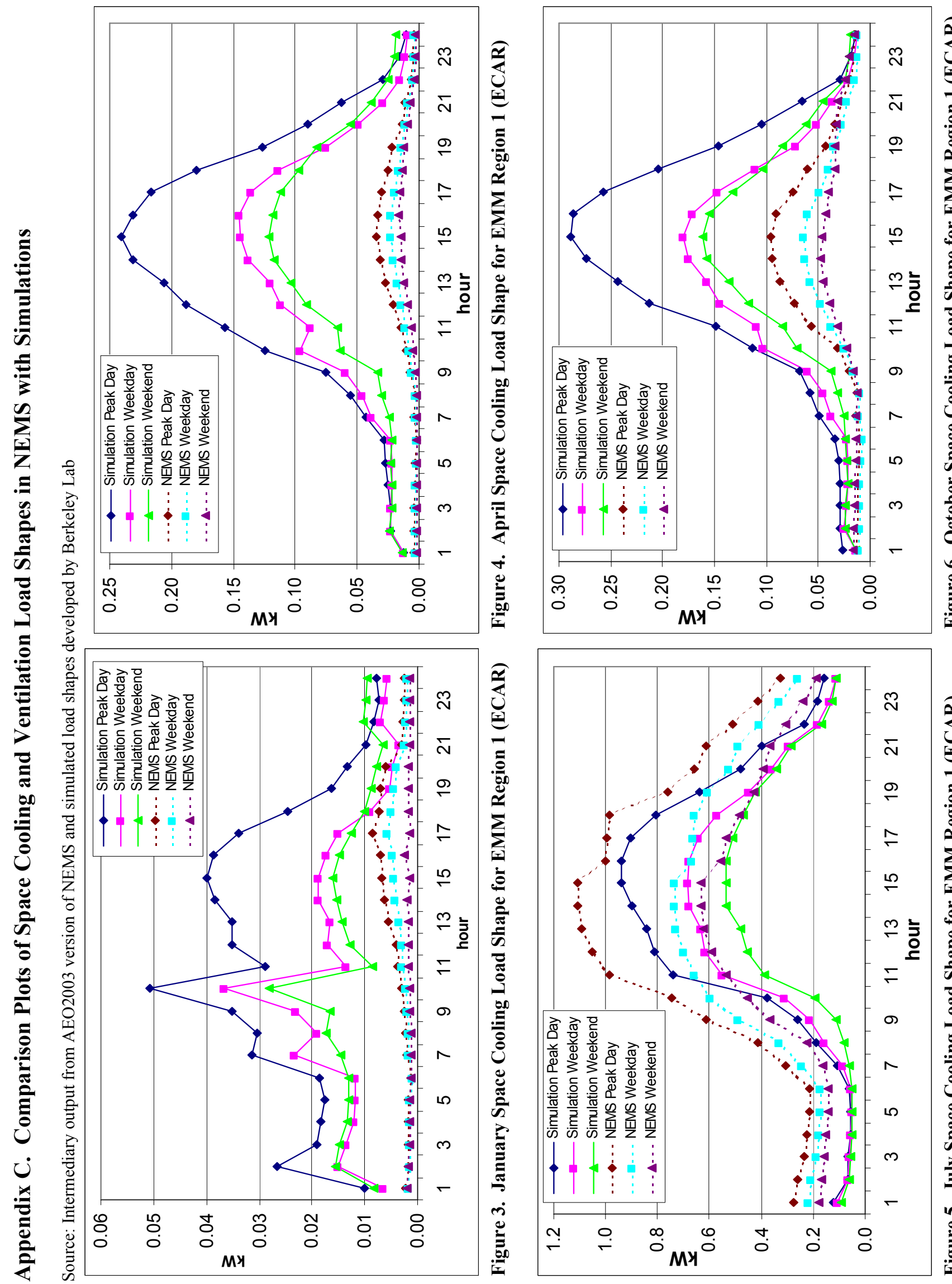

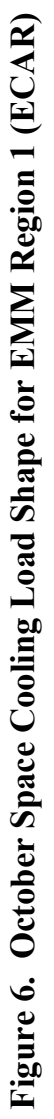

8ิ

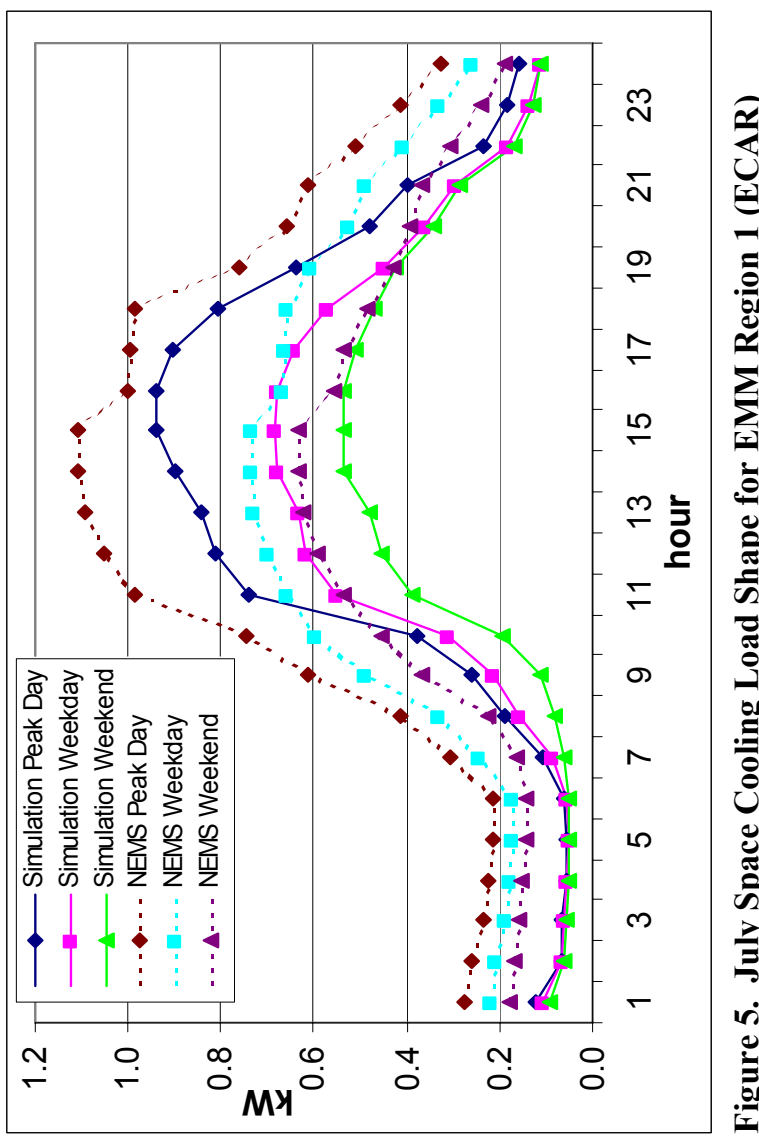



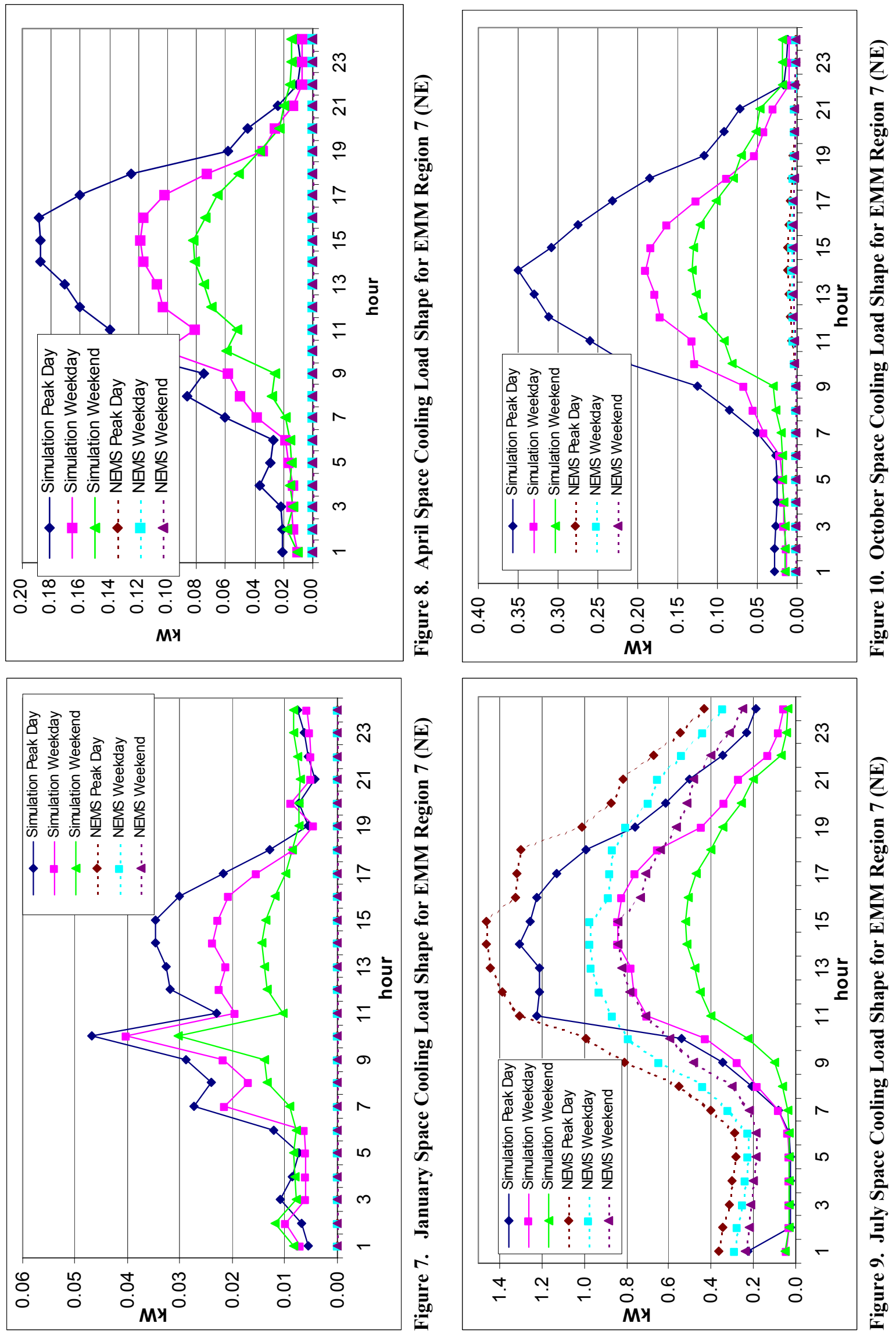

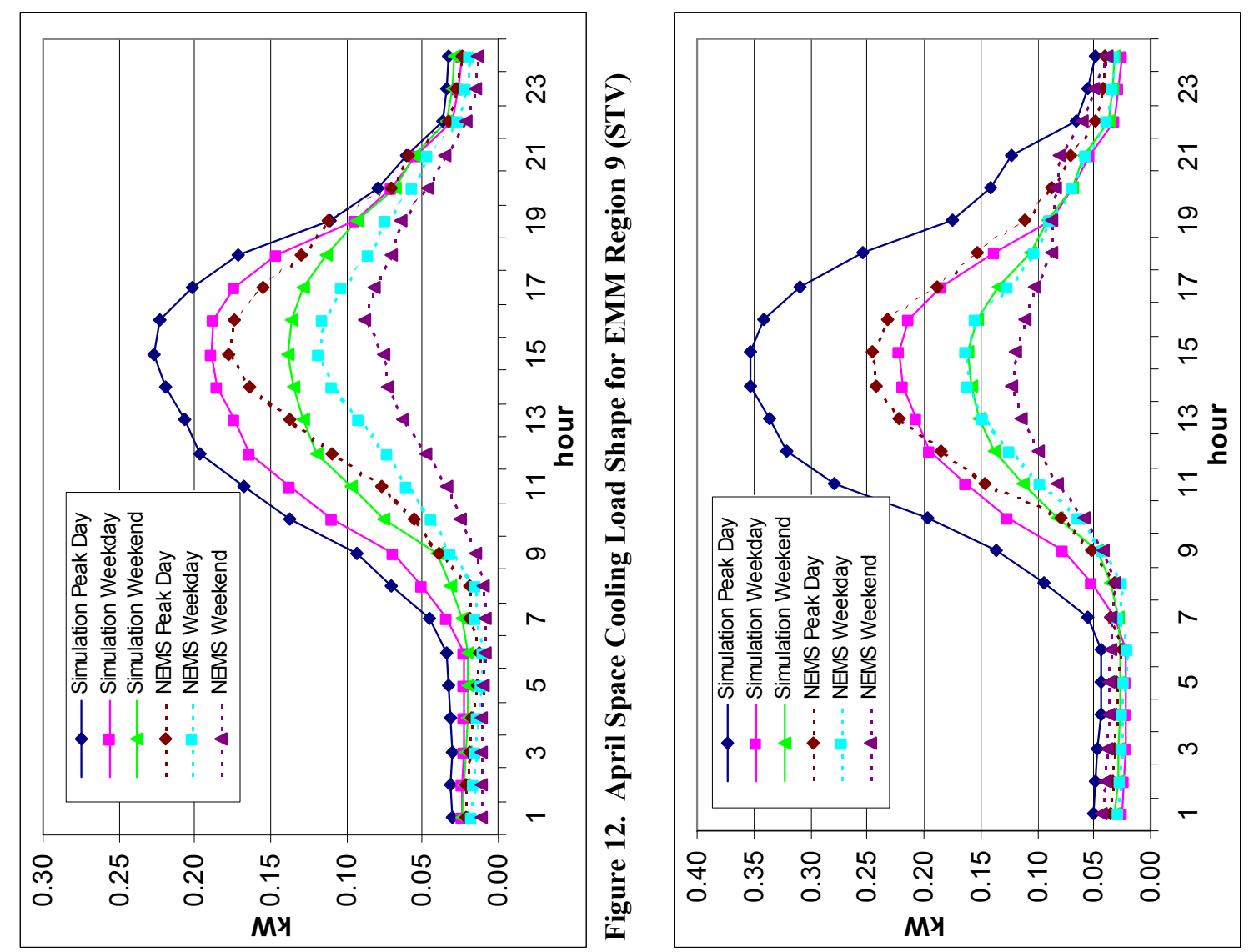

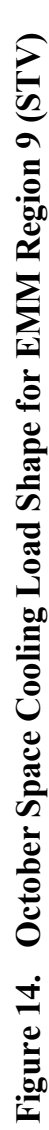
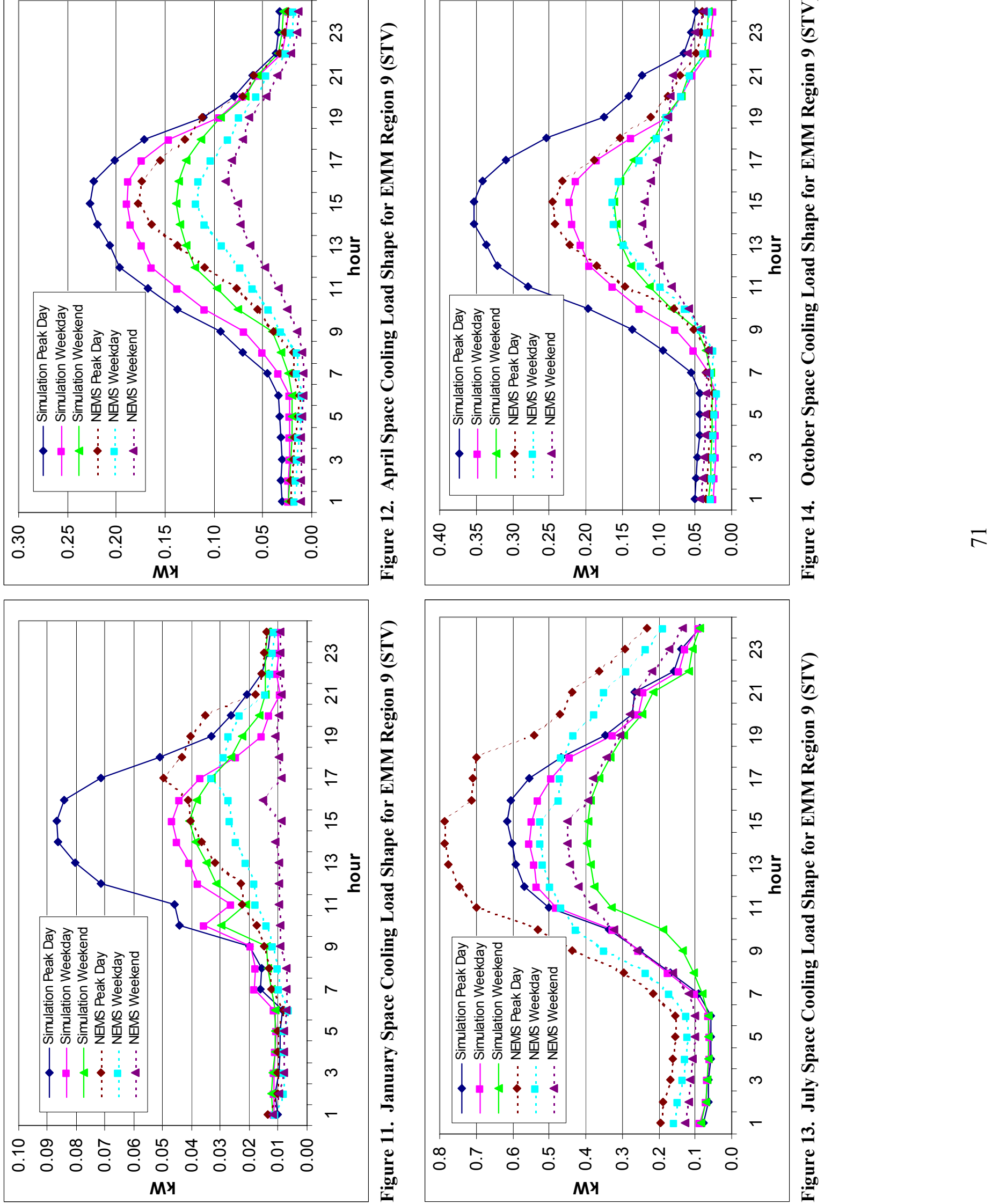

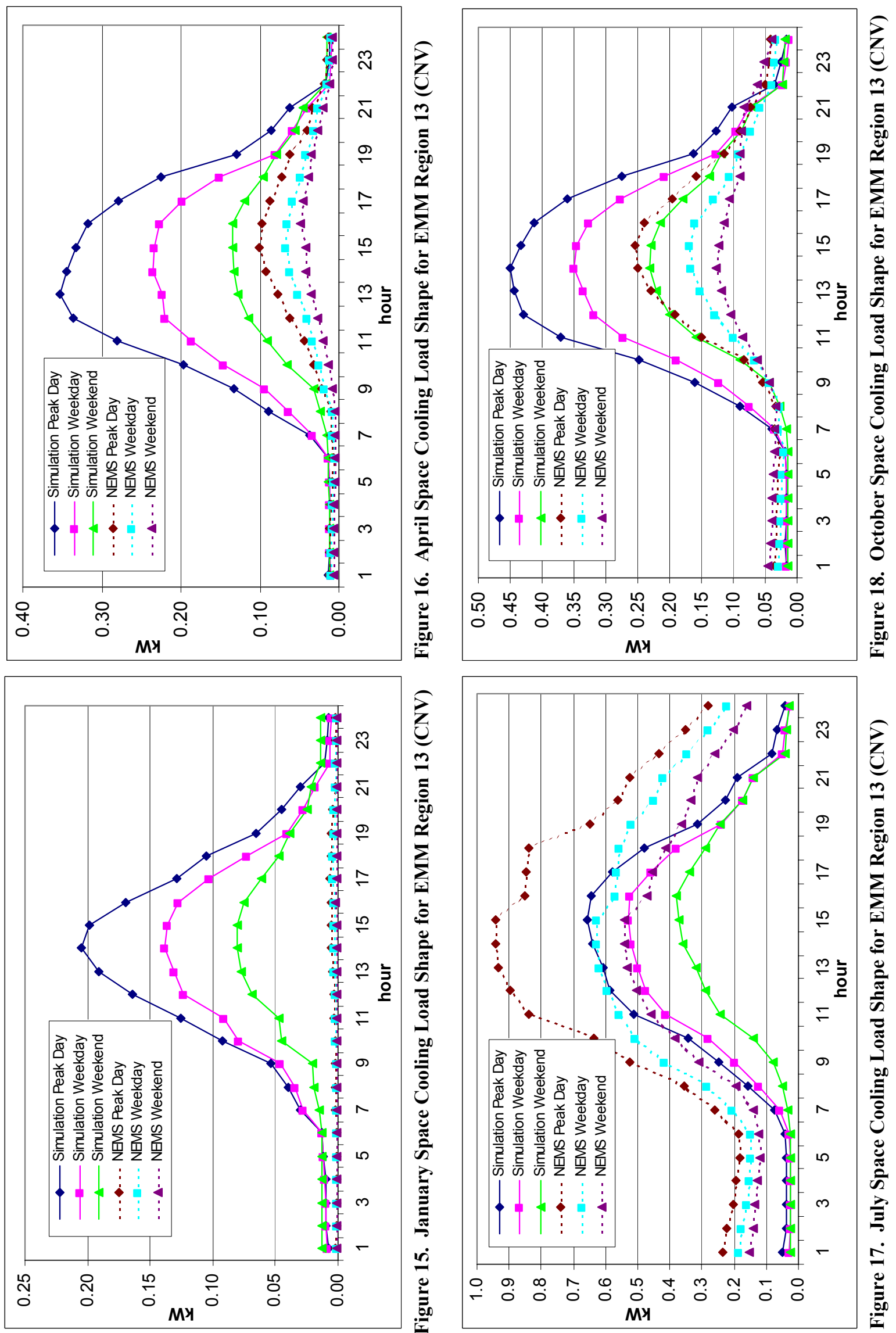

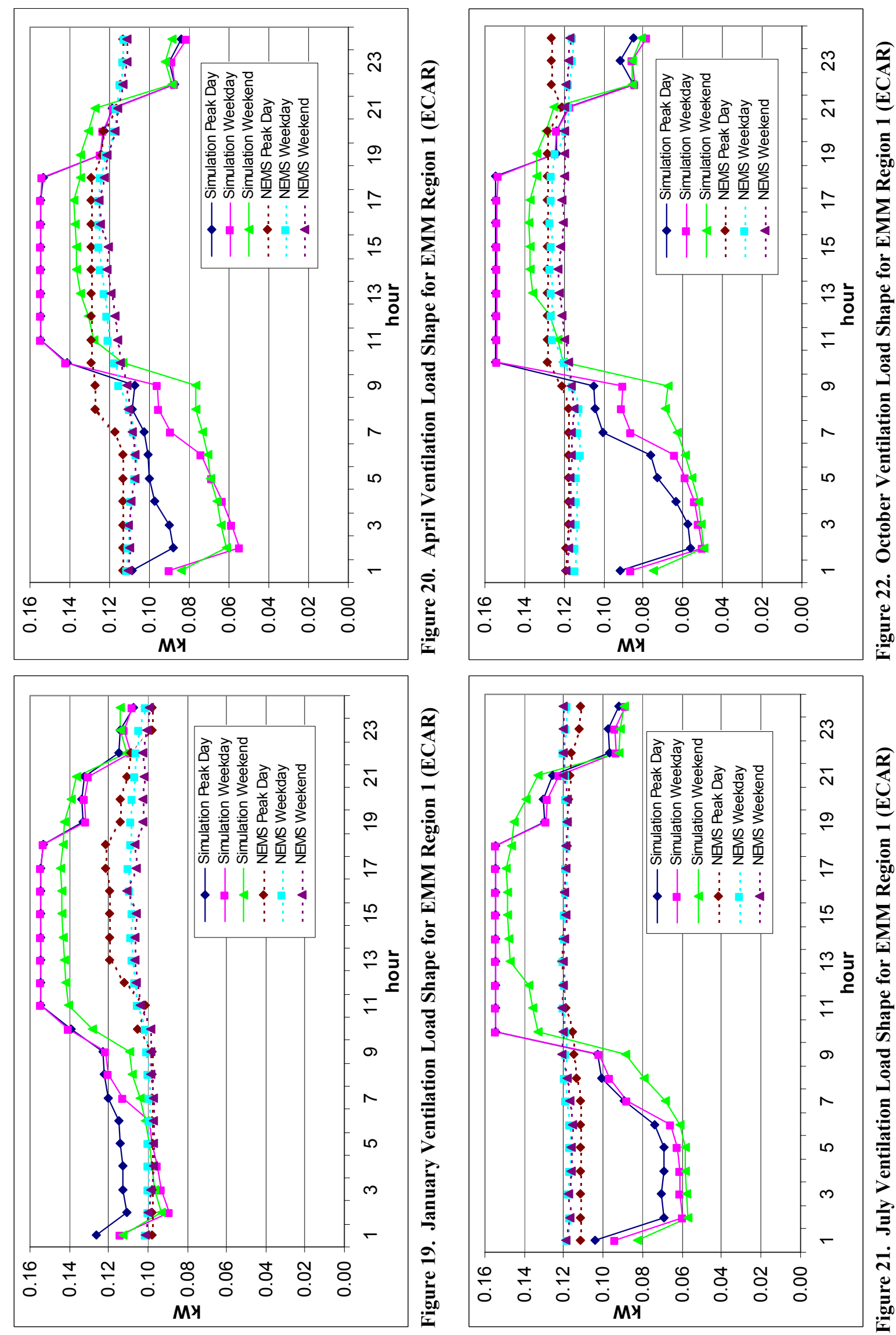

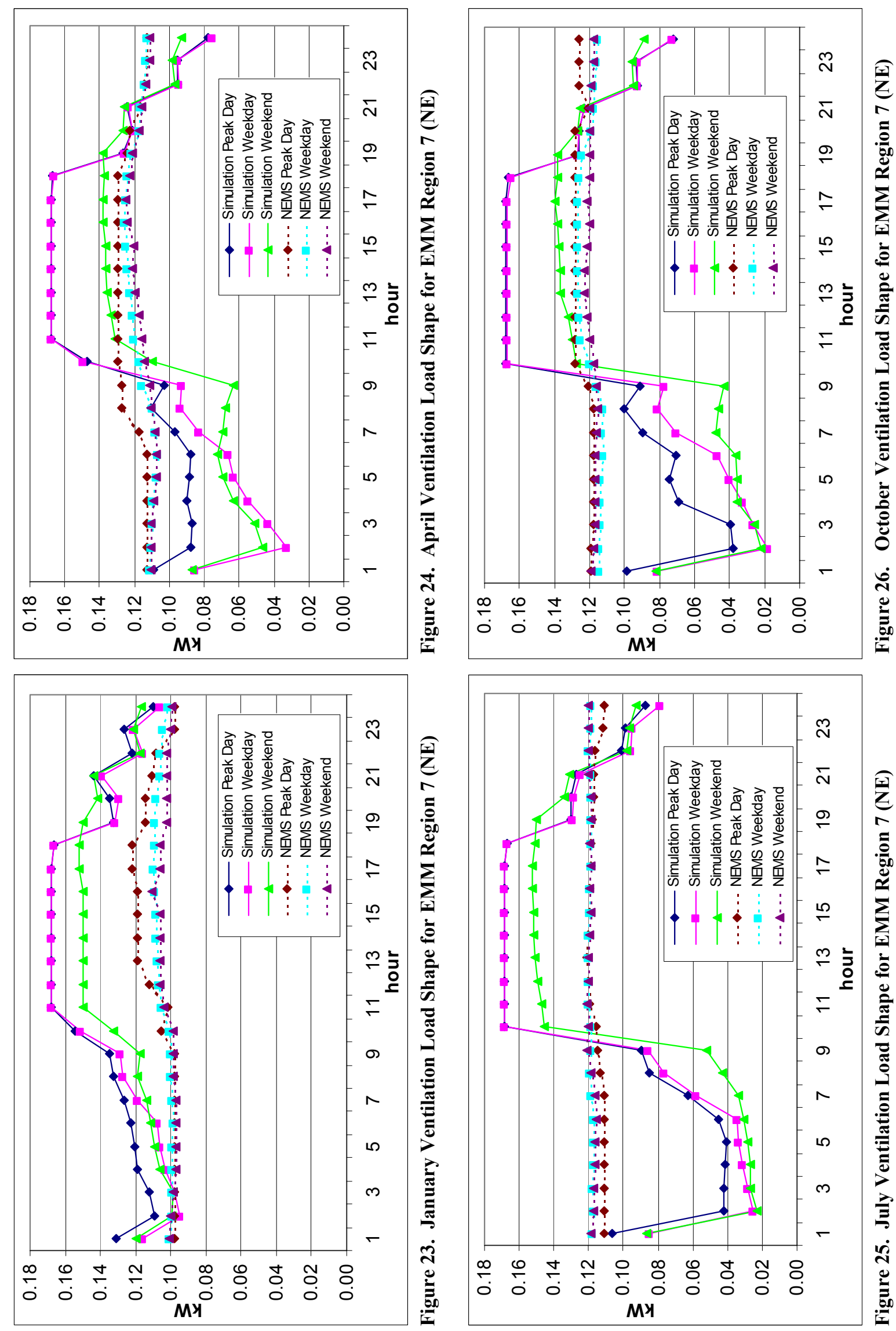

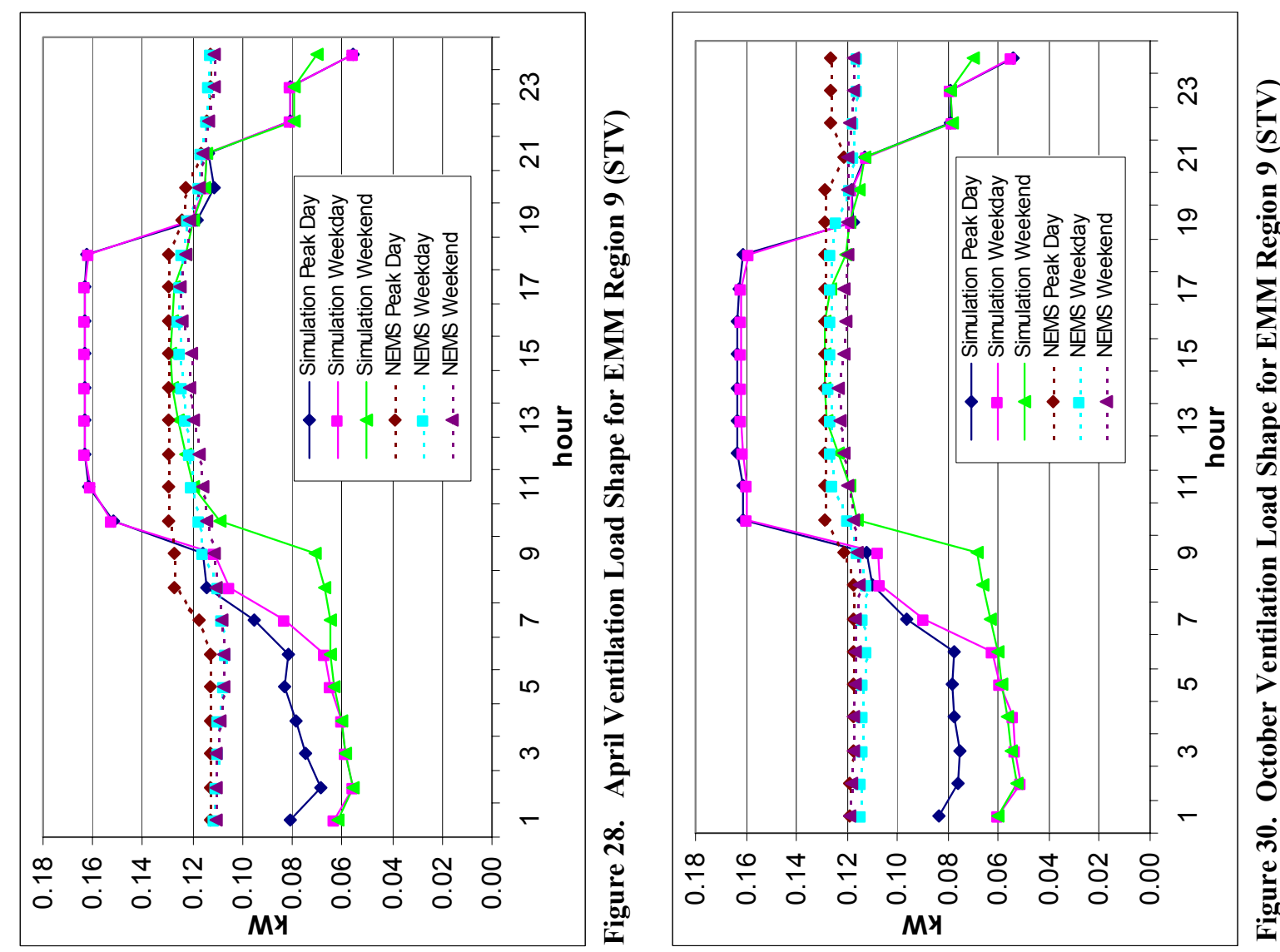

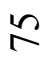
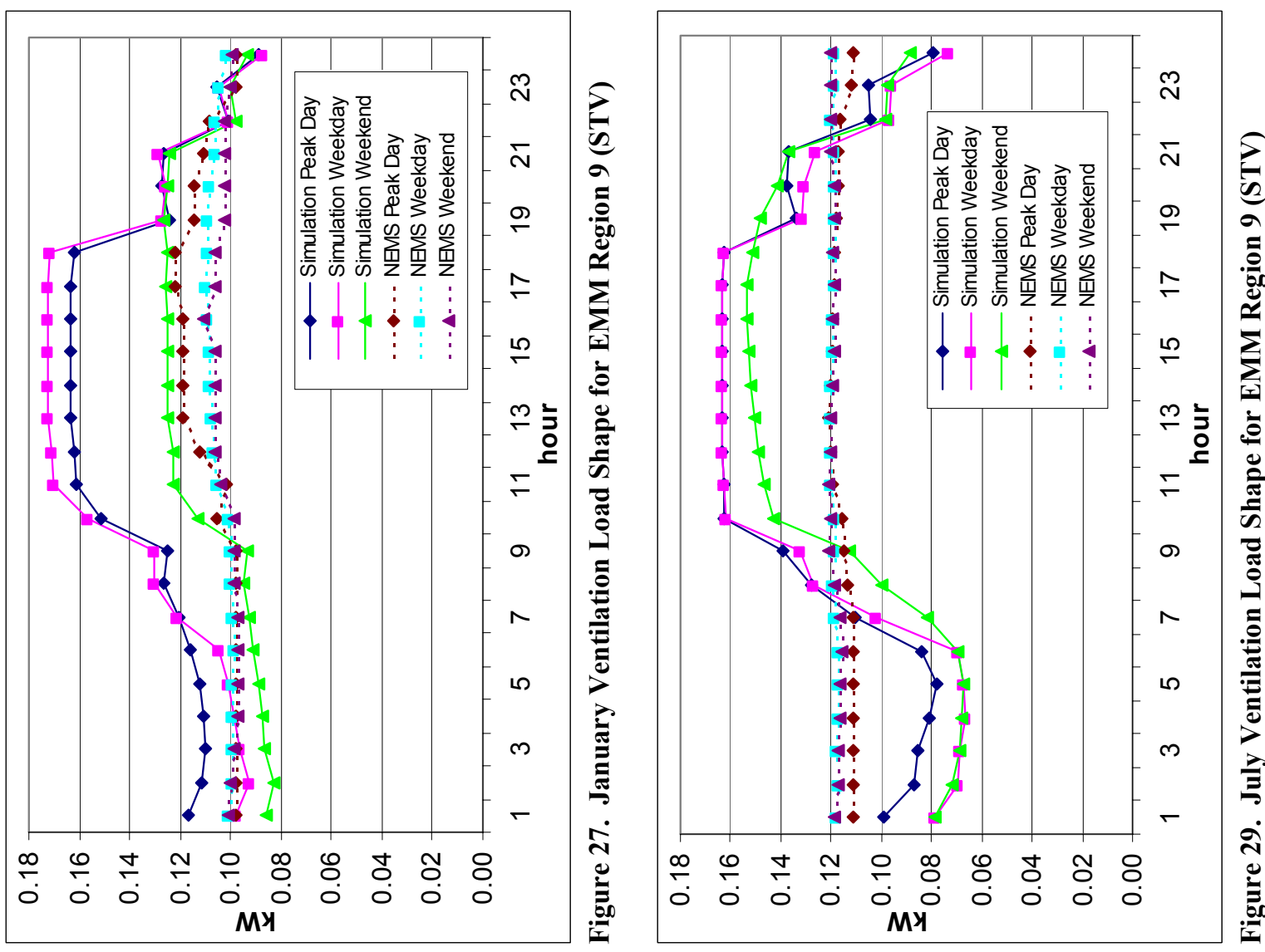

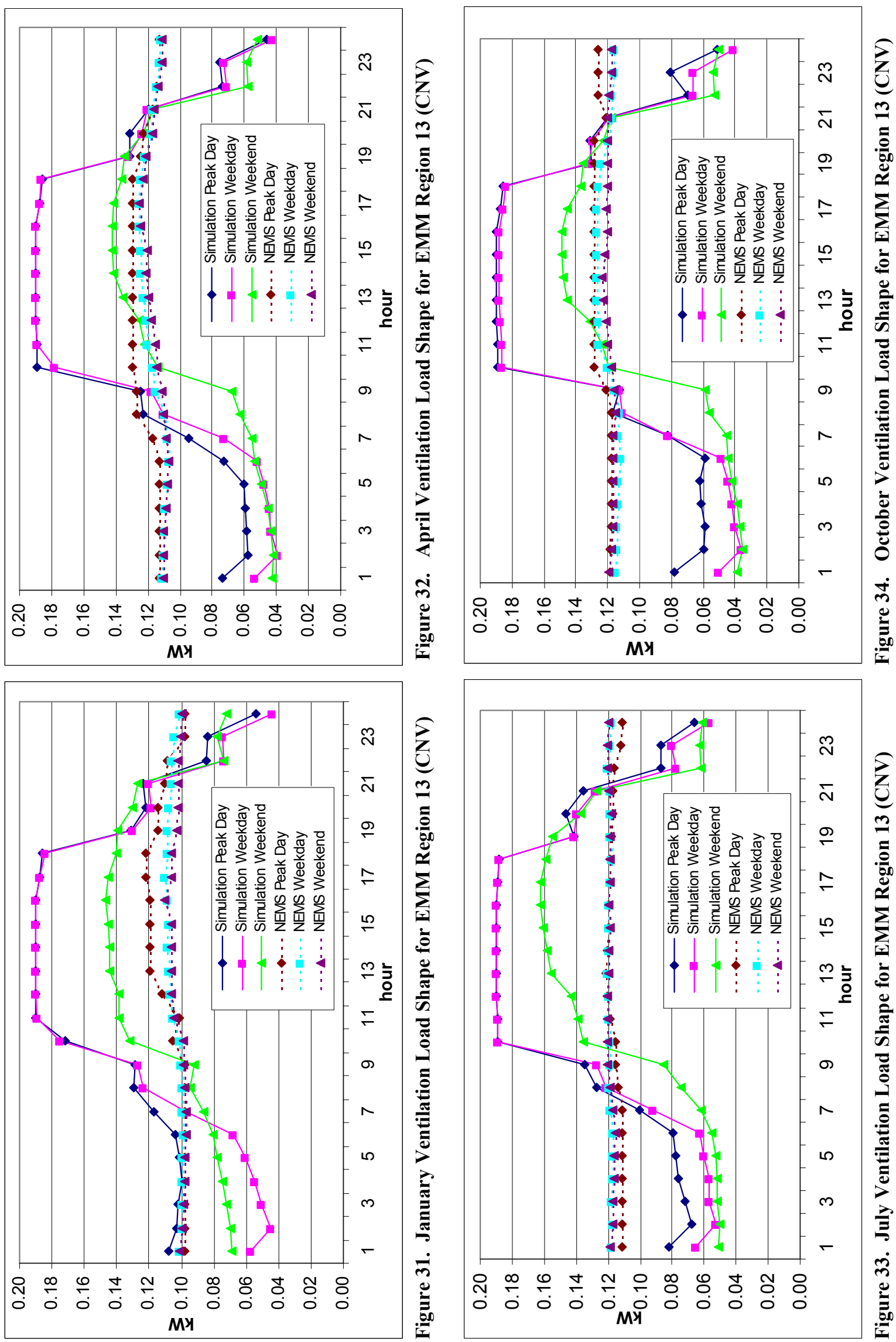


\section{Appendix D. Derivation of Code Changes to Restore Decremented System Hourly Loads}

To construct the system load using a bottom-up approach, the system load at a particular hour $h$ is given by:

$$
\begin{aligned}
\text { SysLoad } & y r \\
\text { where } & E U_{e}^{y r} \text { ill } e \\
& \sum_{e}(h) \cdot E U_{e}^{y r} \\
& p_{e}(h) \text { is the annual energy use of end use } e \text { in year } y r .
\end{aligned}
$$

The total annual energy use for each year $y r, T E^{y r}=\sum_{e}^{\text {all } e} E U_{e}^{y r}$

The method (the squelch approach) used in the NEMS model to calculate the system load at a particular hour $h$ is given by:

$$
\operatorname{SysLoad}^{y r}(h)=p_{s}(h) \cdot T E^{y r}+\sum_{e}^{\text {all e }} p_{e}(h) \cdot\left(E U_{e}^{y r}-\frac{T E^{y r}}{T E^{2001}} \cdot E U_{e}^{2001}\right)
$$

where $p_{s}(h)$ is the fraction of the total annual system energy use at hour $h$, and year 2001 is the base year.

Let SysLoad ${ }^{y r}(h)$ and SysLoad $2^{y r}(h)$ represent the system loads at hour $h$ for the Base Case and the Standards Case respectively.

$$
\begin{aligned}
& \text { SysLoad } 1^{y r}(h)=p_{s}(h) \cdot T E 1^{y r}+\sum_{e}^{\text {all } e} p_{e}(h) \cdot\left(E U 1_{e}^{y r}-\frac{T E 1^{y r}}{T E^{2001}} \cdot E U_{e}^{2001}\right) \\
& \text { SysLoad2 } 2^{y r}(h)=p_{s}(h) \cdot T E 2^{y r}+\sum_{e}^{\text {all } e} p_{e}(h) \cdot\left(E U 2_{e}^{y r}-\frac{T E 2^{y r}}{T E^{2001}} \cdot E U_{e}^{2001}\right)
\end{aligned}
$$

where $T E 1^{y r}-T E 2^{y r}=D^{y r}$

$$
E U 1_{e}^{y r}-E U 2_{e}^{y r}=d_{e}^{y r}
$$

note: $d_{e}^{y r}=0$ for non commercial A/C end uses and $\sum d_{e}^{y r}=D^{y r}$ 
Then

$$
\begin{aligned}
& \text { SysLoad } 1^{y r}(h)-S y s L o a d 2^{y r}(h) \\
& =p_{s}(h) \cdot\left(T E 1^{y r}-T E 2^{y r}\right)+\sum_{e}^{\text {all } e} p_{e}(h) \cdot\left(E U 1_{e}^{y r}-\frac{T E 1^{y r}}{T E^{2001}} \cdot E U_{e}^{2001}-E U 2_{e}^{y r}+\frac{T E 2^{y r}}{T E^{2001}} \cdot E U_{e}^{2001}\right) \\
& =p_{s}(h) \cdot D^{y r}+\sum_{e}^{\text {all e }} p_{e}(h) \cdot\left(E U 1_{e}^{y r}-E U 2_{e}^{y r}-\left(\frac{T E 1^{y r}}{T E^{2000}} \cdot E U_{e}^{2001}-\frac{T E 2^{y r}}{T E^{2000}} \cdot E U_{e}^{2001}\right)\right) \\
& =p_{s}(h) \cdot D^{y r}+\sum_{e}^{\text {all } e} p_{e}(h) \cdot\left(d_{e}^{y r}-\frac{E U_{e}^{2001}}{T E^{2001}} \cdot\left(T E 1^{y r}-T E 2^{y r}\right)\right) \\
& =p_{s}(h) \cdot D^{y r}+\sum_{e}^{\text {all } e} p_{e}(h) \cdot\left(d_{e}^{y r}-\frac{E U_{e}^{2001}}{T E^{2001}} \cdot D^{y r}\right)
\end{aligned}
$$

So, to restore the decremented system load SysLoad ${ }^{y r}(h)$ to the Reference case system load SysLoad ${ }^{y r}(h), D^{y r}$ is added to the term Load1, and $\left(d_{e}^{y r}-\frac{E U_{e}^{2001}}{T E^{2001}} \cdot D^{y r}\right)$ is added to Load2 in equation (1). 


\section{Appendix E. Code Modifications for Outputting the Hourly System Load}

In order to output the hourly system load from a NEMS-BT run, code was added at line 6,277 of the uldsm. $f$ source code. The code modification is shown below and is positioned within other programmatic loops such that all EMM regions are written to an intermediate output file.

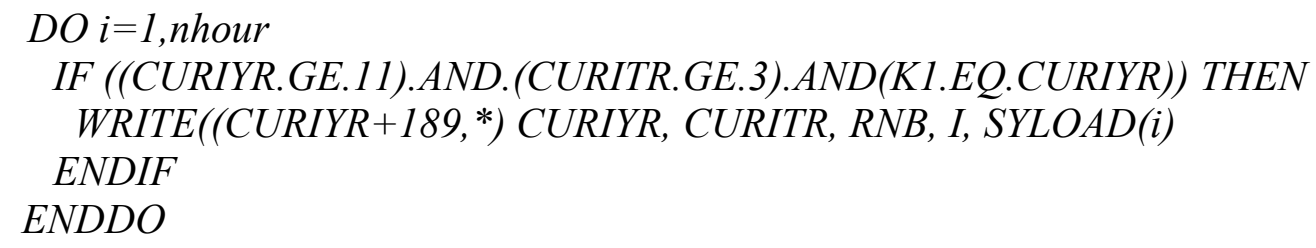

where the NEMS variables are:

$i=$ counter for the number of hours represented in one year

nhour $=$ number of hours to represent the year (864 hours)

CURIYR $=$ current forecast year (when curiyr is 1 it is 1990)

CURITR $=$ iteration number, each year iterates from 3 to 7 times until convergence is met

$K 1=$ look-ahead variable, set to current year or up to 6 years ahead

$R N B=$ EMM region number (1-13)

$S Y L O A D(i)=$ regional system load demand at hour $\mathrm{i}$

The additional lines of code above make analyzing the hourly system load shape very easy for any given run, not just for analysis of a proposed CUAC standard. The code prints out the hourly system load, hour number (1-864), EMM region, iteration, and forecast year. This information is output to a file named fort. $2 X X$, where XX ranges from 00 for year 2000 to 25 for year 2025 .

The intermediate output file is written out when the look-ahead variable is set to the current year (or not looking ahead), the iteration number is three or greater, and the year is 2000 or beyond.

Each month in NEMS is characterized by three different day types - peak day, weekday, or weekend day. The peak day is represented as one day of the month that corresponds to the day with the highest load for the month. Every other day is either a weekday or weekend day where all weekend days and weekdays in a given month are characterized by the same load profile. The 864 hours that represent the entire year in NEMS comes from 24 hours per day times three day types per month times 12 months per year.

The last 11,232 lines of the fort. $2 X X$ represents the final iteration for a given year, where 11,232 is the product of the 13 EMM regions times 864 hours in the year. The hourly system loads are then evaluated in Excel. The spreadsheet analyzes the variation between regional peak hours, measures the hourly effect of the decrement, compares the change in load shapes across regions, and computes what we call the Regional CLF $_{\text {out }}$ by EMM region. 



\section{Appendix F. The Innocence of the Squelch: Understanding the Difference Between the Years 2001 and 2003 "No Squelched" Results}

As noted in this report, our analysis revealed that the removal of a squelching factor in the 2003 version of NEMS resulted in little to no change to the peak impacts, which is different from what we saw in our previous report using the 2001 version of NEMS. This appendix helps explains why the two versions of NEMS produce such different results.

In order to keep the forecasted system load in line with historical trends, NEMS adjusts the sum of end use loads in each forecast year based on the difference between the sum of end use loads in the base year and the historical system load. The original Delta approach uses that difference directly for adjustment while the current Delta approach scales that difference by a scaling factor before adjusting the bottom-up sum.

It is important to point out one very important assumption made in the previous analysis. This original work used the 2001 version of NEMS, which incorporated a different set of end use load shapes than is used in the 2003 version of the model. A number of residential, commercial and industrial load shapes were updated for the 2002 version of NEMS, which accounts for a significant portion of the difference we saw in the results. Essentially, by using the updated end use load shapes, the bottom-up sum of the end use loads in the base year is now much closer to the historical system load. Figures F-1a and F-1b respectively show the difference in the base year between the bottom-up sums and the historical system load (in GW) for NERC region 9 using the AEO2001 and the AEO2003 end use load shapes. In Figure F-1b, the differences between the monthly peaks of the bottom up sums and the historical monthly peaks are much smaller than those in Figure F-1a.

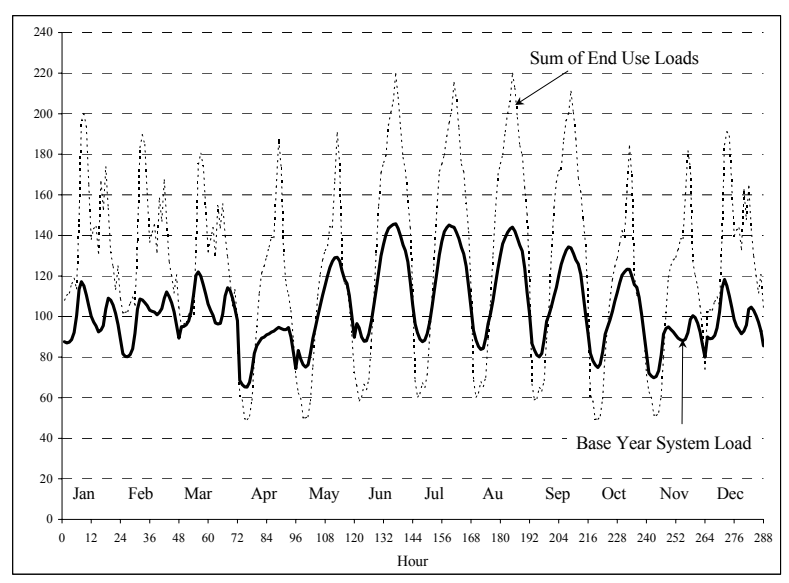

Fig F-1a. Sum of End Use Loads in the Base Year versus Historical System Load - NERC region 9 AEO2003 with AEO2001 Load Shapes

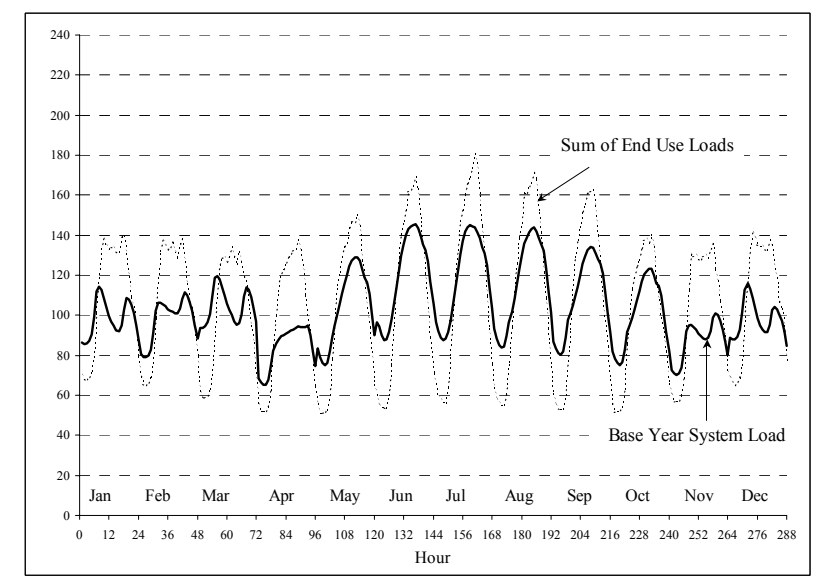

Fig F-1b. Sum of End Use Loads in the Base Year versus Historical System Load - NERC region 9 AEO2003 with current Load Shapes 
When the adjustments based on those differences are smaller using the new set of load shapes, the effect of the scaling factor we have dubbed the squelch is minimized. The scaling factor ranges from 1.0 to $\sim 1.4$ in year 2020. Figures F-2a and F-2b show, respectively, the effect on the adjustments made to the bottom up sum for the Reference Case when the AEO2001 load shapes and the current load shapes are used. When the AEO2001 load shapes are used, the unscaled adjustment for June peak hour is $-69 \mathrm{GW}$ and the squelched adjustment is $-100 \mathrm{GW}$ in year 2020. When the current load shapes are used, the unscaled adjustment for June peak hour is -22 $\mathrm{GW}$ and squelched adjustment is $-32 \mathrm{GW}$ for the same year. In other words, the peak load for the Reference Case is $31 \mathrm{GW}$ lower using the Current Delta approach as compared to the Original Delta approach when the AEO2001 load shapes are used. That difference narrows to 10 GW when the current load shapes are used.

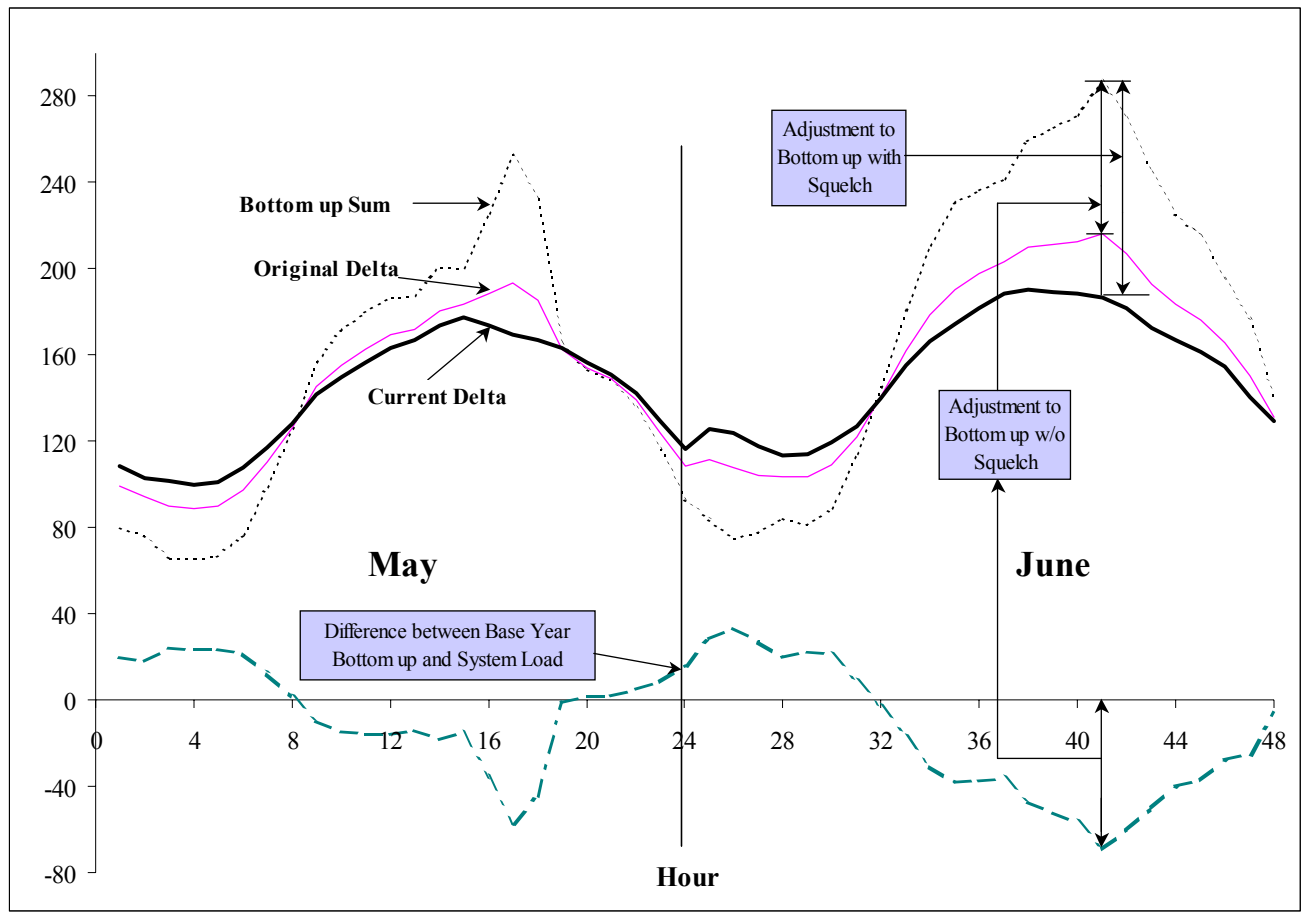

Figure F-2a. Hourly Loads for May and June Peak Days in 2020 - NERC Region 9 AEO2003 with AEO2001 Load Shapes - Reference Case 


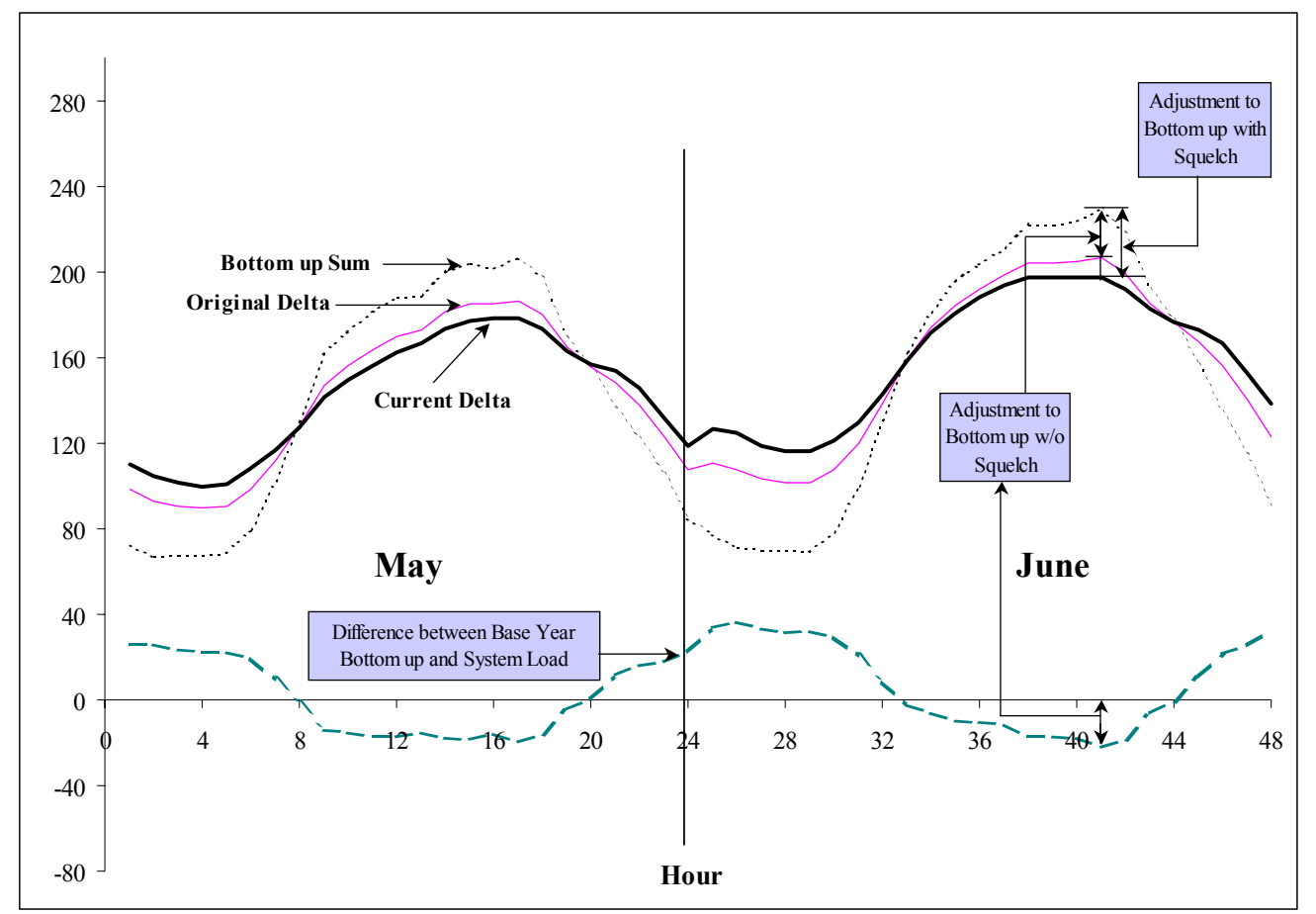

Fig F-2b. Hourly Loads for May and June Peak Days in 2020 - NERC Region 9 AEO2003 with Current Load Shapes - Reference Case

Figures F-3a and F-3b illustrate for EMM region 9 (SERC) how the Original Delta and Current Delta approaches, respectively, affect the reduction of the peak load using the AEO2001 end use load shapes. There are two reasons why the reduction in peak load is higher when the AEO2001 end use load shapes are used. First, as shown in Fig F-2a, the difference between the bottom-up sum of end use loads and the historical system load in the Reference Case is larger. When this difference is scaled up by the squelching factor in the Current Delta approach, the resulting system load for the Reference Case after adjustment has much lower peaks. In Figure F-3b, the June peak for the Reference Case is $187 \mathrm{GW}$, which is much lower than the June peak is 216 GW in Figure F-3a. Secondly, as shown Figures F-3a and F-3b, the hourly decrement (indicated as negative) from the end use is based on the load shape of that end use, which is peaky and noncoincident with the system load shape. This results in a system load shape for the Decrement Case, which is quite different in shape to that of the Reference case. The peak ends up shifting to May from June. These two effects result in the reduction of peak load being much higher in the Original Delta approach (48 GW) than that in the Current Delta approach (28GW).

Figures F-4a and F-4b are similar to Figures F-3a and F-3b except showing the effect using the current end use load shapes to illustrate the more dampened and similar effect between the Delta and Current approaches. EMM region 9 is shown because this region accounts for roughly 15\% of the total U.S. load and therefore has a significant effect on the impact from a proposed standard. 


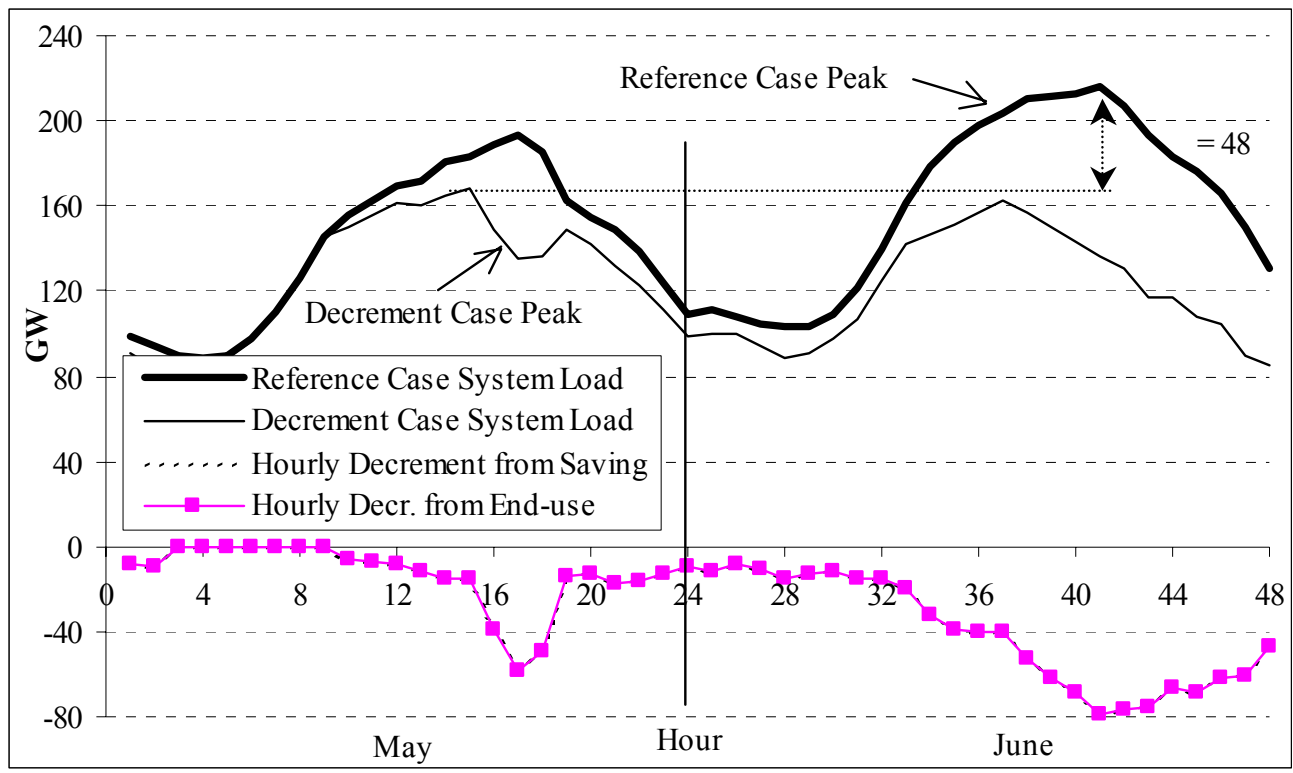

Figure F-3a. Hourly Loads for May and June Peak Days in 2020 - NERC Region 9 AEO2003 with AEO2001 Load Shapes - Original Delta Approach

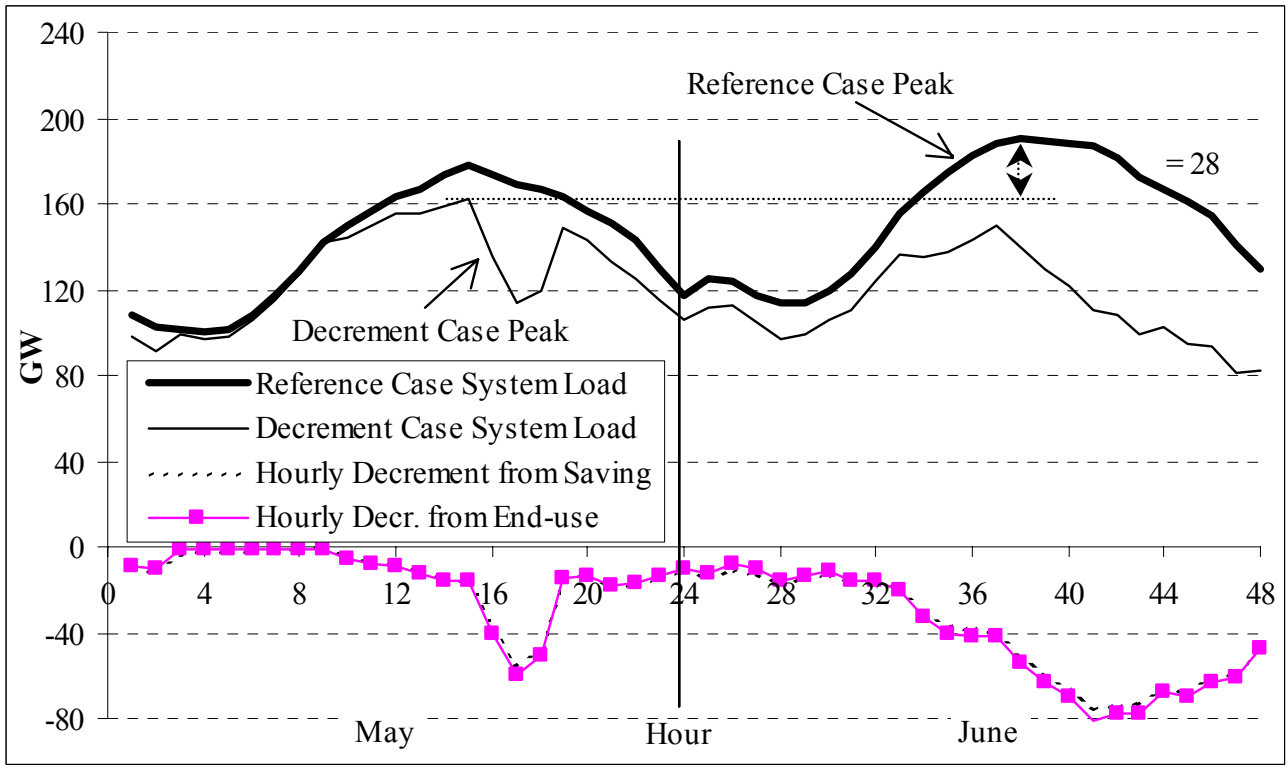

Figure F-3b. Hourly Loads for May and June Peak Days in 2020 - NERC Region 9 AEO2003 with AEO2001 Load Shapes - Current Delta Approach 


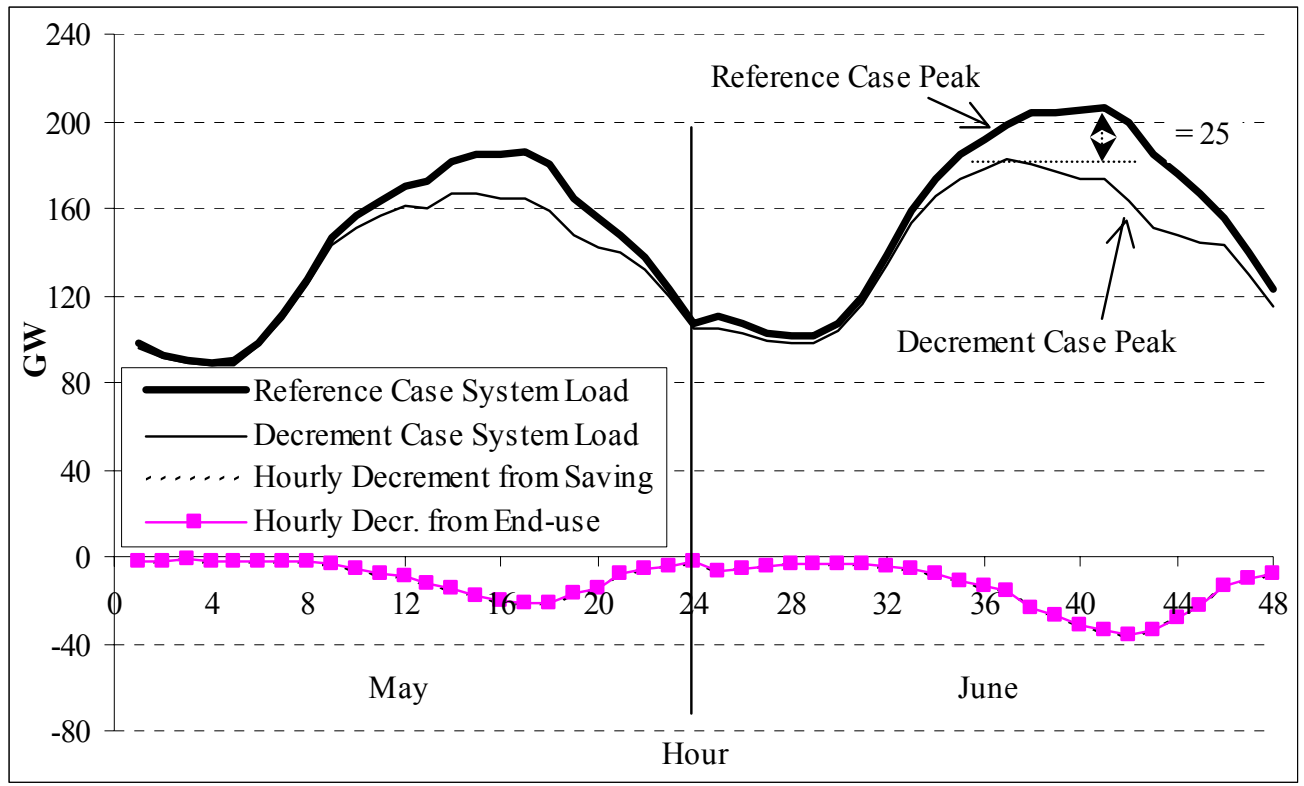

Figure F-4a. Hourly Loads for May and June Peak Days in 2020 - NERC Region 9 AEO2003 with Current Load Shapes - Original Delta Approach

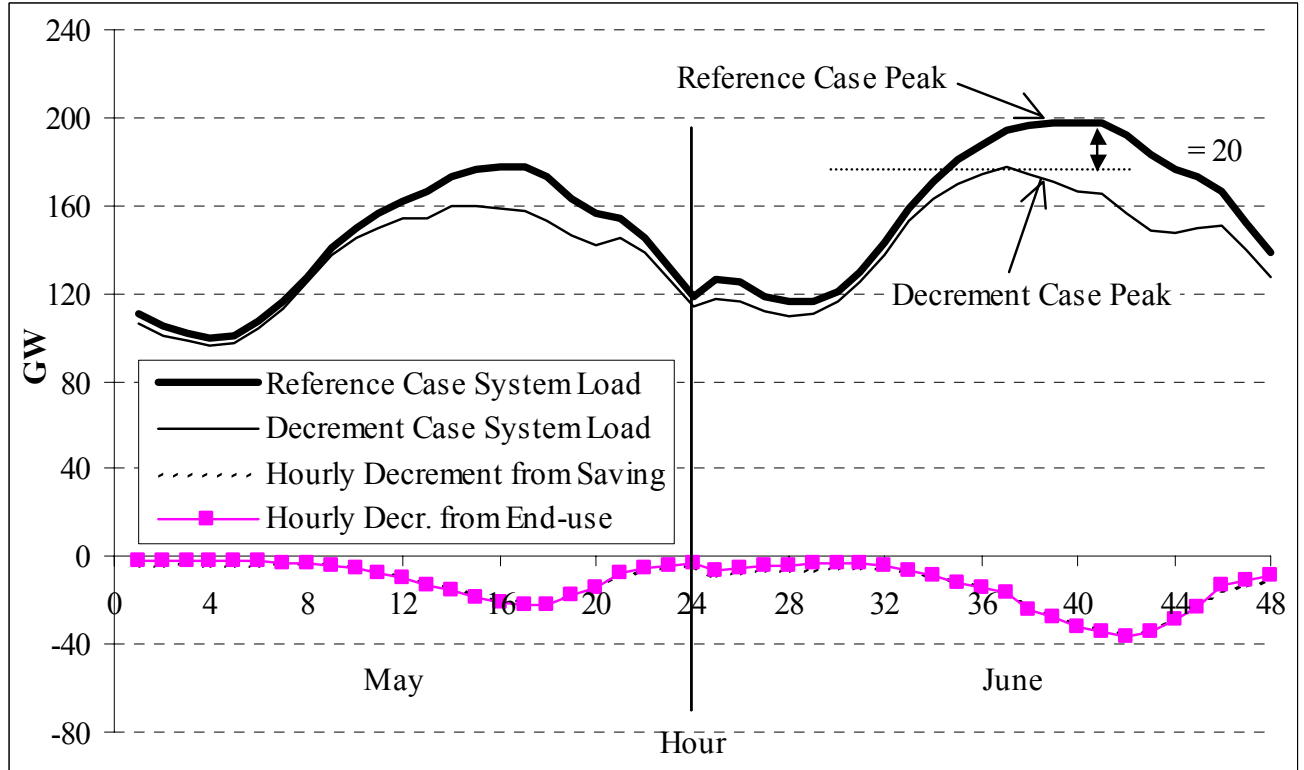

Figure F-4b. Hourly Loads for May and June Peak Days in 2020 - NERC Region 9 AEO2003 with Current Load Shapes - Current Delta Approach

The plots show the peak day for two months in 2020, May and June, to illustrate a shift in the peak hour. The bold black line represents the AEO2003 Reference Case peak day hourly load and the thin black line shows the hourly peak for the decrement case, which in this case is represented by a 4x TSL 4 CUAC run. The pink box-symbol line represents the decrement made as a result of $4 \mathrm{x}$ TSL 4. 
Figures F-3a and F-3b show the change in the peak day in these two months. The decrement to the end-use, as shown by the pink box -symbol line, is almost identical in both figures. The thin dashed line represents the difference between the Reference Case peak and Decrement Case peak lines, which almost exactly matches the decrement made to the end use load shape. Comparing these two figures, we see that the squelch caused the Reference Case peak to lower in magnitude from over $200 \mathrm{GW}$ to under $200 \mathrm{GW}$. Another notable difference between these two figures is the change in the magnitude of the peak hour, which is $48 \mathrm{GW}$ lower in Figure F-1a and $28 \mathrm{GW}$ lower in Figure F-1b from the Reference Case. This amounts to a $20 \mathrm{GW}$ (48 GW - $28 \mathrm{GW}$ ) shift in the peak hour load as a result of using the Original Delta or Current Delta approach with the AEO2001 load shapes. However, this effect is not nearly as significant using the current end use load shapes.

Figures F-4a and F-4b show a similar story except using the current end use load shapes. In these two figures the peak day load difference between the Reference Case and Decrement Case are significantly lower than in Figures F-1a and F-1b. Again, the Reference Case peak lowers between these two figures, although the difference is much less from just above $200 \mathrm{GW}$ to just less than 200 GW. Comparing Figures F-3a and F-3b with Figures F-4a and F-4b illustrates the significant dampening effect that updating the end use load shapes has on the decrement (pink box line). The decrement is clearly smoother and smaller with the new load shapes compared to the original AEO2001 load shapes. With the current load shapes, the reduction of the peak load is less, only $25 \mathrm{GW}$ and $20 \mathrm{GW}$ for the Original and Delta approaches, respectively, compared to the $48 \mathrm{GW}$ and $28 \mathrm{GW}$ using the old load shapes. This amounts to only a $5 \mathrm{GW}(25 \mathrm{GW}-20$ GW) shift as a result of using the Original Delta or Current Delta approach with the current load shapes. Comparing the $5 \mathrm{GW}$ shift using the current load shapes with the $20 \mathrm{GW}$ shift using the AEO2001 load shapes shows how significant the updated load shapes are in bridging the gap between the Original and Delta approaches in NEMS.

This Appendix illustrates the significant effect the updated end use load shapes have in correcting the inconsistency between the Original and Current Delta approaches. As a result of the improved load shapes, the difference between the bottom-up and traditional method for calculating the system load is almost insignificant. That is, the end use loads properly add up to the system load. Thus, the removal of the squelching scaling factor, which impacts the difference between the summed bottom up end use and system loads in the AEO2003 version of NEMS does not produce the significant effect seen in the AEO2001 analysis. 


\section{Appendix G. Effect of Modified TMY System Load}

As noted in this report, our analysis revealed switching out the NEMS system load with the TMY system load results in a $48 \mathrm{GW}$ reduction in the peak load growth forecast by 2025 . This significant difference from the AEO2003 Reference Case initiated an effort to try and minimize this difference.

The NEMS system load is based on historic system load data, although little is known about where this data originated. According to Lessly Goudarzi of OnLocation, Inc., the NEMS system load was likely last updated around the year 2000 version of NEMS, suggesting the current system load is based on data from 1999 or earlier. One major flaw in using actual system load data in NEMS is that the data is almost certainly biased to reflect that year's weather, which could be anomalously hot or cold. This appendix explores the possibility of replacing the NEMS system load with the TMY system load in order to correct for such biases, while minimizing the deviation from the AEO2003 Reference Case.

The TMY system loads are believed to be an improvement to the system loads currently represented in NEMS because it represents typical meteorological conditions. The TMY system load therefore does not include extreme weather years that could potentially bias the system load and lead to over- or underestimations of the forecasted system loads because the system load is forecasted relative to a base year input system load.

Without any correction to the TMY system load, the substitution of this system load into NEMS results in a $48 \mathrm{GW}$ reduction in the peak load forecast, a $4 \%$ deviation from the AEO2003 Reference Case that would be nearly impossible to justify as part of the CUAC Rulemaking analysis. As a result, Berkeley Lab performed a series of runs that increase the peak day of the system load, compensated by an decrease during all non-peak hours by a total of the same amount to ensure the same amount of total energy demanded. Three different scenarios were run that increase the peak day in all 13 EMM regions of the TMY system load by $5 \%, 7 \%$, and $15 \%$ to prove that we could achieve a forecast similar to the AEO2003 Reference Case using the TMY system load shapes.

Based on our scenario runs, a 7\% increase to the peak day in all 13 EMM regions resulted in the closest forecast to the AEO2003 Reference Case. Table 20 shows the total installed generating capacity of the three scenarios and the difference from the AEO2003 Reference Case (in parentheses). The $15 \%$ scenario overshoots the Reference Case by over $70 \mathrm{GW}$ throughout the forecast. In contrast, the $5 \%$ scenario undershoots the target by over $20 \mathrm{GW}$ in 2025 . Of the three scenario runs, the 7\% scenario targets the AEO2003 Reference Case the best, forecasting total installed capacity within $\pm 10 \mathrm{GW}$ from year to year. 
Table 20. Total Installed Capacity (and Difference from AEO2003 Reference Case) in GW

\begin{tabular}{|c|c|c|c|}
\hline & $\mathbf{2 0 1 0}$ & $\mathbf{2 0 2 0}$ & $\mathbf{2 0 2 5}$ \\
\hline AEO2003 Ref Case & 934.8 & $1,085.0$ & $1,182.5$ \\
\hline $\mathbf{5 \%}$ & $\begin{array}{c}935.2 \\
(+0.4)\end{array}$ & $\begin{array}{c}1,069.0 \\
(-16.0)\end{array}$ & $\begin{array}{c}1,160.6 \\
(-21.9)\end{array}$ \\
\hline $\mathbf{7 \%}$ & $\begin{array}{c}945.9 \\
(+11.1)\end{array}$ & $\begin{array}{c}1,083.5 \\
(-1.5)\end{array}$ & $\begin{array}{c}1,179.7 \\
(-2.8)\end{array}$ \\
\hline $\mathbf{1 5 \%}$ & $\begin{array}{c}1008.2 \\
(+73.4)\end{array}$ & $\begin{array}{c}1,164.9 \\
(+79.9)\end{array}$ & $\begin{array}{c}1,258.3 \\
(+75.8)\end{array}$ \\
\hline
\end{tabular}

So based on our experimental runs, this analysis proves that the TMY system load can be modified to better correlate with the NEMS system load. By reducing the annual peak hour of the TMY system load in every region and increasing the equivalent load during off-peak hours, the system load is more consistent with the NEMS system load, yet does not suffer from the influence due to extreme weather phenomena. A 7\% increase to the TMY system load regional peak hour therefore reduces the deviation from the AEO2003 Reference Case, while correcting the system load for possible weather anomalies commonly inherent in real historic data.

Based on this exercise, Berkeley Lab analyzed historic weather maximum temperatures to determine reasonable percentages of deviation to help support a reduction to the TMY system load peak. 